\title{
How Important Are Sectoral Shocks?
}

\author{
Enghin Atalay*
}

June 16, 2014

\begin{abstract}
I quantify the contribution of sectoral shocks to business cycle fluctuations in aggregate output. I develop a multi-industry general equilibrium model in which each industry employs the material and capital goods produced by other sectors, and then estimate this model using data on U.S. industries' sales, output prices, and input choices. Maximum likelihood estimates indicate that industry-specific shocks account for nearly two-thirds of the volatility of aggregate output, substantially larger than previously assessed. Identification of the relative importance of industry-specific shocks comes primarily from data on industries' intermediate input purchases, data that earlier estimations of multi-industry models have ignored.
\end{abstract}

\section{Introduction}

What are the origins of business cycle fluctuations? Do idiosyncratic micro shocksdisturbances at individual firms or industries - have an important role in explaining short-run macroeconomic fluctuations? Or are shocks that prevail on all industries the predominant source?

I address these questions by constructing and estimating a multi-industry dynamic general equilibrium model in which both aggregate and industry-specific shocks have the potential to contribute to aggregate output volatility. I find that sectoral shocks are important: They account for more than three-fifths of the variation in aggregate output growth.

*I thank Frank Limehouse and Arnie Reznek, for help with the data disclosure process. In addition, I am indebted to Fernando Alvarez, Thomas Chaney, Thorsten Drautzburg, Xavier Gabaix, Ali Hortaçsu, Oleg Itskhoki, Tim Kautz, Gita Khun Jush, Sam Kortum, Bob Lucas, Ezra Oberfield, Nancy Stokey, Chad Syverson, Daniel Tannenbaum, and Harald Uhlig, for their helpful comments on earlier drafts, and to Erin Robertson, for her excellent editorial assistance. Disclaimer: Any opinions and conclusions expressed herein are those of the author and do not necessarily represent the views of the U.S. Census Bureau. All results have been reviewed to ensure that no confidential information is disclosed. Updated versions of the paper can be found at home.uchicago.edu/ atalay/sectoral_shocks.pdf . 
This figure is substantially larger than in previous evaluations of multi-industry general equilibrium models.

The primary challenge in identifying the relative importance of industry-specific shocks is that, because of input-output linkages, both aggregate and industry-specific shocks have similar implications for data on industries' sales. To see why, consider the following two scenarios. In the first, some underlying event (e.g., a surprise increase in the target federal funds rate) reduces the demand faced by all industries, including the auto parts manufacturing, steel manufacturing (a supplier of auto parts), and auto assembly industries. In the second scenario, a strike occurs in the auto parts manufacturing industry, which temporarily reduces the demand faced by sheet-metal manufacturers, and increases the cost of establishments engaged in auto assembly. Even if industry-specific shocks are independent of one another, input-output linkages will induce co-movements in these industries' output and employment growth rates, just as in the first scenario. So, distinguishing between aggregate and industry-specific shocks is a complicated task.

Second, the importance of sectoral shocks depends on assumptions regarding the extent to which industries can substitute across their inputs. In particular, the estimated importance of industry-specific shocks hinges on a parameter, which I call $\varepsilon_{Q}$, that measures how elastically each industry can substitute between its intermediate inputs and other inputs (namely, capital and labor). In general, shocks alter the relative prices of each good and, as long as $\varepsilon_{Q} \neq 1$, cause each industry's intermediate input cost share to vary. Estimates of the relative importance of industry-specific shocks depend on the covariance structure of industries' intermediate input cost shares in an intuitive manner: Volatile intermediate input cost shares are a sign either of prominent industry-specific or aggregate shocks. At the same time, movements in industries' intermediate input cost shares that are uncorrelated with one another indicate that industry-specific, not aggregate, shocks are predominant. If $\varepsilon_{Q}$ is restricted to be equal to 1 (as in previous analyses of multi-industry models), the model cannot possibly fit movements in industries' intermediate input cost shares no matter how volatile the productivity or preference shocks are. Data on intermediate input cost shares are not allowed to speak to the relative importance of industry-specific shocks. The challenge, when identifying the relative importance of sectoral shocks, emerges from the paucity of reliable, precise estimates of this key elasticity of substitution. ${ }^{1}$

I confront these two challenges by jointly estimating, via maximum likelihood, the preference and production elasticities of substitution in conjunction with the aggregate and industry-specific components of the exogeneous preference and productivity stochas-

\footnotetext{
${ }^{1}$ Bruno (1984) and Rotemberg and Woodford (1996) are two attempts to estimate $\varepsilon_{Q}$; see Section 4.2 for a discussion.
} 
tic processes. The estimation procedure employs a dataset that tracks industries' sales, prices, and intermediate input purchases across the entire U.S. economy from 1960 to 2005.

In the data, industries' intermediate input cost shares are both volatile and positively correlated to the industry-specific intermediate input prices. As a result, the estimation procedure assigns a relatively low value of $\varepsilon_{Q}$ : The maximum likelihood estimates of $\varepsilon_{Q}$ range between 0 and 0.15 , depending on the specification, and are always significantly less than 1. In other words, intermediate input and other inputs are highly complementary to one another.

Also in the data, the cross-industry correlation of industries' intermediate input cost shares is low. This empirical pattern, in combination with the low estimate of $\varepsilon_{Q}$, implies that industry-specific shocks account for a large fraction of aggregate volatility. I provide a variance decomposition, computing the fraction of the variation in aggregate output growth that can be explained by industry-specific (versus aggregate) shocks. I find that $63 \%$ of the variation in aggregate output growth is attributable to the industry-specific components of the preference and productivity shocks. In contrast, Foerster, Sarte, and Watson (2011) compute that less than half of the variation in output growth is due to industry-specific shocks. When I impose unitary elasticities of substitution on my model, I estimate a similar number for the aggregate importance of industry-specific shocks. ${ }^{2}$ In sum, these results indicate that sectoral shocks are more important than previously thought, and that the difference is largely due to past papers' imposition of a unitary elasticity of substitution between intermediate inputs and capital/labor. These results are robust to time period, industry classification schemes, treatment of trends, and (for the most part) countries.

This paper resolves the hypothesis, first advanced in Long and Plosser (1983), that independent industry-specific shocks generate patterns characteristic of modern business cycles. Models of business cycles typically portray fluctuations as the result of economy-wide, aggregate disturbances to production technologies and preferences. These disturbances, however, are difficult to justify independently, and may simply represent "a measure of our ignorance." ${ }^{3}$ Given the results of the current paper, future research on the sources of business cycle fluctuations would benefit from moving beyond the predominant one-sector framework.

\footnotetext{
${ }^{2}$ See Section 4.2 for a discussion of why the numbers reported in Foerster, Sarte, and Watson (2011) may differ from the estimates I provide here.

${ }^{3}$ This phrase was coined by Abramovitz (1956), when discussing the sources of long-run growth, but applies to our understanding of short-run aggregate fluctuations, as well. More recently, Summers (1986) and Cochrane (1994) have argued that it is a priori implausible that aggregate shocks can exist at the scale needed to engender the business cycle fluctuations that we observe.
} 


\subsection{Literature Review and Outline}

The current paper falls within the literature on multi-industry real business cycle models, first introduced in Long and Plosser (1983). Long and Plosser present a model in which the economy is comprised of a collection of perfectly competitive industries. Each industry produces its output by employing a combination of capital, labor, and intermediate inputs. The capital and intermediate input bundles of each industry are, in turn, combinations of goods that are purchased from other industries. Long and Plosser (1983) and others in this literature (e.g., Horvath 1998, 2000, Dupor 1999, Acemoğlu et al. 2012, and Acemoğlu, Özdağlar, and Tahbaz-Salehi 2013) use this framework to argue that idiosyncratic shocks to industries' productivities, by themselves, have the potential to generate substantial aggregate fluctuations. ${ }^{4}$ These papers, however, do not allow for aggregate shocks; they are not attempting to assess the relative importance of industry-specific and aggregate shocks. ${ }^{5}$

With an appreciation of this issue, Foerster, Sarte, and Watson (2011) present a methodology that allows them to recover the underlying productivity shocks from data on industries' output growth. The authors perform a factor analysis on the recovered productivity shocks. They find that aggregate productivity shocks - the first two common factors from the factor analysis - represent most of the variation in the first part of their sample (1972 to 1983), and decline in volatility during the Great Moderation (1984 to 2007). As a result, industry-specific shocks account for $20 \%$ and $50 \%$ of the variation in industrial production during the two parts of their sample.

Compared to the Long and Plosser literature in general - and Foerster, Sarte, and Watson (2011) in particular - the current paper makes three advances, all of which are necessary to properly gauge the contribution of sectoral shocks to aggregate volatility. First, I examine the implications of industry-specific and aggregate shocks on other observable variables - industry level output prices and intermediate input purchases - that have up to now been ignored. To be able to compare data on prices and intermediate input purchases to their theoretical counterparts, I include non-technology shocks (namely, shocks to the preferences of the representative consumer over the industries' outputs). In the context of one-sector models, preference shocks account for a large portion of business cycle fluctuations, and thus should also be included in a multi-industry analysis. ${ }^{6}$ Second, I allow for flexible

\footnotetext{
${ }^{4}$ Within this literature, Dupor (1999) is somewhat unique: Instead of arguing that industry-specific shocks have the potential to produce business cycle fluctuations, he does the converse: He provides conditions on the input-output matrix under which industry-specific shocks are irrelevant.

${ }^{5}$ Horvath (2000) includes aggregate shocks in his analysis, but does not attempt to estimate the relative magnitudes of the aggregate and sectoral shocks.

${ }^{6}$ Although there is some contention on this point, technology shocks alone cannot explain most of the business cycle variation of aggregate activity (see, for example, Galí and Rabanal 2004 and Smets and Wouters 2007 for two analyses of one-sector economies).
} 
substitution patterns in consumers' preferences and industries' production technologies. In particular, Foerster, Sarte, and Watson (2011) and earlier papers impose unitary elasticities of substitution in consumers' preferences (across the goods produced by each industry) and in industries' production functions (across inputs). ${ }^{7}$ In contrast, I estimate these elasticities. Allowing for a non-unitary elasticity of substitution between intermediate inputs and other inputs turns out to be critical: With the unit elasticity assumption, the model substantially understates the relative importance of industry-specific shocks. Finally, I make a sequence of smaller advances: I allow for consumption good durability, consider a dataset that covers the entire economy, ${ }^{8}$ and examine data from several developed economies. ${ }^{9}$

The model is delineated in Section 2. Section 3 introduces the three main datasetsthe Bureau of Economic Analysis (BEA) Input-Output Table, the BEA Capital Flows Table, and Dale Jorgenson's 35-industry KLEMS dataset - and discusses two patterns in the data which will guide the estimation. Section 4 describes the estimation procedure, the main empirical results, and a sensitivity analysis of the benchmark results. Section 5 contains a simple example, which provides intuition as to how the parameters are identified and why allowing $\varepsilon_{Q}$ to be freely estimated yields higher estimates of the relative importance of sectoral shocks. Section 6 concludes. ${ }^{10}$

\footnotetext{
${ }^{7}$ Horvath (2000) accommodates non-unitary elasticities of substitution in consumers' preferences (across goods) and in the production of the intermediate input bundle (across inputs purchased from upstream industries), but imposes a unitary elasticity of substitution among labor, capital, and the intermediate input bundle. As I argue in this paper, this last parameter is the most important. Another difference between the current paper and Horvath (2000) is that the earlier paper does not attempt to estimate the values of these elasticities of substitution. Instead, he performs a sensitivity analysis of his results around his benchmark specification (in which all of the aforementioned elasticities of substitution are equal to 1); see Section 5.2 of that paper.

${ }^{8}$ Foerster, Sarte, and Watson (2011) is unique in its application of the Federal Reserve Board's dataset on industrial production, a dataset that spans only the goods-producing sectors of the U.S. economy. Other papers (e.g., Long and Plosser 1983 and Horvath 2000), employ a dataset that covers the entire economy.

${ }^{9}$ Another line of research attempts to gauge the relative importance of industry-specific shocks by estimating vector autoregressions (see Long and Plosser 1987, Stockman 1988, Shea 2002, or Holly and Petrella 2012).

There are other explanations, in addition to the input-output-channel explanation, for the relevance of micro shocks. Gabaix (2011) demonstrates that individual firms, because of their size, engender substantial aggregate fluctuations. Along these lines, Carvalho and Gabaix (2013) show that certain industries, those with particularly volatile productivities, account for an outsize fraction of aggregate volatility.

${ }^{10}$ Additional robustness checks related to Section 4's results (Appendix A), details on the dataset (Appendices $\mathrm{B}$ and $\mathrm{C}$ ), and ancillary calculations (Appendices D and E) are all contained in the Appendix. Finally, in Appendix F, I exploit micro data from selected manufacturing industries to provide an alternative, corroboratory estimate of the elasticity of substitution between industries' intermediate input purchases and their purchases of capital and labor.
} 


\section{Model}

In this section, I present a multi-industry general equilibrium model, along the lines of Long and Plosser (1983) and Foerster, Sarte, and Watson (2011). This is the simplest model that can be used to compare the importance of industry-specific and aggregate disturbances and to estimate the elasticities of substitution in preferences and production. The model is populated by a representative consumer and $N$ perfectly competitive industries. I first describe the representative consumer's preferences, then the production technology of each industry, and finally the evolution of the exogeneous variables.

\subsection{Preferences}

The consumer has balanced-growth-consistent preferences over leisure and the services provided by the $N$ different consumption goods.

The preferences of the consumer are given by the following utility function:

$$
\begin{aligned}
\mathcal{U}= & \sum_{t=0}^{\infty} \beta^{t}\left\{D_{t, A g g} \cdot\left(\sum_{J=1}^{N} \xi_{J} \cdot D_{t J}\right) \cdot \log \left[\left(\sum_{J=1}^{N}\left(\xi_{J} \cdot D_{t J}\right)^{\frac{1}{\varepsilon_{D}}} \cdot\left(\delta_{C_{J}} \cdot C_{t J}\right)^{\frac{\varepsilon_{D}-1}{\varepsilon_{D}}}\right)^{\frac{\varepsilon_{D}}{\varepsilon_{D}-1}}\right]\right. \\
& \left.-\frac{\varepsilon_{L S}}{\varepsilon_{L S}+1} \cdot\left(\sum_{J=1}^{N} L_{t J}\right)^{\frac{\varepsilon_{L S}+1}{\varepsilon_{L S}}}\right\} .
\end{aligned}
$$

The demand parameters, $\xi_{J}$, reflect the time-invariant differences in the importance of industries' goods in the consumer's preferences. Preferences over each industry's consumption good evolve stochastically, with an aggregate $\left(D_{t, A g g}\right)$ and an industry-specific component $\left(D_{t J}\right)$. The aggregate component affects each industry symmetrically, while the industry-specific component affects individual industries independently. $C_{t J}$ equals the stock of durable goods when $J$ is a durable-good-producing industry and equals the expenditures on good/service $J$ otherwise. For durable goods, $J$, the evolution of the stock of each consumption good, $C_{t J}$, is given by

$$
C_{t J}=C_{t-1, J} \cdot\left(1-\delta_{C_{J}}\right)+\tilde{C}_{t J}
$$

where $\tilde{C}_{t J}$ equals the consumer's new purchases on good $J$ at time $t$ and $\delta_{C_{J}}$ parameterizes the depreciation rate of good $J$. The elasticities of substitution parameterize how easily the representative consumer substitutes across the different consumption goods $\left(\varepsilon_{D}\right)$ and how 
responsive the consumer's desired labor supply is to the prevailing wage $\left(\varepsilon_{L S}\right) .{ }^{11}$

To see more clearly how the preference shocks operate, suppose for a moment that there are no durable goods so that $\delta_{C_{J}}=1$ for all industries. Let $P_{t J}$ denote the Lagrange multiplier on the period $t$ goods market clearing condition for good $J$ (see Equation 8 below), and let $P_{t}$ denote the ideal price index at time $t .{ }^{12}$ Take the first-order condition with respect to consumption of good $J$ at date $t$ :

$$
P_{t J}=D_{t, A g g} \cdot\left(\sum_{I=1}^{N} \xi_{I} \cdot D_{t I}\right) \cdot \frac{\left(\xi_{J} \cdot D_{t J}\right)^{\frac{1}{\varepsilon_{D}}} \cdot\left(C_{t J}\right)^{-\frac{1}{\varepsilon_{D}}}}{\sum_{I=1}^{N}\left(\xi_{I} \cdot D_{t I}\right)^{\frac{1}{\varepsilon_{D}}} \cdot\left(C_{t I}\right)^{\frac{\varepsilon_{D}-1}{\varepsilon_{D}}}}
$$

After some manipulation, one can show that the utility function given in Equation 1 implies that the representative consumer has the following demand function for good $J$ at date $t$ :

$$
C_{t J}=\xi_{J} \cdot D_{t J} \cdot D_{t, A g g} \cdot\left(\frac{P_{t J}}{P_{t}}\right)^{-\varepsilon_{D}} \cdot \frac{1}{P_{t}} .
$$

The $D$ s thus act to shift the demand curve for good $J$ at time $t$. The industry-specific component $\left(D_{t J}\right)$ shifts only the demand for good $J$, while the aggregate component $\left(D_{t}\right)$ shifts all time- $t$ demand curves. The same forces remain when some goods do not fully depreciate each period, just in a more opaque form.

\subsection{Production and Market Clearing}

Each industry produces a quantity $\left(Q_{t J}\right)$ of good $J$ at date $t$ using capital $\left(K_{t J}\right)$, labor $\left(L_{t J}\right)$, and intermediate inputs $\left(M_{t J}\right)$ according to the following constant-returns-to-scale

\footnotetext{
${ }^{11}$ Horvath (2000) and Kim and Kim (2006) use a more flexible specification regarding the disutility from supplying labor. In their specification, the second line of Equation 1 is replaced by

$$
-\frac{\varepsilon_{L S}}{\varepsilon_{L S}+1} \cdot\left(\sum_{J=1}^{N}\left(L_{t J}\right)^{\frac{\tau+1}{\tau}}\right)^{\frac{\tau}{\tau+1} \frac{\varepsilon_{L S}+1}{\varepsilon_{L S}}} .
$$

The idea behind this specification is to "capture some degree of sector specificity to labor while not deviating from the representative consumer/worker assumption." Horvath (2000, p. 76) As it turns out, neither the volatility of aggregate economic activity nor the covariances of output across industries are particularly sensitive to the value of $\tau$ (see Table 9 of that paper). Moreover, since wages and hours are not among the observable variables that I am trying to match, the data that I employ in the following sections would have trouble identifying $\tau$. For these reasons, I use the simpler specification of the disutility from labor supply.

${ }^{12}$ The ideal price index is:
}

$$
P_{t} \equiv\left[\sum_{I=1}^{N} \frac{\xi_{I} \cdot D_{t I} \cdot D_{t A g g}}{\sum_{J=1}^{N} \xi_{J} \cdot D_{t J} \cdot D_{t A g g}}\left(P_{t I}\right)^{1-\varepsilon_{D}}\right]^{\frac{1}{1-\varepsilon_{D}}}
$$


production function:

$$
\begin{aligned}
Q_{t J}= & A_{t J} \cdot A_{t, A g g} \\
& \times\left[\left(1-\mu_{J}\right)^{\frac{1}{\varepsilon_{Q}}}\left(\left(\frac{K_{t J}}{\alpha_{J}}\right)^{\alpha J}\left(\frac{B_{t J} \cdot B_{t, A g g} \cdot L_{t J}}{1-\alpha_{J}}\right)^{1-\alpha_{J}}\right)^{\frac{\varepsilon_{Q}-1}{\varepsilon_{Q}}}+\left(\mu_{J}\right)^{\frac{1}{\varepsilon_{Q}}}\left(M_{t J}\right)^{\frac{\varepsilon_{Q}-1}{\varepsilon_{Q}}}\right]^{\frac{\varepsilon_{Q}}{\varepsilon_{Q}-1}} .
\end{aligned}
$$

The parameters $\mu_{J}$ and $\alpha_{J}$ reflect long-run averages in each industry's usage of intermediate inputs, labor, and capital. These parameters will eventually be inferred from the factor cost shares of each industry. $A_{t, A g g} \cdot A_{t J}$ and $B_{t, A g g} \cdot B_{t J}$ are, respectively, the factor-neutral and the labor-augmenting productivity of industry $J$ at time $t$. As with the preference parameters, each of these productivity terms consists of an industry-specific component and a component that is common to all industries.

The parameter $\varepsilon_{Q}$ dictates how easily factors of production are substituted. From the cost-minimization condition of the industry $J$ representative firm, the relationship between the intermediate input cost share of industry $J$ and the industry $J$ specific intermediate input price (denoted $P_{t J}^{m a t}$ ) is log-linear, with slope $1-\varepsilon_{Q}:^{13}$

$$
\log \left(\frac{P_{t J}^{m a t} \cdot M_{t J}}{P_{t J} \cdot Q_{t J}}\right)=\log \mu_{J}+\left(1-\varepsilon_{Q}\right) \log \left(\frac{P_{t J}^{m a t}}{P_{t J}}\right)+\left(\varepsilon_{Q}-1\right) \log \left(A_{t J} \cdot A_{t, A g g}\right) .
$$

When $\varepsilon_{Q}=1$, as assumed in previous papers, an industry's intermediate input cost share is constant, independent of the price of its intermediate inputs, a prediction that I will show to be at odds with the data.

The evolution of capital, for each industry $J$, is given in Equation 5.

$$
K_{t+1, J}=\left(1-\delta_{K}\right) K_{t J}+X_{t J}
$$

The capital stock is augmented via an industry-specific investment good, $X_{t J}$, and de-

\footnotetext{
${ }^{13}$ The equivalence between sales and costs in the denominator of the left-hand side of Equation 4 comes from the assumption that each industry is perfectly competitive, with a constant returns-to-scale production function. chases:

$$
\begin{aligned}
P_{t J}^{m a t} & =P_{t J} \cdot \frac{\partial Q_{t J}}{\partial M_{t J}} \\
& =P_{t J} \cdot\left(A_{t J} \cdot A_{t, A g g}\right)^{\frac{\varepsilon_{Q}-1}{\varepsilon_{Q}}}\left(M_{t J}\right)^{-\frac{1}{\varepsilon_{Q}}}\left(\mu_{J} \cdot Q_{t J}\right)^{\frac{1}{\varepsilon_{Q}}} . \\
\left(P_{t J}^{m a t}\right)^{\varepsilon_{Q}} & =\left(P_{t J}\right)^{\varepsilon_{Q}}\left(A_{t J} \cdot A_{t, A g g}\right)^{\varepsilon_{Q}-1}\left(M_{t J}\right)^{-1} \mu_{J} \cdot Q_{t J} .
\end{aligned}
$$
}

To derive Equation 4, take first-order conditions of Equation 3 with respect to intermediate input pur-

Taking logs and re-arranging gives Equation 4. 
preciates at a rate $\delta_{K}$ that is common across industries.

The industry-specific investment good is produced by combining the goods produced by other industries. The $\Gamma_{I J}^{X}$ indicate how important industry $I$ is in the production of the industry $J$ specific investment good, while $\varepsilon_{X}$ parameterizes the substitutability of different inputs in the production of each industry's investment bundle:

$$
X_{t J}=\left(\sum_{I=1}^{N}\left(\Gamma_{I J}^{X}\right)^{\frac{1}{\varepsilon_{X}}}\left(X_{t, I \rightarrow J}\right)^{\frac{\varepsilon_{X}-1}{\varepsilon_{X}}}\right)^{\frac{\varepsilon_{X}}{\varepsilon_{X}-1}}
$$

Analogously, the intermediate input bundle of industry $J$ is produced through a combination of the goods purchased from other industries:

$$
M_{t J}=\left(\sum_{I=1}^{N}\left(\Gamma_{I J}^{M}\right)^{\frac{1}{\varepsilon_{M}}}\left(M_{t, I \rightarrow J}\right)^{\frac{\varepsilon_{M}-1}{\varepsilon_{M}}}\right)^{\frac{\varepsilon_{M}}{\varepsilon_{M}-1}}
$$

In Equation 7, $\varepsilon_{M}$ parameterizes the substitutability of different goods in the production of each industry's intermediate input bundle. The $\Gamma_{I J}^{M}$ indicate how important industry $I$ is in the production of the industry $J$ specific intermediate input.

To emphasize, the parameters $\Gamma_{I J}^{M}, \Gamma_{I J}^{X}, \alpha_{J}$, and $\mu_{J}$ are time invariant. As such, movements in the share of $J$ 's expenditures spent on different factors of production are due, only, to the shocks to industries' productivity and consumers' preferences.

Finally, the market-clearing condition for each industry states that output can be used for consumption, as an intermediate input, or to increase one of the $N$ capital stocks:

$$
Q_{t I}=C_{t I}-\left(1-\delta_{C_{I}}\right) C_{t-1, I}+\sum_{J=1}^{N}\left(M_{t, I \rightarrow J}+X_{t, I \rightarrow J}\right)
$$

\subsection{Evolution of the Exogeneous Variables}

The three sets of exogenous variables - to factor-neutral productivity, labor-augmenting productivity, and preferences - follow stochastic processes each of a similar form. Each variable has an industry-specific and an aggregate component, both of which follow a firstorder autoregressive process.

The industry-specific components take the form described by Equations 9 to 11:

$$
\begin{aligned}
& \log A_{t+1, J}=\rho_{A, I n d} \cdot \log A_{t J}+\sigma_{A, I n d} \cdot \omega_{t J}^{I n d, A} . \\
& \log B_{t+1, J}=\rho_{B, \text { Ind }} \cdot \log B_{t J}+\sigma_{B, \text { Ind }} \cdot \omega_{t J}^{\text {Ind,B }} . \\
& \log D_{t+1, J}=\rho_{D . \text { Ind }} \cdot \log D_{t J}+\sigma_{D, \text { Ind }} \cdot \omega_{t J}^{I n d, D} .
\end{aligned}
$$


The aggregate components take the form characterized by Equations 12 to 14:

$$
\begin{aligned}
& \log A_{t+1 \text { Agg }}=\rho_{A, A g g} \cdot \log A_{t A g g}+\sigma_{A . A g g} \cdot \omega_{t}^{A g g, A} . \\
& \log B_{t+1 A g g}=\rho_{B . A g g} \cdot \log B_{t A g g}+\sigma_{B, A g g} \cdot \omega_{t}^{A g g, B} . \\
& \log D_{t+1, A g g}=\rho_{D, A g g} \cdot \log D_{t, A g g}+\sigma_{D . A g g} \cdot \omega_{t}^{A g g, D} .
\end{aligned}
$$

In Equations 9 to 14, the ws are independent standard normal random variables.

Several assumptions are embedded within Equations 9 to 14. First, the persistence and standard deviations of each of the industry-specific components is assumed to be the same for all industries (e.g., $\sigma_{I n d, D}$ and $\rho_{I n d, D}$ are common across all industries.) In reality, industries may differ in how persistent and volatile their productivity and demand are. Moro (2012) and Carvalho and Gabaix (2013), for example, argue that productivity is substantially more volatile in manufacturing and finance than in other industries. Second, Equations 9 to 14 place strong restrictions on the covariance matrix of the productivities (or the covariance matrices of preferences) across industries. For example, the correlation between the productivity growth of two industries is the same for all pairs. ${ }^{14}$ Despite their restrictive nature, the assumptions embedded in Equations 9 to 14 are useful: they yield a parsimonious comparison of the importance of the industry-specific and aggregate components of the shocks to the exogeneous variables. ${ }^{15}$

\section{Data and Descriptive Statistics}

The three datasets employed to evaluate the model are Dale Jorgenson's 35-Sector KLEMS database, the 1992 BEA Input-Output Table, and the 1992 BEA Capital Flows Table. The first dataset is used to measure fluctuations in sales, inputs, and prices, while the second and third datasets are employed to measure long-run flows of inputs across pairs of industries. I describe the three databases, in turn. Additional details can be found in Appendix B.

Dale Jorgenson's 35-Sector KLEMS dataset contains information on industries' pro-

\footnotetext{
${ }^{14}$ The growth of industry $J$ 's factor-neutral productivity equals:

$\log \left[\frac{A_{t+1, J} \cdot A_{t+1, A g g}}{A_{t J} \cdot A_{t, A g g}}\right]=\left(\rho_{A, A g g}-1\right) \cdot \log A_{t, A g g}+\left(\rho_{A, I n d}-1\right) \cdot \log A_{t J}+\sigma_{A, I n d} \cdot \omega_{t J}^{I n d, A}+\sigma_{A, A g g} \cdot \omega_{t}^{A g g, A}$.

Thus, conditional on the productivities of industries $J$ and $J^{\prime}$ at time $t$, the correlation of the factor-neutral productivity growth of the two industries equals $\left[1+\left(\sigma_{A, I n d} \div \sigma_{A, A g g}\right)^{2}\right]^{-1}$.

${ }^{15}$ In Appendix A, I examine the consequences of relaxing the restrictions discussed in this paragraph.
} 
duction and input usage patterns at an annual level, from 1960 to 2005. ${ }^{16}$ As its name suggests, the dataset contains information on 35 industries, roughly at the 2-digit level for the manufacturing sector and at the 1 to 2-digit level for other sectors. I drop the "Government Enterprises" industry, leaving 34 industries in my dataset. There are two main advantages of this dataset, compared to others that track industries' production fluctuations. First, unlike the NBER - CES Manufacturing database or the Federal Reserve Board's Industrial Production database, Dale Jorgenson's dataset contains information on the entire economy, not just the goods-producing sectors. Second, unlike the Industrial Production database, the dataset that I am working with tracks intermediate input prices and purchases for each industry. These data are critical in evaluating the shape of industries' production technologies.

The BEA Input-Output Table and Capital Flows Table provide information on the flows of intermediate inputs and capital goods, across pairs of industries. While these data are published every five years, I use only the 1992 version of the two tables. By taking only one vintage of the Input-Output and Capital Flows Tables, I am assuming that the strength of the linkages across industries (as parameterized by the $\Gamma_{I J}^{M} \mathrm{~s}$ and $\Gamma_{I J}^{X} \mathrm{~s}$ ) are unchanged throughout the sample period.

The four industry-level time series that I consider are gross output $\left(Y_{t I}\right),{ }^{17}$ the intermediate input expenditure share $\left(M_{t I}^{\text {share }}\right)$, the price for the good produced by the industry $\left(P_{t I}\right)$, and the price for the intermediate input used by the industry $\left(P_{t I}^{m a t}\right)$. Gross output is the product of the industry output price $\left(P_{t I}\right)$ and the quantity of the good produced $\left(Q_{t I}\right)$. I compute the intermediate input expenditure share by taking the ratio of expenditures on intermediate inputs to the total expenditure on capital goods, labor, and intermediate inputs.

I perform three transformations on the variables of interest, with the aim of harmonizing the data and Section 2's model. First, I consider growth rates of each of the variables, with the aggregate price level subtracted off of the sales, output price, and input price measures. ${ }^{18}$ To mitigate the effect of outliers on the parameter estimates, I winsorize the variables at the top and bottom 0.5 percentiles. ${ }^{19}$ Finally, because there is no trend

\footnotetext{
${ }^{16}$ KLEMS is an acronym for capital, labor, energy, materials, and services. The data can be found on Dale Jorgenson's home page (see http://scholar.harvard.edu/jorgenson/data).

${ }^{17}$ I will use the terms gross output and sales interchangeably.

${ }^{18}$ The rationale for subtracting the aggregate price level stems from Section 2's model's omission of monetary considerations. Because this model is not equipped to distinguish between technology growth from money supply growth as the source of aggregate price fluctuations, I have decided to simply remove aggregate price variation from the data. In the estimation stage, I also construct the model counterpart to changes in the aggregate price level and subtract this series from industries' sales and price measures.

${ }^{19}$ When winsorizing, I pool across all industries, compute the growth rate of the variable of interest across industries and years, and then trim the top and bottom $0.5 \%$ observations within this pooled sample. In
} 
present in the model, I linearly de-trend the four industry level variables. ${ }^{20}$ Throughout this section and the next two, I use $\Delta v$ to refer to the transformed version of variable $V$.

Having introduced the data sources and discussed the industry definitions, I now present two patterns which will guide the empirical analysis of Section 4. The first pattern is simply that activity is correlated across industries. Over the $35^{2}$ pairs of industries, the correlation of industries' sales growth rates is, on average, $27.3 \%$. The correlation of the growth rates of industries' intermediate input cost shares is $22.2 \%$ for the average industry pair. As discussed in the introduction, there are two possible explanations for the positive values of these correlations. Aggregate events - such as a change in monetary or fiscal policy or a financial crisis - no doubt play some role in explaining these co-movements. At the same time, because of the input-output relationships that exist between industries, pairs of industries' sales (or input purchases) will co-move even with independent, industry-specific shocks. Disentangling the two alternatives is the primary goal of the model. In general, the estimation will assign greater importance to aggregate (versus industry-specific) shocks the higher the value of the cross-industry correlations.

Table 1 presents the second set of patterns: the volatility and average correlations in the growth rates of the four industry-level characteristics, now pooled across all industryyears. Here, the standard deviation of the growth rate of gross output is $7.2 \%$ in the pooled sample. Output and input prices are less volatile: The standard deviations of the growth of the price variables are $4.8 \%$ and $2.7 \%$, respectively. Finally, the intermediate input cost share is the least volatile. Critically, however, the cost share fluctuates over time and is positively correlated with input prices. The fluctuating intermediate input cost share is a first indication that sectoral production technologies are not well-described by a Cobb-Douglas production function.

Motivated by Equation 4, define $\Delta \pi_{t I} \equiv \Delta p_{t I}^{m a t}-\Delta p_{t I}$ as the change in the ratio of industry I's intermediate input price to its output price. According to Equation 4, the strength and direction of the relationship between $\Delta m_{t I}^{\text {share }}$ and $\Delta \pi_{t I}$ depends critically on

Appendix A, I consider the effect of varying this $0.5 \%$ cut-off to $0.25 \%$ or $1.0 \%$.

${ }^{20} \mathrm{In}$ estimations of dynamic general equilibrium models, the choice of the de-trending procedure is potentially important; see Canova (2013). In Appendix A, I re-estimate the model with alternative de-trending procedures. Both the relative importance of industry-specific shocks and the estimate of $\varepsilon_{Q}$ are robust to the alternative procedures.

An alternative - intuitively appealing but unfortunately infeasible - way to deal with trends would be to include both transitory and permanent shocks in the model. This would obviate the need to de-trend the data before estimation; the parameters governing the permanent and transitory shock processes would be jointly estimated in a single stage. I do not pursue this approach, mainly because of the difficulty of scaling the model by the permanent shocks. Doing so requires a clean characterization of the changes in the industrylevel observable variables as functions of the permanent shocks, something that exists only for a few special cases of the model (such special cases can be found in, for example, Ngai and Pissarides 2007 and Acemoğlu and Guerreri 2008). 


\begin{tabular}{lcccc}
\hline & $\Delta y_{t I}$ & $\Delta p_{t I}$ & $\Delta m_{t I}^{\text {share }}$ & $\Delta p_{t I}^{\text {mat }}$ \\
\hline$\Delta y_{t I}$ & 1 & & & \\
$\Delta p_{t I}$ & $0.610^{*}$ & 1 & & \\
$\Delta m_{t I}^{\text {share }}$ & $0.107^{*}$ & -0.010 & 1 & \\
$\Delta p_{t I}^{\text {mat }}$ & $0.451^{*}$ & $0.745^{*}$ & $0.244^{*}$ & 1 \\
$\Delta \pi_{t I}$ & $-0.516^{*}$ & $-0.841^{*}$ & $0.212^{*}$ & $-0.265^{*}$ \\
$\mathrm{SD}$ & 0.072 & 0.048 & 0.025 & 0.027 \\
\hline
\end{tabular}

Table 1: Correlations and standard deviations of the growth rates of industry-level statistics.

Notes: Stars indicate that the correlation is statistically different from 0 , at the $5 \%$ level.

$\varepsilon_{Q}$. The positive, $21 \%$, correlation between $\Delta \pi_{t I}$ and $\Delta m_{t I}^{\text {share }}$ indicates that the elasticity of substitution between intermediate inputs and other inputs may be less than 1 . The intermediate input cost share and the relative price of intermediate inputs are positively related over longer horizons, as well: The correlation between $\Delta m_{t I}^{\text {share }}$ and $\Delta \pi_{t I}$ equals $9.1 \%$, $25.0 \%$, and $37.5 \%$, over 3 -year, 5-year, and 10-year intervals, respectively, thus indicating that the low substitutability between intermediate inputs and other inputs is not just a short-run phenomenon.

As I will argue below in Sections 4 and 5, the estimate of $\varepsilon_{Q}$ both hinges on the relationship between $\Delta \pi_{t I}$ and $\Delta m_{t I}^{\text {share }}$ and is a crucial component in an assessment of the relative importance of industry-specific shocks. For these reasons, it will be useful to examine the correlation between $\Delta \pi_{t I}$ and $\Delta m_{t I}^{\text {share }}$ in more detail. Figure 1 depicts the cross-sectional (left panel) and time series (right panel) relationships between these variables. In the left panel, I plot $\Delta \pi_{t I}$ and $\Delta m_{t I}^{\text {share }}$ for a typical year, 1984: In this year the correlation equals $18 \%$. The right panel plots $\Delta m_{t I}^{\text {share }}$ and $\Delta \pi_{t I}$ for a single industry, Miscellaneous Manufacturing, across the entire 45-year sample period. For this industry, input prices increased substantially between 1971 and $1974 .^{21}$ During this time, the intermediate input cost share increased moderately, as well, from $48 \%$ to $52 \%$ of total expenditures.

Were it not for the omitted variable of industry $J$ productivity (the final term on the right-hand side), Equation 4 would yield an unbiased estimate of $\varepsilon_{Q}$ : I would simply need to compute the slope of the relationship between $\log \left(P_{t J}^{\text {mat }} \div P_{t J}\right)$ and industries' $\log \left(M_{t J}\right)$. However, because industries' productivities and output prices are (negatively) correlated, such an exercise would yield a biased estimate of $\varepsilon_{Q}$. The exercise to which I now turn - jointly estimating the preference and technology elasticities in conjunction with the parameters of the exogeneous productivity and demand processes - circumvents these problems.

\footnotetext{
${ }^{21}$ During this period there was a broad increase in commodity prices. See Cooper and Lawrence (1975) and Radetzki (2006) for two accounts of this commodity price boom.
} 

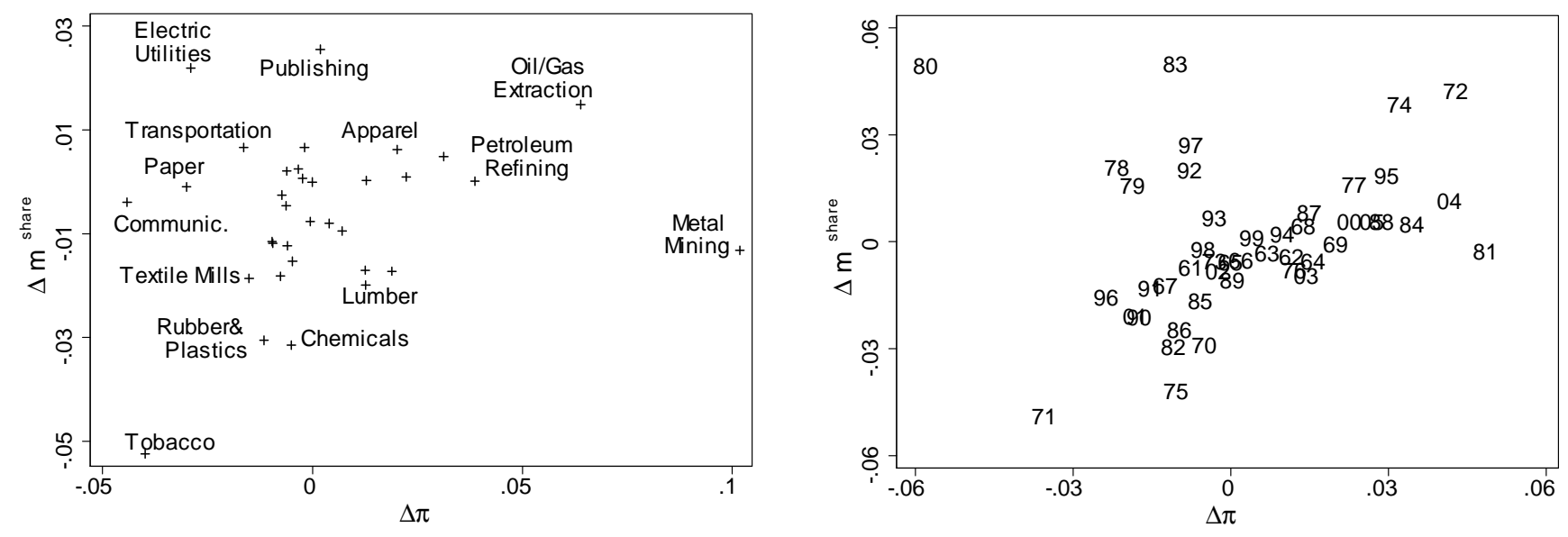

Figure 1: Relationship between $\Delta m^{\text {share }}$ and $\Delta \pi$.

Notes: Left panel: Data from 1984. Right panel: Data from the Miscellaneous Manufacturing industry.

\section{Estimation and Results}

This section contains the main empirical content of the paper. In this section, I describe the estimation procedure (Section 4.1), present the model's MLE estimates and corresponding variance decompositions (Section 4.2), and examine the sensitivity of the benchmark results to changes in sample, industry definition, period length, country, and other details of the estimation procedure (Section 4.3).

\subsection{Estimation Procedure}

I apply a combination of moment matching and maximum likelihood to empirically evaluate the model.

The parameters $\xi_{J}, \mu_{J}, \alpha_{J}, \Gamma_{I J}^{X}$, and $\Gamma_{I J}^{M}$ are chosen to match the model-predicted cost shares to the corresponding values in the data. These parameters contain only information about the steady-state of the equilibrium allocation. The demand shares, $\xi_{J}$, are chosen so that the model's steady-state consumption choices are proportional to the amount that the industry sells; the $\xi_{J}$ are restricted to sum to 1 . The other parameters are chosen to match factor intensities, for each industry-factor pair. For instance, $\mu_{J}$ is the value that equates the model-predicted intermediate input cost share with the empirical counterpart. ${ }^{22}$ The empirical values that are used to calibrate the factor intensities are described in Ap-

\footnotetext{
${ }^{22}$ When $\varepsilon_{Q}=1$, the intermediate input cost share and $\mu_{J}$ are equal to one another. Alternatively, when intermediate inputs are gross complements or gross substitutes to other factors of production, the modelpredicted cost share will also depend on the relative prices of the intermediate input bundle and the price of the other factors of production.
} 
pendix B. Appendix D.2 provides additional details on the calibration of the parameters relevant to the steady state. ${ }^{23}$

I choose $\beta, \delta_{K}, \delta_{C_{J}}$, and $\varepsilon_{L S}$ based on the values used in past analyses. I set the discount factor, $\beta$, to 0.96 and the capital good depreciation rate, $\delta_{K}$, to 0.10 . The durable good depreciation rates, $\delta_{C_{J}}$, are taken from computations published by the BEA (see Appendix B for these depreciation rates). In the benchmark calculations, I set the Frisch labor supply elasticity to be equal to 1, in line with Prescott (2006). In the appendix, I re-estimate the model using larger values for $\varepsilon_{L S}$, closer to the values given in Chetty et al. (2011).

The other parameters - the elasticities of substitution and the parameters characterizing the exogeneous processes - are estimated via maximum likelihood. The maximum likelihood procedure compares the model's predictions over the growth rates of industries' sales, prices, and intermediate input cost shares to their data counterparts. ${ }^{24}$

I allow for measurement error in industries' intermediate input cost shares. There is considerable evidence that the values of industries' intermediate inputs are measured with error, and that this measurement error is more severe than for the other variables. First, as Jorgenson, Gollop, and Fraumeni (1987) write in their description of the KLEMS dataset, information on industries' intermediate input purchases are, in general, taken as a residual of the gross output of a given industry and the labor and capital value added of that industry (see p. 159). Any measurement error in labor or capital inputs will show up in the intermediate input cost shares, as well. For manufacturing industries, it is possible to gauge the extent to which intermediate input cost shares are mismeasured in the Jorgenson KLEMS Dataset. The NBER - CES manufacturing dataset, which draws on data from the Census Bureau's Annual Survey of Manufacturers, is an alternate source of information on industry level sales, prices, and input cost shares. Applying the same industry classification and using the same sample period as in the current paper, I compute that the standard deviation of the growth rate of industries' intermediate input cost shares is $1.8 \%$ for the NBER - CES dataset and $2.1 \%$ for the Jorgenson KLEMS dataset. Since these two datasets measure the same thing, the difference in these standard deviations serves as a lower bound for the

\footnotetext{
${ }^{23}$ In Appendix A, I examine the sensitivity of Section 4's results to using 1972, instead of 1992, as the year to which the steady-state allocation is calibrated.

${ }^{24}$ All computations are performed in Dynare. The value of the likelihood function, at any parameter configuration, is the result of the Kalman filter algorithm applied to the first-order approximation to the model introduced in Section 2. Regarding the Kalman filter, see Canova (2007, Chapter 6) for a textbook introduction, and Adjeman et al. (2011) for a description of the practical implementation. To find the numerical maximum of the log likelihood function, I use a simplex search algorithm, and try different starting points to check that the search algorithm is finding a global optimum.
} 
measurement error present in the Jorgenson KLEMS dataset.

The measurement errors serve a second, more practical, role in the empirical analysis. Without these measurement errors, specifications in which $\varepsilon_{Q}$ is restricted to 1 cannot possibly be estimated with the aforementioned procedure. With a unitary elasticity of substitution between intermediate inputs and value added, the intermediate input cost share must be constant. Thus, when $\varepsilon_{Q}$ equals 1 , the log likelihood would be negative infinity for all combinations of the other parameters.

In the benchmark calculations, I assume that the measurement error for each industry has an industry-specific and an aggregate component (call these $M_{t J}^{\text {error }}$ and $M_{t, A g g}^{\text {error }}$, respectively). Thus, the observed intermediate input cost share is specified by the following equation:

$$
M_{t J}^{\text {share }} \equiv \frac{P_{t J}^{m a t} \cdot M_{t J}}{Y_{t J}} \cdot M_{t J}^{\text {error }} \cdot M_{t, A g g}^{\text {error }} .
$$

The logarithm of each component of an industry's measurement error follows an firstorder autoregressive process, with a serial autocorrelation of 0.8 and innovations that have a standard deviation of $0.2 \%{ }^{25}$ I choose these values to be roughly consistent with the evidence described above and to allow the productivity and demand shocks to explain almost all of the variation in industries' intermediate input purchases.

\subsection{Results}

Parameter estimates are collected in Table 2.

The full specification is presented in the first column. The first four rows give the estimates of the elasticities of substitution; the next six rows give the estimates of the standard deviations of the innovations to productivities and preferences; and the final six give the estimates of the serial autocorrelations of the exogeneous processes. The estimate for the elasticity of substitution, $\varepsilon_{Q}$, between intermediate inputs and value added is 0.05; intermediate inputs and value added are used in (almost) fixed proportions. The elasticity of substitution, $\varepsilon_{D}$, in consumer's preferences, is 0.65 , indicating the the goods produced by different industries are also gross complements. Finally the elasticity of substitution in the production of the intermediate input bundle, $\varepsilon_{M}$, is close to 0 .

In columns (2) to (6), I restrict various combinations of the elasticities of substitution to be equal to 1 . The point of this exercise is to understand the impact of the assumptions made by previous authors, such as Foerster, Sarte, and Watson (2011) and Acemoğlu et al. (2012), regarding these elasticities of substitution. The largest drop in the log likelihood

\footnotetext{
${ }^{25}$ In Appendix A, I show that the results of the current section are robust to moderate changes to assumptions on these measurement error terms.
} 


\begin{tabular}{ccccccc}
\hline Specification & $(1)$ & $(2)$ & $(3)$ & $(4)$ & $(5)$ & $(6)$ \\
\hline$\varepsilon_{D}$ & 0.654 & 1 & 1 & 0.587 & 1 & 1 \\
$\varepsilon_{Q}$ & 0.046 & 0.053 & 0.020 & 1 & 1 & 1 \\
$\varepsilon_{M}$ & 0.034 & 0.031 & 1 & 0.128 & 0.010 & 1 \\
$\varepsilon_{X}$ & 2.870 & 0.001 & 1 & 2.313 & 0.731 & 1 \\
$\sigma_{A, \text { Ind }}$ & 0.046 & 0.045 & 0.042 & 0.034 & 0.035 & 0.034 \\
$\sigma_{B, \text { Ind }}$ & 0.110 & 0.113 & 0.110 & 0.000 & 0.000 & 0.000 \\
$\sigma_{D, \text { Ind }}$ & 0.062 & 0.072 & 0.103 & 0.061 & 0.071 & 0.105 \\
$\sigma_{A, \text { Agg }}$ & 0.010 & 0.000 & 0.008 & 0.010 & 0.009 & 0.007 \\
$\sigma_{B, \text { Agg }}$ & 0.040 & 0.038 & 0.040 & 0.001 & 0.016 & 0.015 \\
$\sigma_{D, \text { Agg }}$ & 0.001 & 0.006 & 0.000 & 0.050 & 0.001 & 0.021 \\
$\rho_{A, \text { Ind }}$ & 1.000 & 0.981 & 1.000 & 1.000 & 1.000 & 1.000 \\
$\rho_{B, \text { Ind }}$ & 0.889 & 0.937 & 0.894 & 1.000 & 1.000 & 0.999 \\
$\rho_{D, \text { Ind }}$ & 0.949 & 0.944 & 0.957 & 0.964 & 0.933 & 0.956 \\
$\rho_{A, \text { Agg }}$ & 1.000 & 0.552 & 0.934 & 1.000 & 0.860 & 0.850 \\
$\rho_{B, \text { Agg }}$ & 0.984 & 0.973 & 0.962 & 0.978 & 1.000 & 0.781 \\
$\rho_{D, \text { Agg }}$ & 1.000 & -0.257 & 1.000 & 0.964 & 1.000 & 1.000 \\
\hline Log Likelihood & 6743.0 & 6682.1 & 6397.6 & -94288.6 & -94374.2 & -94677.1 \\
\hline
\end{tabular}

Table 2: MLE Estimates.

Notes: Each column gives the results from a different specification. Whenever a "1" appears in the first four rows, the corresponding elasticity is set equal to 1 prior to estimating the other parameters. ${ }^{26}$

function occurs in specifications for which $\varepsilon_{Q}$ is fixed at 1: The model simply cannot fit movements in industries' intermediate input cost shares. Imposing $\varepsilon_{Q}=1$ also alters the estimated values of the exogeneous processes. Most importantly, the estimated value $\sigma_{B, \text { Ind }}$ is considerably larger in the first three columns.

The estimates of $\varepsilon_{Q}$ and $\varepsilon_{D}$ given in Table 2 broadly accord with the few existing estimates for these parameters, with $\varepsilon_{Q}$ on the lower end of existing estimates. With respect to the estimate of $\varepsilon_{D}$, the most appropriate comparison would probably be Ngai and Pissarides (2007) and its cited sources. The authors argue that the "observed positive correlation between employment growth and relative price inflation across two-digit sectors" (p. 430) is consistent with an estimate of $\varepsilon_{D}$ that is less than 1. ${ }^{27}$ Bruno (1984) estimates $\varepsilon_{Q}$ by running an industry panel regression of manufacturing industries' intermediate input

\footnotetext{
${ }^{26}$ Standard errors are omitted to preserve space. These standard errors are almost universally small, on the order of $1 \%$ or less.

${ }^{27}$ To emphasize, $\varepsilon_{D}$ parameterizes how easily the consumer can substitute across coarsely-defined industries' products (for example the elasticity of substitution between automobiles and furniture, or between apparel and construction). Broda and Weinstein (2006) and Foster, Haltiwanger, and Syverson (2008), among others, estimate a much lager elasticity of substitution in consumers' preferences. These larger elasticities of substitution are estimated using within-industry variation, and characterize how easily consumers substitute between, for example, ready-mix concrete produced by two different plants, or between different varieties of red wine.
} 


\begin{tabular}{lrrrrrr}
\hline Specification & $(1)$ & $(2)$ & $(3)$ & $(4)$ & $(5)$ & $(6)$ \\
\hline Aggregate Shocks & 36.9 & 28.7 & 41.4 & 56.6 & 54.8 & 52.0 \\
Aggregate, Factor-Neutral Productivity & 10.0 & 0.0 & 11.8 & 36.2 & 42.6 & 28.4 \\
Aggregate, Labor-Augmenting Productivity & 26.9 & 28.7 & 29.7 & 0.1 & 12.2 & 18.7 \\
Aggregate, Demand & 0.0 & 0.0 & 0.0 & 20.3 & 0.0 & 4.8 \\
Industry-Specific Shocks & 63.1 & 71.2 & 58.6 & 43.4 & 45.2 & 48.0 \\
Industry, Factor-Neutral Productivity & 21.3 & 25.9 & 17.9 & 37.8 & 40.5 & 35.5 \\
Industry, Labor-Augmenting Productivity & 40.2 & 43.5 & 36.5 & 0.0 & 0.0 & 0.0 \\
Industry, Demand & 1.7 & 1.8 & 4.1 & 5.6 & 4.7 & 12.5 \\
\hline & & & $\varepsilon_{D}$ & & $\varepsilon_{D}$ & \\
Which Elasticities are Restricted to 1? & None & $\varepsilon_{D}$ & $\varepsilon_{M}$ & $\varepsilon_{Q}$ & $\varepsilon_{Q}$ & All \\
& & & $\varepsilon_{X}$ & & & \\
\hline
\end{tabular}

Table 3: Variance Decompositions.

Notes: Each row gives the fraction of the variance in aggregate output growth that is due to the specified type of shock. The columns correspond to the specifications estimated in Table 2.

expenditure shares against the relative price of intermediate inputs. Bruno's benchmark specification yields an estimate of $\varepsilon_{Q}=0.3$; other specifications in this paper have $\varepsilon_{Q}$ estimated to be anywhere in the range of -0.2 to 0.9. Rotemberg and Woodford (1996) run a similar regression, but instrument the relative price of intermediate inputs using the price of crude oil. For industries within the manufacturing sector, Rotemberg and Woodford estimate that $\varepsilon_{Q}=0.7$.

Table 3 presents the forecast error variance decompositions. The table apportions the fraction of the variance of the change in aggregate output that is due to these six sets of shocks. In the unrestricted specification, industry-specific demand, factor-neutral productivity, and labor-augmenting productivity shocks account, respectively, for $2 \%, 21 \%$, and $40 \%$ of aggregate output growth variation, meaning that $63 \%$ of the variability of aggregate output growth originates from industry-specific shocks; see column 1. Restricting $\varepsilon_{Q}=1$, as I do in the fourth, fifth, and sixth columns of Table 3, decreases the estimated importance of industry-specific shocks to approximately $43 \%$ to $48 \%$, close to the values reported by Foerster, Sarte, and Watson (2011). (As a reminder, the authors impose that $\varepsilon_{Q}=\varepsilon_{D}=\varepsilon_{M}=\varepsilon_{X}=1$.) In that paper, the authors report that approximately $40 \%$ of the variability of industrial production growth is due to industry-specific shocks. ${ }^{28}$

\footnotetext{
${ }^{28}$ Foerster, Sarte, and Watson (2011) perform a factor analysis on industries' productivity shocks and then compute the fraction of industrial production growth that is due to the first two factors. The remaining variation can be considered equivalent to the industry-specific productivity shocks in the current paper. The two common factors explain $80 \%$ of the variation in overall industrial production growth in the first third of the sample (1972 to 1983) and 50\% in the latter two-thirds (1984 to 2007).

There are a few potential explanations for the difference. The biggest difference is that the Foerster, Sarte, and Watson (2011) analysis is restricted to the goods-producing sectors of the economy, while I study the entire private economy. Other differences include a difference in sample period (1960 to 2005 in the
} 
Tables 2 and 3 contain the main results of the paper. The remainder of the paper is devoted to studying the robustness of the MLE estimates, explaining how the elasticities of substitution are identified, and discussing a simple example that explains why freely estimating $\varepsilon_{Q}$ corresponds to larger estimates for the relative importance of industry-specific shocks.

\subsection{Robustness Checks}

\section{Industry Definition, Sample Period, and Period Length}

Table 4 considers three robustness checks: to the industry classification scheme, to the sample period, and to the period length. Throughout the remainder of the section, I consider two specifications: In the first, all elasticities are freely estimated, while the second sets all elasticities equal to 1 (corresponding to columns 1 and 6 of Table 2). The motivation for presenting both specifications is to establish the impact of trying to fit the data on industries' intermediate input cost shares, something that is only possible when $\varepsilon_{Q} \neq 1$.

In the first two columns, I establish that the results of Tables 2 and 3 are qualitatively robust to an 8-industry partition of the economy. ${ }^{29}$ The relative importance of industryspecific shocks is now somewhat larger than in the benchmark specification, representing $71 \%$ of the variation in aggregate output growth. The primary difference, compared to the benchmark specification, is that the demand and productivity processes are substantially less volatile. This difference reflects the "averaging-out" of the idiosyncratic shocks within each of the 8 coarsely-defined industries.

Columns 3 through 6 examine the sample period stability of the parameter estimates. Consistent with the large literature on the Great Moderation, the estimated standard deviations are smaller in the second half of the sample period. The decline in dispersion is attributable mainly to the decline of aggregate shocks, similar to Foerster, Sarte, and Watson (2011): The fraction of variability due to industry-specific shocks is $60 \%$ in 1960 to 1982 and $70 \%$ in 1983 to 2005.

In the final columns, I re-estimate the model using biennial data. The motivation behind this exercise is to examine whether the low values of $\varepsilon_{Q}$ or $\varepsilon_{M}$ are due to adjustment

current paper, compared to 1972 to 2008 in Foerster, Sarte, and Watson 2011), period length (one quarter in Foerster, Sarte, and Watson 2011 versus one year, here), my inclusion of shocks to demand, which are absent in Foerster, Sarte, and Watson (2011), and Foerster, Sarte, and Watson (2011)'s imposition of unit roots in the stochastic process governing the productivity of each industry.

${ }^{29}$ These industries are primary inputs (industries 1 to 5 , according to Table 11), construction (industry 6), non-durable goods (industries 7 to 10 and 13 to 18), durable goods (industries 11, 12, and 19 to 27), transport (industries 28 to 31), wholesale and retail (industry 32), finance, insurance, and real estate (industry 33), and personal and business services (industry 34). While it would be interesting to test the sensitivity of these results to a finer industry classification scheme, the necessary data are unavailable. 


\begin{tabular}{ccccccccc}
\hline & \multicolumn{2}{c}{ Coarse Industry } & \multicolumn{2}{c}{$1960-1982$} & \multicolumn{2}{c}{$1983-2005$} & \multicolumn{2}{c}{ Period Length= } \\
& \multicolumn{2}{c}{ Definition } & \multicolumn{2}{c}{ Years } \\
\hline$\varepsilon_{D}$ & 0.812 & 1 & 0.749 & 1 & 0.616 & 1 & 0.579 & 1 \\
$\varepsilon_{Q}$ & 0.020 & 1 & 0.055 & 1 & 0.063 & 1 & 0.031 & 1 \\
$\varepsilon_{M}$ & 0.030 & 1 & 0.0 .37 & 1 & 0.034 & 1 & 0.033 & 1 \\
$\varepsilon_{X}$ & 0.061 & 1 & 0.364 & 1 & 1.628 & 1 & 2.953 & 1 \\
$\sigma_{A, \text { Ind }}$ & 0.029 & 0.023 & 0.045 & 0.035 & 0.044 & 0.031 & 0.067 & 0.050 \\
$\sigma_{B, \text { Ind }}$ & 0.055 & 0.014 & 0.105 & 0.000 & 0.110 & 0.000 & 0.166 & 0.001 \\
$\sigma_{D, \text { Ind }}$ & 0.038 & 0.045 & 0.069 & 0.106 & 0.055 & 0.098 & 0.100 & 0.173 \\
$\sigma_{A, \text { Agg }}$ & 0.000 & 0.005 & 0.010 & 0.009 & 0.007 & 0.002 & 0.016 & 0.014 \\
$\sigma_{B, \text { Agg }}$ & 0.020 & 0.009 & 0.033 & 0.023 & 0.041 & 0.019 & 0.068 & 0.041 \\
$\sigma_{D, \text { Agg }}$ & 0.017 & 0.023 & 0.017 & 0.001 & 0.000 & 0.025 & 0.000 & 0.007 \\
$\rho_{A, \text { Ind }}$ & 0.948 & 1.000 & 0.986 & 1.000 & 0.954 & 1.000 & 0.918 & 0.977 \\
$\rho_{B, \text { Ind }}$ & 0.888 & 0.211 & 0.902 & 1.000 & 0.821 & -0.990 & 0.769 & 0.654 \\
$\rho_{D, \text { Ind }}$ & 0.942 & 1.000 & 0.797 & 0.887 & 0.999 & 1.000 & 0.912 & 0.920 \\
$\rho_{A, \text { Agg }}$ & 0.357 & 0.874 & 0.999 & 0.807 & 0.999 & 1.000 & 0.864 & 1.000 \\
$\rho_{B, \text { Agg }}$ & 0.301 & 0.999 & 0.824 & 0.727 & 0.999 & 1.000 & 0.896 & 1.000 \\
$\rho_{D, \text { Agg }}$ & 0.471 & 1.000 & 0.931 & 1.000 & 0.999 & 0.422 & 0.999 & 1.000 \\
\hline Log Likelihood & 1975.3 & -8106.8 & 3145.9 & -48565.7 & 3543.5 & -35526.4 & 2486.8 & -20266.3 \\
\hline$\%$ of Variation & & & & & & & & \\
from Industry- & 70.7 & 64.8 & 60.2 & 32.2 & 69.6 & 72.2 & 55.8 & 45.0 \\
Specific Shocks & & & & & & & & \\
\hline
\end{tabular}

Table 4: MLE Estimates, Robustness Checks: Industry Definition, Sample Period, and Period Length.

Notes: The final row gives the fraction of aggregate output growth volatility that is due to industry-specific demand and productivity shocks.

costs - or some other friction - that prevent industries from substituting across its factors of production in the very short run. To the extent that this is the case, the results in the final columns of Table 4 should differ from those in the benchmark specification. It turns out that the change in period length alters neither the relative importance of industry-specific shocks nor the estimates of $\varepsilon_{Q}$ or $\varepsilon_{M}$. The primary difference between these specifications are larger values for the standard deviations of the productivity and demand shocks, and a smaller estimate of the preference elasticity of substitution $\left(\varepsilon_{D}\right)$.

\section{Which Shocks Should the Estimation Include?}

It is possible that other disturbances - in addition to, or perhaps instead of, shocks to demand or productivity — drive movements in industries' sales, prices, and intermediate 
input cost shares. ${ }^{30}$ Here, I explore the effects of the addition and deletion of sources of variation on the model's estimates.

\begin{tabular}{ccccc}
\hline & \multicolumn{2}{c}{ Investment } & \multicolumn{2}{c}{$\sigma_{B, \text { Ind }}=0$} \\
& \multicolumn{2}{c}{$\sigma_{B, \text { Agg }}=0$} \\
\hline$\varepsilon_{D}$ & 0.749 & 1 & 0.669 & 1 \\
$\varepsilon_{Q}$ & 0.052 & 1 & 0.754 & 1 \\
$\varepsilon_{M}$ & 0.029 & 1 & 0.029 & 1 \\
$\varepsilon_{X}$ & 2.573 & 1 & 0.000 & 1 \\
$\sigma_{A, \text { Ind }}$ & 0.047 & 0.034 & 0.041 & 0.034 \\
$\sigma_{B, \text { Ind }}$ & 0.102 & 0.000 & & \\
$\sigma_{D, \text { Ind }}$ & 0.062 & 0.095 & 0.295 & 0.104 \\
$\sigma_{I, \text { Ind }}$ & 0.327 & 0.330 & & \\
$\sigma_{A, \text { Agg }}$ & 0.011 & 0.007 & 0.031 & 0.008 \\
$\sigma_{B, \text { Agg }}$ & 0.039 & 0.000 & & \\
$\sigma_{D, \text { Agg }}$ & 0.006 & 0.000 & 0.217 & 0.001 \\
$\sigma_{I, \text { Agg }}$ & 0.001 & 0.238 & & \\
$\rho_{A, \text { Ind }}$ & 1.000 & 1.000 & 1.000 & 1.000 \\
$\rho_{B, \text { Ind }}$ & 0.914 & 0.997 & & \\
$\rho_{D, \text { Ind }}$ & 0.989 & 0.905 & 1.000 & 0.955 \\
$\rho_{I, \text { Ind }}$ & -0.078 & 0.820 & & \\
$\rho_{A, \text { Agg }}$ & 0.890 & 0.921 & 0.999 & 0.800 \\
$\rho_{B, \text { Agg }}$ & 0.881 & 1.000 & & \\
$\rho_{D, \text { Agg }}$ & -0.079 & 0.992 & -0.002 & 0.943 \\
$\rho_{I, \text { Agg }}$ & -0.363 & 0.833 & & \\
\hline Log Likelihood & 6766.2 & -94628.7 & -88401.4 & -94676.9 \\
\hline$\%$ of Variation & & & & \\
from Industry- & 62.9 & 31.3 & 30.5 & 51.7 \\
Specific Shocks & & & & \\
\hline & & & & \\
\hline
\end{tabular}

Table 5: MLE Estimates, Robustness Checks: Different Sets of Shocks.

Notes: The final row gives the fraction of aggregate output growth volatility that is due to industry-specific demand and productivity shocks.

Analyses of one-sector economies indicate that investment-specific technology shocks account for a large fraction of the business cycle variation in output and (see Fisher 2006 and Justiniano, Primiceri, and Tambalotti 2010). In the context of the model presented in Section 2, I alter Equation 5 to include shocks to the investment technology:

$$
K_{t+1, J}=\left(1-\delta_{K}\right) \cdot K_{t J}+\iota_{t J} \cdot \iota_{t, A g g} \cdot X_{t J} .
$$

\footnotetext{
${ }^{30}$ Canova, Ferroni, and Matthes (2013, Section 4) show that parameter estimates can be sensitive to the choice of shocks and observable variables used in the estimation procedure. Guerron-Quintana (2010) and Ríos-Rull et al. (2012) make a similar point.
} 
In Equation 16, $\iota_{t J}$ and $\iota_{t, A g g}$ are industry-specific and aggregate investment technology shocks. These shocks alter the efficiency by which an industry's investment good is transformed into its next-period capital stock. As with the other stochastic processes, assume that the $\log \iota_{t J}$ and $\log \iota_{t, A g g}$ are each first-order autoregressive processes.

Including investment shocks alters neither the estimated relative importance of industry-specific shocks nor the estimates of the model's elasticities of substitution (see the first two columns of Table 5). These shocks are, however, moderately important, representing $22 \%$ of output volatility. There are two potential explanations why investment shocks play a less prominent role here than in to Fisher (2006) or Justiniano, Primiceri, and Tambalotti (2010). First, Justiniano, Primiceri, and Tambalotti (2010) show that investment shocks are particularly important in models that also incorporate price and wage stickiness. Their absence in the model of Section 2 may account for the discrepancy between my multi-industry model and results from one-sector models. Second, it is possible that the mere consideration of a model of multiple industries may reduce the scope of investment technology shocks. As in the one-sector models, investment shocks alter the relative price of capital goods. Unlike these models, however, productivity shocks to the few capital-producing industries - Construction, Non-electrical Machinery, Electrical Machinery, and Transportation Equipment - will have a similar effect on the relative price of capital goods. While the reason behind the limited importance of investment shocks may be unclear, it is clear that industry-specific shocks are the predominant source of aggregate fluctuations, as in the benchmark specification.

In columns 3 and 4 , I remove the labor-augmenting productivity shocks $\left(B_{t, A g g}\right.$ and the $\left.B_{t J} \mathrm{~s}\right)$ as a source of variation. The main goal of this exercise is to show why the laboraugmenting productivity shocks are included in the benchmark specification in the first place: Without these shocks, the model cannot possibly match the dynamics of industries' intermediate input purchases (compare the log likelihood of column 3 to that given in the first column of Table 2). ${ }^{31}$ The $B$ shocks alter the marginal product of labor and thus alter the relative marginal productivity of intermediate inputs to other inputs. In turn, these $B$ shocks drive much of the variation in industries' intermediate input cost shares. A secondary goal of this exercise is to provide an example (albeit a dubious one) in which aggregate shocks explain the bulk, roughly $70 \%$, of GDP growth variation. It turns out that only aggregate shocks, and not industry-specific shocks, can account for the volatile intermediate input cost shares that are observed in the data when $\sigma_{B, A g g}=\sigma_{B, \text { Ind }}=0$. I

\footnotetext{
${ }^{31}$ I experimented with several other specifications that also omitted labor-augmenting productivity shocks as a potential source of variation, and always found that the maximized likelihood was several orders of magnitude smaller than the maximum of the benchmark specification.
} 
explain why this is the case, using a simple example, in Section 5.1.

\section{International Evidence}

Table 6 presents results from estimations involving data from other countries. For all countries, $\varepsilon_{Q}$ is less than 0.15 , and always significantly less than 1 . With the exception of Italy, industry-specific shocks account for the bulk of the variation in aggregate output growth.

Similar to the United States, restricting $\varepsilon_{Q}=1$ diminishes the relative importance of these shocks for three of the countries in the sample: Denmark, the Netherlands, and Spain. For the other three countries (France, Italy, and Japan), the restricted specification has a more prominent estimated role for industry-specific shocks. In the data, the distinguishing features of these two sets of countries are the cross-industry correlation of industries' sales and the cross-industry correlation of industries' intermediate input cost shares. In the restricted specification, intermediate input cost shares are uninformative about the model's parameters. For countries that have highly correlated sales, across industries, aggregate shocks will explain most of the output variation. When $\varepsilon_{Q}$ is freely estimated, intermediate input cost shares will also now inform the estimates of the stochastic productivity and demand processes. All things equal, the specification with estimated $\varepsilon_{Q}$ will indicate that industry-specific shocks are relatively more important for the countries for which sales are highly correlated and intermediate input cost shares are uncorrelated. ${ }^{32}$

In summation, industry-specific shocks are the primary source of aggregate fluctuations for most, but not all, countries. Including intermediate input cost shares as an observable variable, only possible when $\varepsilon_{Q}$ is freely estimated, increases the estimated importance of industry-specific shocks for countries with uncorrelated intermediate input growth rates, and decreases the estimated importance of micro shocks for the remaining countries.

\footnotetext{
${ }^{32}$ To provide some support for this argument, consider the relationship between the following two variables. The first variable is the difference, across the free and restricted specifications, in the fraction of aggregate output variation that is explained by industry-specific shocks. These values for Denmark, France, Italy, Japan, the Netherlands, Spain, and U.S. are $-6 \%,-37 \%, 57 \%, 29 \%,-14 \%, 34 \%$, and $-15 \%$, respectively (see the last rows of Tables 3 and 6). The second variable is the ratio of the two across-industry correlations, as described in the text. These ratios are 1.31, 1.04, 1.45, 1.07, 1.54, and 1.23. The correlation between the two variables is $77 \%$.
} 


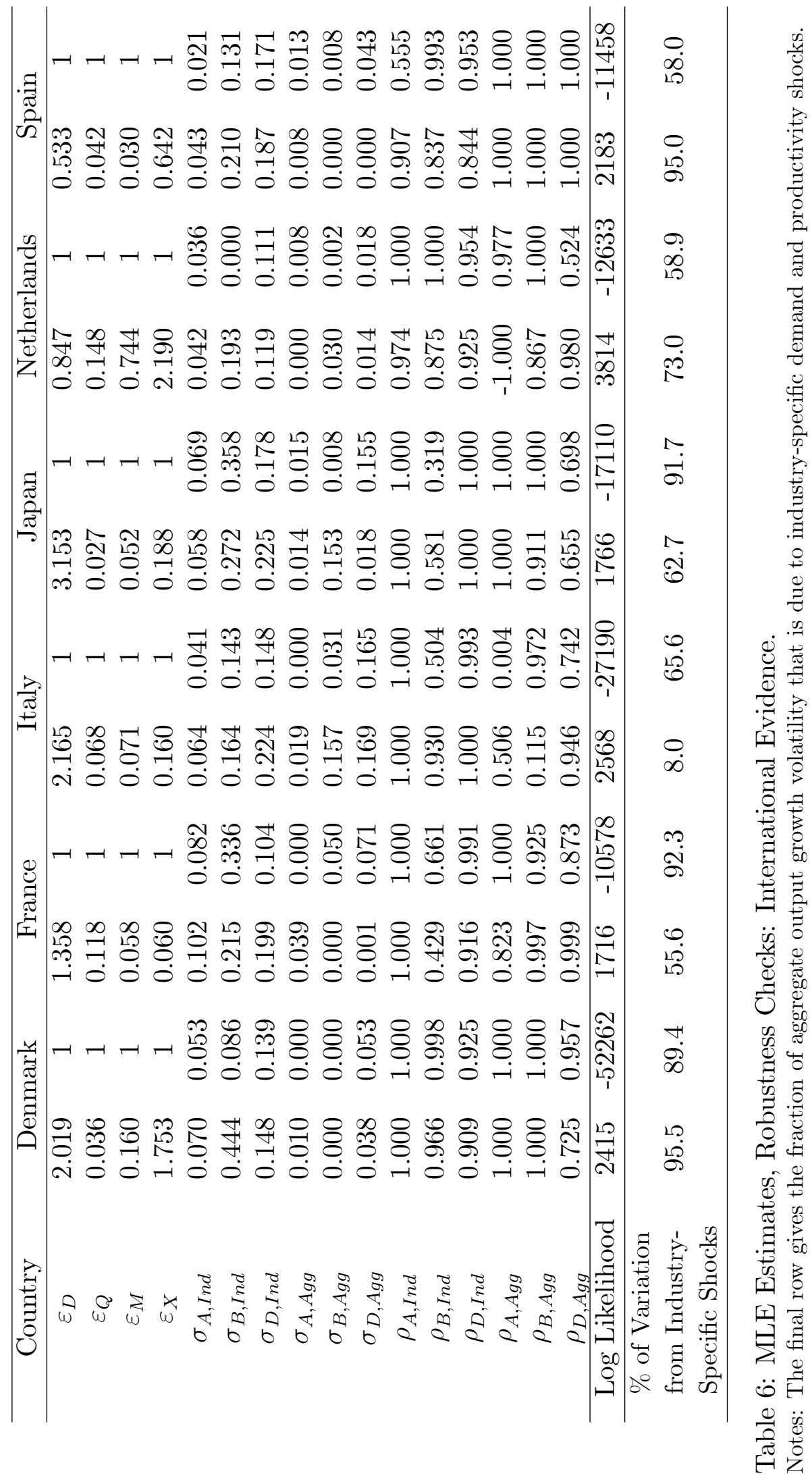




\section{Additional Robustness Checks}

Additional robustness checks are given in Appendix A. There, I explore robustness checks to the extent of measurement error in intermediate input cost shares, winsorization of the observed variables, the de-trending procedure, the covariance structure of the stochastic processes, and the calibrated values of $\varepsilon_{L S}, \Gamma_{I J}^{M}, \alpha_{J}, \mu_{J}$ and $\xi_{J}$. Overall, the main results of the paper - that the estimate of $\varepsilon_{Q}$ is close to 0 and that industry-specific shocks are of primary importance - are robust to these different specifications.

\section{$5 \quad$ How are the parameters identified?}

The purpose of this section is to provide some intuition as to how the model's parameters are identified. I do this in two ways. First, in Section 5.1, I consider an example economy for which I can derive expressions for the covariances among industries prices, sales, and intermediate input cost shares. Second, in Section 5.2, I numerically relate $\varepsilon_{Q}$ and $\varepsilon_{D}$ to various model-predicted moments (setting all other parameters to the Table-2 MLE estimates). The aim of this second exercise is to illustrate how these two elasticities are identified, and to show that the analytical results obtained in Section 5.1's simple example are pertinent.

Section 5.1 demonstrates that if $\varepsilon_{Q}<1$, then only industry-specific shocks can account for the intermediate input cost shares that are both volatile and uncorrelated across industries (as documented in Section 3). The primary takeaway from Section 5.2 is that $\varepsilon_{Q}$ is estimated to be less than 1 mainly because of volatile intermediate input shares that are positively correlated with the industries' own intermediate input prices. In combination, these two findings explain why industry-specific shocks are important.

\subsection{A Simple Example ${ }^{33}$}

In this section, I study a simple economy for which analytic expressions are available. The goal of this exercise is to explain why industry-specific shocks are more prominent when $\varepsilon_{Q}$ is freely estimated. To summarize the results of this exercise, when $\varepsilon_{Q}=1$ only measurement error can possibly generate any variation in the observed intermediate input cost shares. On the other hand, when $\varepsilon_{Q}$ is less than 1, industry I's intermediate input cost shares also co-vary with its own industry-specific labor-augmenting productivity and

\footnotetext{
${ }^{33}$ This subsection is related to the technical appendix of Carvalho and Gabaix (2013). The main differences are that Carvalho and Gabaix impose that $\varepsilon_{Q}=1$ and also allow for some adjustment costs to aggregate labor.
} 
the aggregate factor-neutral productivity. When the aggregate factor-neutral productivity term is large, industries' intermediate input cost shares co-move. Thus, to fit the volatile, uncorrelated intermediate input cost shares, the MLE procedure assigns higher values to $\sigma_{B, \text { Ind }}$ when $\varepsilon_{Q}$ is freely estimated.

Compared to the benchmark model given in Section 2, I make a number of simplifying assumptions. I assume that a) all goods depreciate fully each period; b) there is no physical capital in production; c) the exogeneous productivity and preference processes have zero persistence; d) each industry has identical production functions; e) the consumer's preference weight is the same for each of the $N$ goods; f) the input-output matrix has $\frac{1}{N}$ in each entry; and g) $\varepsilon_{M}=0$. For the reader's convenience, I re-write the utility function and each industry's sectoral production function, incorporating these assumptions. Via assumptions (a) through (c), the equilibrium allocation can be solved period by period. For this reason, I omit time subscripts in this section.

The output of industry $J$ equals:

$$
Q_{J}=A_{J} \cdot A_{A g g}\left((1-\mu)^{\frac{1}{\varepsilon_{Q}}}\left(B_{J} \cdot B_{A g g} \cdot L_{J}\right)^{\frac{\varepsilon_{Q}-1}{\varepsilon_{Q}}}+\mu^{\frac{1}{\varepsilon_{Q}}}\left[\frac{1}{N} \min _{I} M_{I \rightarrow J}\right]^{\frac{\varepsilon_{Q}-1}{\varepsilon_{Q}}}\right)^{\frac{\varepsilon_{Q}}{\varepsilon_{Q}-1}}
$$

Output is produced using labor $L_{J}$ and intermediate inputs $M_{I \rightarrow J}$ purchased from other sectors. Note that the restriction of $\varepsilon_{M}=0$ is already incorporated in Equation 17. Finally, to emphasize, each sector's production function is distinguished only by the industry-specific components of the two productivity terms. The cost share parameters $\left(\mu_{J}\right.$ and $\left.\Gamma_{I J}^{M}\right)$, which were previously allowed to differ by industry, are now the same for each industry.

The representative consumer has preferences over leisure and the $N$ consumption goods, parameterized by the following utility function:

$$
\mathcal{U}=\left(D_{A g g} \cdot \sum_{J=1}^{N} \frac{D_{J}}{N}\right) \cdot \log \left[\left(\sum_{J=1}^{N}\left(\frac{D_{J}}{N}\right)^{\frac{1}{\varepsilon_{D}}}\left(C_{J}\right)^{\frac{\varepsilon_{D}-1}{\varepsilon_{D}}}\right)^{\frac{\varepsilon_{D}}{\varepsilon_{D}-1}}\right]-\frac{\varepsilon_{L S}}{\varepsilon_{L S}+1}\left(\sum_{J=1}^{N} L_{J}\right)^{\frac{\varepsilon_{L S}+1}{\varepsilon_{L S}}} .
$$

As before, $\varepsilon_{D}$ and $\varepsilon_{L S}$ parameterize, respectively, the elasticity of substitution across the consumption goods and the elasticity of labor supply. For future reference, define the ideal price index of the consumption-good bundle as:

$$
P \equiv\left[\sum_{J=1}^{N} \frac{D_{J}}{\sum_{I=1}^{N} D_{I}}\left(P_{J}\right)^{1-\varepsilon_{D}}\right]^{\frac{1}{1-\varepsilon_{D}}}
$$


where $P_{J}$ is again the price of the industry $J$ output.

Given the maintained assumptions, the solution to the equilibrium allocation is straightforward. The first step is to solve for the relative price of each industry's output and each industry's intermediate input cost share. The first-order condition of intermediate input purchases yields the following expression for the observed cost share (letting $W$ denote the Lagrange multiplier on the labor-market clearing condition, and $P_{J}^{m a t}$ the price of a unit of the intermediate bundle for industry $J$ ):

$$
\begin{aligned}
M_{J}^{\text {share }} & =\mu \cdot\left(A_{A g g} \cdot A_{J}\right)^{\varepsilon_{Q}-1} \cdot\left(\frac{P_{J}^{\text {mat }}}{P_{J}}\right)^{1-\varepsilon_{Q}} \cdot M_{J}^{\text {error }} \cdot M_{\text {Agg }}^{\text {error }} \\
& =\frac{\mu \cdot\left(P_{J}^{\text {mat }}\right)^{1-\varepsilon_{Q}}}{\mu\left(P_{J}^{\text {mat }}\right)^{\varepsilon_{Q}-1}+(1-\mu) W^{1-\varepsilon_{Q}} \cdot\left(B_{J} \cdot B_{A g g}\right)^{\varepsilon_{Q}-1}} \cdot M_{J}^{\text {error }} \cdot M_{A g g}^{\text {error }} \\
& =\frac{\mu \cdot\left(\frac{1}{N} \sum_{I=1}^{N} P_{I}\right)^{1-\varepsilon_{Q}}}{\mu\left(\frac{1}{N} \sum_{I=1}^{N} P_{I}\right)^{1-\varepsilon_{Q}}+(1-\mu) W^{1-\varepsilon_{Q}} \cdot\left(B_{J} \cdot B_{A g g}\right)^{\varepsilon_{Q}-1}} \cdot M_{J}^{\text {error }} \cdot M_{A g g}^{\text {error }}
\end{aligned}
$$

Equation 20 gives a first indication why, provided $\varepsilon_{Q} \neq 1$, the intermediate input share is influenced primarily by labor-augmenting productivity shocks. The only industry-specific factors present in this equation are $B_{J}$ and $M_{J}^{e r r o r}$. If an industry's intermediate input cost share is to display any variation that is uncorrelated with other industries' cost shares, it must be due to either $B_{J}$ or $M_{J}^{\text {error }}{ }^{34}$

The cost-minimization condition of industry $J$ implies that

$$
P_{J}=\frac{1}{A_{J} \cdot A_{A g g}} \cdot\left[(1-\mu)\left(\frac{W}{B_{J} \cdot B_{A g g}}\right)^{1-\varepsilon_{Q}}+\mu\left(\sum_{J=1}^{N} \frac{1}{N} P_{J}\right)^{1-\varepsilon_{Q}}\right]^{\frac{1}{1-\varepsilon_{Q}}} .
$$

According to Equation 21, the price of industry J's output depends on its productivity, the wage, and the price of all other goods in the economy. Solving this system of equations (see Appendix E) yields expressions for the relative prices of each of the goods of the economy in terms of industries' productivities. Then, plugging the relative prices into Equation 20 gives the intermediate input cost shares in terms of the exogeneous variables.

Throughout the remainder of this section, I consider a log-linear approximation

\footnotetext{
${ }^{34}$ This stark result is due to the assumption that all rows of the input-output matrix are identical. In reality, the diagonal elements of the input-output matrix are substantially greater than $\frac{1}{N}$ (and, more generally, rows of the input-output matrix are dissimilar from one another). As the diagonal elements increase, the relationship between each industry's intermediate input cost share and its own price strengthens. The main idea represented in Equation 20-that the intermediate input share of each industry is responsive to average (and not its own) prices - would also follow from a more realistic input-output matrix.
} 
around the point at which all of the $A \mathrm{~s}, B \mathrm{~s}$, and $D$ s are equal to 1 . The relative prices and cost shares are:

$$
\begin{aligned}
\log \left(\frac{P_{J}}{P}\right) \approx & -\log A_{J}-(1-\mu) \log B_{J}+\frac{1}{N} \sum_{I=1}^{N} \log A_{I}+(1-\mu) \log B_{I} \\
\log \left(M_{J}^{\text {share }}\right) \approx & \left(\varepsilon_{Q}-1\right) \log \left(A_{A g g}\right)-\left(\varepsilon_{Q}-1\right)(1-\mu) \log \left(B_{J}\right) \\
& +\left(\varepsilon_{Q}-1\right) \cdot\left[\frac{1}{N} \sum_{I=1}^{N} \log A_{I}+(1-\mu) \log B_{I}\right]+\log \left(M_{J}^{\text {error }} \cdot M_{A g g}^{\text {error }}\right)
\end{aligned}
$$

According to Equation 22, the relative price of an industry's good is inversely related to the relative total factor productivity of that industry. Because we are looking at relative prices, the aggregate productivity terms, $A_{A g g}$ and $B_{A g g}$, do not appear in Equation 22 . On the other hand, the intermediate input cost share of each industry depends on the aggregate factor-neutral productivity term and the industry-specific labor-augmenting productivity. The sensitivity of $M_{J}^{\text {share }}$ to $A_{A g g}$ or $B_{J}$ is a $U$-shaped function of the production elasticity of substitution, with a minimum at $\varepsilon_{Q}=1$. When $\varepsilon_{Q}=1$, productivity shocks have no impact on the intermediate input cost shares.

Equation 24 gives the sales of each industry (again, see Appendix E for a derivation).

$$
\begin{aligned}
\log \left(\frac{Y_{J}}{P}\right) \approx & \frac{1}{N} \sum_{I=1}^{N} \frac{1-\mu\left(1-\varepsilon_{Q}\right)}{1-\mu} \log \left(A_{I} \cdot A_{A g g}\right)+\log \left(B_{I} \cdot B_{A g g}\right)+\frac{\varepsilon_{L S}}{\varepsilon_{L S}+1} \log \left(D_{A g g} \cdot D_{I}\right) \\
& +\frac{1}{N} \sum_{I=1}^{N}\left\{\left(1-\varepsilon_{D}(1-\mu)\right)\left[\log \left(\frac{A_{I}}{A_{J}}\right)+(1-\mu) \log \left(\frac{B_{I}}{B_{J}}\right)\right]\right. \\
& \left.+\log \left(\frac{1}{1-\mu}\right)+(1-\mu) \log \left(\frac{D_{J}}{D_{I}}\right)\right\}
\end{aligned}
$$

To understand Equation 24, the terms in the first line equal (the logarithm of) aggregate GDP. The terms on the second and third lines of the equation give the (logarithm of the) Domar-weight of industry $J$. The definition of a Domar weight is the ratio of sales in industry $J$ to GDP. The weight is a function of the industry's demand shock (relative to other industries' demand shocks) and productivity (relative to the productivities of other industries). Industries with higher demand shocks comprise a higher share of real GDP, and as a result have an unambiguously higher Domar weight. High-productivity industries may have a higher or lower Domar weight depending on $\varepsilon_{D}$. In the relevant part of the parameter space, the lowest-productivity sectors have the highest weight.

In the remainder of this section, I will use Equations 22 to 24 to compute the covariances of industry-level observable variables as functions of the elasticities of substitution 
and the variances of the exogeneous demand and productivity processes.

Proposition 1 Given the previously stated assumptions (a) through (g), up to a first-order approximation around the steady state, and ignoring terms of order $\frac{1}{N} .^{35}$

$$
\begin{aligned}
\operatorname{Cov}\left(\log \frac{P_{I}}{P}, \log \frac{P_{J}}{P}\right)= & \mathbf{1}_{I=J}\left(\sigma_{A, \text { Ind }}^{2}+(1-\mu)^{2} \sigma_{B, \text { Ind }}^{2}\right) \\
\operatorname{Cov}\left(\log \frac{P_{I}}{P}, \log \frac{Y_{J}}{P}\right)= & \mathbf{1}_{I=J}\left(1-\varepsilon_{D}(1-\mu)\right)\left(\sigma_{A, \text { Ind }}^{2}+(1-\mu)^{2} \sigma_{B, \text { Ind }}^{2}\right) \\
\operatorname{Cov}\left(\log \frac{P_{I}}{P}, \log M_{J}^{\text {share }}\right)= & \mathbf{1}_{I=J}(1-\mu)^{2}\left(\varepsilon_{Q}-1\right) \sigma_{B, \text { Ind }}^{2} \\
\operatorname{Cov}\left(\log \frac{Y_{I}}{P}, \log \frac{Y_{J}}{P}\right)= & \left(\frac{1-\mu\left(1-\varepsilon_{Q}\right)}{1-\mu}\right)^{2} \sigma_{A, A g g}^{2}+\sigma_{B, A g g}^{2} \\
& +\left(\frac{\varepsilon_{L S}}{\varepsilon_{L S}+1}\right)^{2} \sigma_{D, A g g}^{2}+\mathbf{1}_{I=J}(1-\mu)^{2} \sigma_{D, \text { Ind }}^{2} \\
\operatorname{Cov}\left(\log \frac{Y_{I}}{P}, \log M_{J}^{\text {share }}\right)= & \left(\varepsilon_{Q}-1\right) \frac{1-\mu\left(1-\varepsilon_{D}(1-\mu)\right)^{2}\left(\sigma_{A, \text { Ind }}^{2}+(1-\mu)^{2} \sigma_{B, \text { Ind }}^{2}\right)}{1-\mu} \sigma_{A, \text { Agg }}^{2} \\
\operatorname{Cov}\left(\log M_{I}^{\text {share }}, \log M_{J}^{\text {share }}\right)= & \left(\varepsilon_{Q}-1\right)^{2} \sigma_{A, A g g}^{2}+\mathbf{1}_{I=J}\left(\varepsilon_{Q}-1\right)^{2} \sigma_{B, \text { Ind }}^{2} \\
& \mathbf{1}_{I=J} \sigma_{M, \text { Ind }}^{2}+\sigma_{M, \text { Agg }}^{2}
\end{aligned}
$$

Proposition 1 provides several insights into the way the model's parameters are identified.

First, the variance in industries' relative prices identifies the dispersion of the industryspecific productivity shocks (see Equation 25).

Second, combining Equations 25 and 26, when $I=J$, yields: ${ }^{36}$

$$
\frac{\mathbb{E}\left(\log \frac{P_{I}}{P} \cdot \log \frac{Y_{I}}{P}\right)}{\mathbb{E}\left(\left(\log \frac{P_{I}}{P}\right)^{2}\right)} \approx \frac{\operatorname{Cov}\left(\log \frac{P_{I}}{P}, \log \frac{Y_{I}}{P}\right)}{\operatorname{Var}\left(\log \frac{P_{I}}{P}\right)} \approx 1-\varepsilon_{D} \cdot(1-\mu)
$$

In other words, assuming that the value of the intermediate input cost share $(\mu)$ is known, the preference elasticity of substitution can be read off of a regression of an industry's sales on its relative price. As goods are more and more substitutable in the representative consumer's preferences, the relationship between sales and prices is weaker and weaker. In the special case in which intermediate inputs are not used in production $(\mu=0)$, industry sales and

\footnotetext{
${ }^{35}$ The terms that are of order $\frac{1}{N}$ are omitted, here, for expositional purposes but can be found in Appendix E.

${ }^{36}$ The first approximation follows because $\mathbb{E}\left(\log \frac{P_{I}}{P}\right) \approx 0$ (see Equation 22$)$.
} 
consumption are equal, meaning that sales and prices are positively related if and only if goods are gross substitutes in preferences.

Third, Equation 27 explains how the data help identify whether inputs are gross complements or gross substitutes (i.e., whether $\varepsilon_{Q}<1$ or $\varepsilon_{Q}>1$ ). When labor and intermediate are gross complements $\left(\varepsilon_{Q}<1\right)$, the observed relationship between the intermediate input cost share and the relative price of intermediate inputs $\left(\Pi_{I} \equiv \frac{P_{I}^{\text {mat }}}{P_{I}}\right)$ should be positive. Because $\Pi_{I}=\left(\frac{P_{I}}{P}\right)^{-1}$ in this section's example, a negative observed relationship between relative prices and intermediate input cost shares indicates that labor and intermediate inputs are complements to one another.

Fourth, because the demand shock terms only appear in Equation 28, industry sales data are crucial in identifying the relative importance of demand shocks. When industries' real sales are volatile, either the industry-specific or the common demand shocks will be volatile. If the cross-industry correlation of industries' sales is large, then the estimation will assign high volatilities to the aggregate demand shock and relatively low volatilities to the industry-specific component.

Fifth, according to Equation 30, variation in industries materials' shares emerges from measurement error and, when $\varepsilon_{Q} \neq 1$, productivity shocks. When $\varepsilon_{Q}$ is restricted to be equal to 1, data on industries' intermediate cost shares are uninformative about the industryspecific labor-augmenting shocks or the aggregate factor-neutral productivity shocks. On the other hand, when labor and intermediate inputs are gross complements, the covariance matrix of industries' intermediate input cost shares helps identify these two volatilities. Large values of elements of this covariance matrix are consistent with a large value of either $\sigma_{A, A g g}$ or $\sigma_{B, I n d}$, while uncorrelated cost shares are consistent with a relatively large value of the industry-specific labor-augmenting shock and a small value of the aggregate neutral shock. Because, individual industries' observed cost shares are sufficiently varied and uncorrelated in the data, the inclusion of data on industries' cost shares, which is only possible when $\varepsilon_{Q}$ is freely estimated, drives up the estimate of $\sigma_{B, I n d}^{2}$.

Sixth, Equation 30 indicates why adding additional measurement error will lead to a lower estimate of $\sigma_{A, A g g}^{2}$ and/or $\sigma_{B, I n d}^{2}$ it will reduce the scope for productivity shocks to 
explain the variance of intermediate input cost shares. ${ }^{37,38}$

Finally, Proposition 1 also explains why the main result of the paper, that industryspecific shocks have aggregate consequences, breaks down in the specification that omits labor-augmenting productivity shocks (as in the final columns of Table 5). Without laboraugmenting productivity shocks, variation in $A_{A g g}$ is the only potential source of variation in intermediate input cost shares. Because the intermediate input bundle combines inputs from different industries, the price of this bundle depends on aggregate, rather than industryspecific, disturbances. As a result, to fit the volatile intermediate input cost shares that we actually observe in the data, the estimation procedure assigns high values to the dispersions of aggregate shocks. ${ }^{39}$

To recap, the model cannot possibly fit the evolution of industries' intermediate input purchases when $\varepsilon_{Q}$ is restricted to be equal to 1: the unitary elasticity of substitution implies that the intermediate input cost shares can vary only because of measurement error. When $\varepsilon_{Q}<1$, the intermediate input cost share can potentially depend on industry-specific or aggregate shocks. Because, in the data, movements in industries' intermediate input cost shares are relatively volatile and uncorrelated, the model assigns high estimates of $\sigma_{B, \text { Ind }}$ when $\varepsilon_{Q}$ is freely estimated.

\footnotetext{
${ }^{37}$ One could supplement some of these arguments more formally by comparing the model predictions of Equations 25 to 30 to their data counterparts. Indeed, because there is no persistence in this simple example economy, Equations 25 to 30 contain all possible information that could be inferred from data on industries' intermediate input purchases, output prices, and sales. The likelihood function corresponding to this estimation is

$$
\log \mathcal{L}=\text { trace }\left(\Sigma_{\text {Model }}+\Sigma_{\text {Model }}^{-1} \cdot \Sigma_{\text {Data }}\right),
$$

where $\Sigma_{\text {Model }}$ is the variance-covariance matrix implied by Equations 25 to 30 and $\Sigma_{\text {Data }}$ is the empirical counterpart. The MLE estimates from this simple exercise affirm the estimates from the full model given in Section 4.2. In particular, the estimate of standard deviation of the industry-specific productivity is larger when $\varepsilon_{Q}$ is freely estimated.

${ }^{38} \mathrm{~A}$ final lesson from Proposition 1: When $\varepsilon_{Q}=1$, factor-neutral productivity shocks and laboraugmenting productivity shocks are not separably identifiable. Rather, the data only permit identification of $\sigma_{A, A g g}^{2}+(1-\mu)^{2} \sigma_{B, A g g}^{2}$ (and $\sigma_{A, I n d}^{2}+(1-\mu)^{2} \sigma_{B, I n d}^{2}$ ). (This result follows from the assumption that all industries have the same labor cost shares. In the full model of Section 2 the two parameters can be separately identified even when $\varepsilon_{Q}=1$ ).

${ }^{39}$ One feature that this simple example cannot capture is the increased importance of aggregate demand shocks in the specification where both $\varepsilon_{Q}$ is freely estimated and labor-augmenting productivity shocks are omitted. This deficiency is due to the absence of capital in the current section's simple example. Aggregate demand shocks increase the relative price of current-period consumption, and as a result, increase the relative price of capital. (Shocks to individual industries' demand have a much smaller effect on the relative price of capital.) Following an aggregate demand shock, the ratio of $P_{J}^{m a t}$ to $P_{J}$ increases for industries with capitalintensive production technologies and decreases for the other industries in the economy, thus generating an increase in the intermediate input cost shares for the capital-intensive industries (and, again, a decrease in the intermediate input cost share for the other industries), provided $\varepsilon_{Q}$ is less than 1.
} 


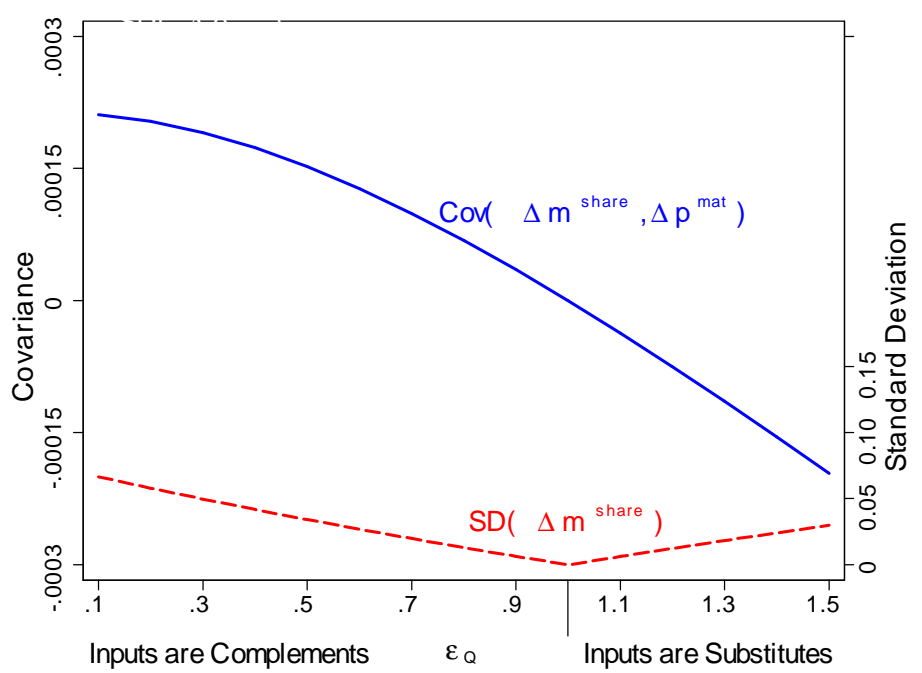

Figure 2: Covariances and standard deviations, for various values of $\varepsilon_{Q}$.

Notes: The solid line depicts the covariance between $\Delta m^{\text {share }}$ and $\Delta p^{\text {mat }}$. Values for the covariances are given on the left axis. The standard deviation of $\Delta m^{\text {share }}$ is plotted in dashed lines. Corresponding values are given on the right axis.

\subsection{How are $\varepsilon_{Q}$ and $\varepsilon_{D}$ identified?}

In this subsection, I perform two comparative statics exercises, with the aim of illustrating how $\varepsilon_{Q}$ and $\varepsilon_{D}$ are identified. In the first exercise, I vary $\varepsilon_{Q}$; in the second, I vary $\varepsilon_{D}$. All other parameters are set equal to the maximum likelihood estimates given in the first column of Table 2. To emphasize, the assumptions used in producing these figures are those described in Section 2 (not those introduced in Section 5.1).

In Figure 2, I vary $\varepsilon_{Q}$, the elasticity of substitution in the sectoral production functions. For each set of parameters, I solve the model and then compute the model predicted covariances and standard deviations of $\Delta m_{t I}^{\text {share }}$, and $\Delta p_{t I}^{\text {mat }}$. The values that are plotted in Figure 2 are the average correlations and standard deviations, across industries.

The first takeaway from Figure 2 is the U-shaped relationship between $\varepsilon_{Q}$ and the dispersion of $\Delta m^{\text {share }}$ : the industry-specific materials cost share approaches 0 as $\varepsilon_{Q}$ approaches 1 , and is roughly $3 \%$ for $\varepsilon_{Q}=0.5$ or 1.5 . (To contrast, the dispersions of the other variables are unchanged in $\varepsilon_{Q}$.) Second, the relationship between the intermediate input cost share and the price of the intermediate input bundle is positive for $\varepsilon_{Q}<1$ and negative for $\varepsilon_{Q}>1$. As a reminder, in Table 1 we observed that the empirical correlation between the intermediate input cost share and price is positive, and that the dispersion of the intermediate input cost share is substantial. Taken together, these patterns indicate that the model and is consistent with the data, provided $\varepsilon_{Q}<1$. Finally, the patterns depicted in Figure 2 align with the relevant parts of Proposition 1, namely Equations 27 and 


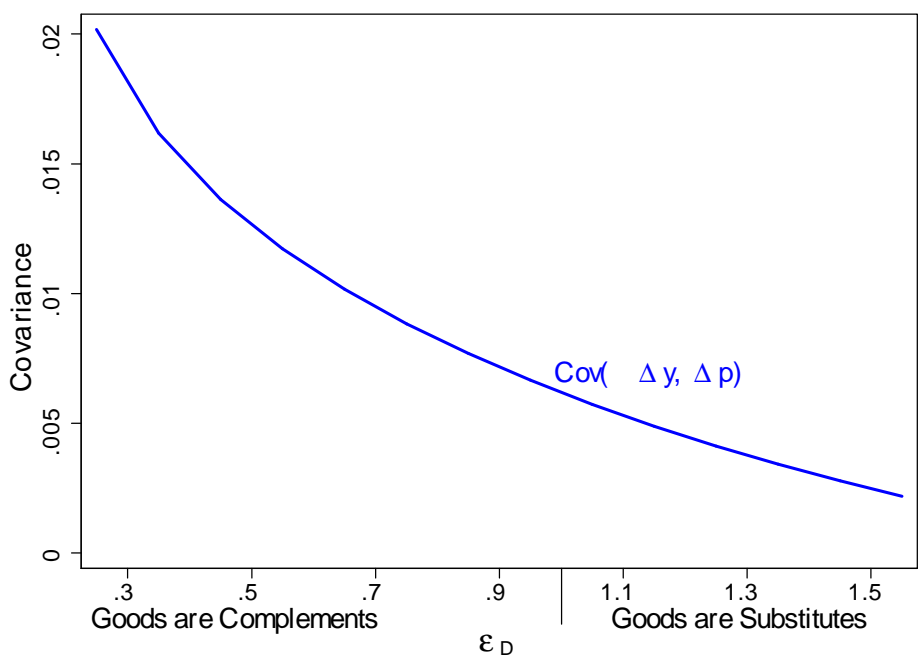

Figure 3: Covariance between $\Delta y$ and $\Delta p$, for various values of $\varepsilon_{D}$.

30.

In Figure 3, I now vary $\varepsilon_{D}$ instead of $\varepsilon_{Q}$. As the consumer's preferences, over the different goods, becomes more elastic, the correlation between $\Delta y$ and $\Delta p$ decreases: When $\varepsilon_{D}$ is high, any price increase causes the consumer to substitute sharply towards other goods. ${ }^{40}$ These patterns match the prediction of the previous subsection's simple example; see, in particular, Equation 26.

\section{Conclusion}

This paper develops and estimates a multi-industry real business cycle model. Data on industries' sales, intermediate input purchases, and output prices are employed to evaluate how easily industries substitute across inputs, how easily consumers substitute across consumption goods, and the magnitude of the industry-specific and aggregate components of preference and productivity shocks. The positive relationship between industries' intermediate input prices and cost shares indicates that intermediate inputs and capital/labor are complements. Because of this complementarity, the industry-specific components of the productivity shocks have large estimated standard deviations. Almost two-thirds of the variation in aggregate output growth originates from industry-specific, as opposed to aggregate, shocks. This contrasts with the Cobb-Douglas-based specification - and with the results of

\footnotetext{
${ }^{40}$ Neither of the patterns of Figure 2 (the U-shaped relationship between the elasticity of substitution and $\Delta m^{\text {share }}$, and the positive-to-negative change of the correlation between $\Delta m^{\text {share }}$ and $\Delta p^{\text {mat }}$ ) are present in Figure 3.
} 
Foerster, Sarte, and Watson (2011) - in which industry-specific shocks are responsible for less than half of the variation in aggregate output growth.

The paper complements analyses in other areas of economics, such as development and growth, international trade, and monetary economics, that use input-output linkages as an amplification mechanism. With respect to the literature on development and growth, Jones $(2011,2013)$ argues that a small change in factor misallocations has the potential to yield large changes in GDP per capita. In the international trade literature, Yi (2003) and Caliendo and Parro (2011) argue that small reductions in tariffs can explain the large growth in cross-border gross trade flows that has been observed over the last few decades. Finally, Basu (1995) and Bouakez, Cardia, and Ruge-Murcia (2009, 2011) have included nominal rigidities in their multi-industry general equilibrium models, showing that inputoutput linkages magnify and prolong the effect of monetary policy shocks. The current paper's main results, particularly the sensitivity of the input-output amplification mechanism to the value of $\varepsilon_{Q}$, are of relevance to this literature which has, in general, assumed higher values for this critical elasticity of substitution.

The paper's results are also of relevance for policymakers: The potential efficacy and necessity of policies that target distressed industries depend on the extent to which events in individual industries cascade throughout the economy.

The primary implication of the paper is that business cycle fluctuations emerge from industry-specific shocks. Independent of this industry-specific versus aggregate distinction, research on the sources of business cycles has offered several additional explanations for aggregate fluctuations: financial crises, increases in uncertainty about future productivity, and news about future economic activity, to name a few. An exciting avenue for future research would be to re-examine these well-known sources of short-run fluctuations with the new-found appreciation that these sources appear at the micro level.

\section{References}

Abramovitz, Moses, 1956. "Resource and Output Trends in the United States Since 1870." National Bureau of Economic Research, 1-23.

Acemoğlu, Daron, Vasco M. Carvalho, Asuman Özdağlar, and Alireza Tahbaz-Salehi, 2012. "The Network Origins of Aggregate Fluctuations." Econometrica, 80(5): 1977-2016.

Acemoğlu, Daron and Veronica Guerrieri, 2008. "Capital Deepening and Nonbalanced Economic Growth." Journal of Political Economy, 116(3): 467-498.

Acemoğlu, Daron, Asuman Özdağlar, and Alireza Tahbaz-Salehi, 2013. "The Network 
Origins of Large Economic Downturns." mimeo.

Adjemian, Stéphane, Houtan Bastani, Michel Juillard, Ferhat Mihoubi, George Perendia, Marco Ratto, and Sébastien Villemot, 2011. "Dynare: Reference Manual, Version 4." Dynare Working Papers, 1.

Basu, Susanto, 1995. "Intermediate Goods and Business Cycles: Implications for Productivity and Welfare." American Economic Review, 85(3): 512-531.

Basu, Susanto, 1996. "Procyclical Productivity: Increasing Returns or Cyclical Utilization?" Quarterly Journal of Economics, 111(3): 719-751.

Bouakez, Hafedh, Emanuela Cardia, and Francisco J. Ruge-Murcia, 2009. "The Transmission of Monetary Policy in a Multisector Economy." International Economic Review, 50(4): 1243-1266.

Bouakez, Hafedh, Emanuela Cardia, and Francisco J. Ruge-Murcia, 2011. "Durable Goods, Inter-Sectoral Linkages and Monetary Policy." Journal of Economic Dynamics and Control, 35(5): 730-746.

Broda, Christian and David E. Weinstein, 2006. "Globalization and the Gains from Variety." Quarterly Journal of Economics, 121(2): 541-585.

Bruno, Michael, 1984. "Raw Materials, Profits, and the Productivity Slowdown." Quarterly Journal of Economics, 99(1): 1-30.

Caliendo, Lorenzo and Fernando Parro, 2011. "Estimates of the Trade and Welfare Effects of NAFTA." mimeo.

Canova, Fabio, 2007. Methods for Applied Macroeconomic Research. Vol. 13. Princeton University Press.

Canova, Fabio, 2013. "Bridging DSGE Models and the Raw Data." mimeo.

Canova, Fabio, Filippo Ferroni, and Christian Matthes, 2013. "Choosing the Variables to Estimate Singular DSGE Models." mimeo.

Carvalho, Vasco M. and Xavier Gabaix, 2013. " The Great Diversification and Its Undoing." American Economic Review, 103(5): 1697-1727.

Chetty, Raj, Adam Guren, Day Manoli, and Andrea Weber, 2011. "Are Micro and Macro Labor Supply Elasticities Consistent? A Review of Evidence on the Intensive and Extensive Margins." American Economic Review, 101(3): 471-475.

Cochrane, John, 1994. "Shocks." Carnegie-Rochester Conference Series on Public Policy, 41: $295-364$.

Cooper, Richard N. and Robert Z. Lawrence, 1975. " "The 1972-75 Commodity Boom." Brookings Papers on Economic Activity, 1975(3): 671-723.

Dupor, Bill, 1999. "Aggregation and Irrelevance in Multi-Sector Models." Journal of 
Monetary Economics, 43(2): 391-409.

Fisher, Jonas, 2006. "The Dynamic Effects of Neutral and Investment-Specific Technology Shocks." Journal of Political Economy, 114(3): 413-451.

Foerster, Andrew, Pierre-Daniel Sarte, and Mark Watson, 2011. "Sectoral vs. Aggregate Shocks: A Structural Factor Analysis of Industrial Production." Journal of Political Economy, 119(1): 1-38.

Foster, Lucia, John Haltiwanger, and Chad Syverson, 2008. "Reallocation, Firm Turnover, and Efficiency: Selection on Productivity or Profitability?" American Economic Review, 98(1): 394-425.

Gabaix, Xavier, 2011. "The Granular Origins of Aggregate Fluctuations." Econometrica, 79(3): 733-772.

Galí, Jordi and Pau Rabanal, 2005. "Technology Shocks and Aggregate Fluctuations: How Well Does the Real Business Cycle Model Fit Postwar U.S. Data?" NBER Macroeconomics Annual, 19: 225-318.

Guerron-Quintana, Pablo A., 2010. "What You Match Does Matter: The Effects of Data on DSGE Estimation." Journal of Applied Econometrics, 25(5): 774-804.

Holly, Sean and Ivan Petrella, 2012. "Factor Demand Linkages, Technology Shocks and the Business Cycle." Review of Economics and Statistics, 94(4): 948-963.

Horvath, Michael, 1998. "Cyclicality and Sectoral Linkages: Aggregate Fluctuations from Independent Sectoral Shocks." Review of Economic Dynamics, 1(4): 781-808.

Horvath, Michael, 2000. "Sectoral Shocks and Aggregate Fluctuations." Journal of Monetary Economics, 45(1): 69-106.

Jones, Charles I., 2011. "Intermediate Goods and Weak Links in the Theory of Economic Development." American Economic Journal: Macroeconomics, 3(2): 1-28.

Jones, Charles I., 2013. "Misallocation, Economic Growth, and Input-Output Economics." In Advances in Economics and Econometrics, Tenth World Congress, Cambridge University Press.

Jorgenson, Dale W., Frank Gollop, and Barbara Fraumeni, 1987. Productivity and U.S. Economic Growth, Harvard University Press.

Justiniano, Alejandro, Giorgio E. Primiceri, and Andrea Tambalotti, 2010. "Investment Shocks and Business Cycles." Journal of Monetary Economics, 57(2): 132-145.

Kim Kunhong and Young Sik Kim, 2006. "How Important Is the Intermediate Input Channel in Explaining Sectoral Employment Comovement Over the Business Cycle?" Review of Economic Dynamics, 9(4): 659-682.

Long, John B. and Charles I. Plosser, 1983. "Real Business Cycles." Journal of Political 
Economy, 91(1): 39-69.

Long, John B. and Charles I. Plosser, 1987. "Sectoral vs. Aggregate Shocks In The Business Cycle." American Economic Review, 77(2): 333-336.

Moro, Alessio, 2012. "The Structural Transformation Between Manufacturing and Services and the Decline in the US GDP Volatility." Review of Economic Dynamics, 15(3): 402415 .

Ngai, L. Rachel, and Christopher A. Pissarides, 2007. "Structural Change in a Multisector Model of Growth." American Economic Review, 97(1): 429-443.

Prescott, Edward C., 2006. "Nobel Lecture: The Transformation of Macroeconomic Policy and Research." Journal of Political Economy, 114(2): 203-235.

Radetzki, Marian, 2006. "The Anatomy of Three Commodity Booms." Resources Policy, 31(1): 56-64.

Ríos-Rull, José-Víctor, Frank Schorfheide, Cristina Fuentes-Albero, Maxym Kryshko, and Raül Santaeulàlia-Llopis, 2012. "Methods Versus Substance: Measuring the Effects of Technology Shocks." Journal of Monetary Economics, 59(8): 826-846.

Rotemberg, Julio J. and Michael Woodford, 1996. "Imperfect Competition and the Effects of Energy Price Increases on Economic Activity." Journal of Money, Credit, and Banking, 28(4): 549-577.

Shea, John, 2002. "Complementarities and Comovements." Journal of Money, Credit, and Banking, 34(2): 412-433.

Smets, Frank and Rafael Wouters, 2007. "Shocks and Frictions in US Business Cycles: A Bayesian DSGE Approach." American Economic Review, 97(3): 586-606.

Stockman, Alan C., 1988. "Sectoral and National Aggregate Disturbances to Industrial Output in Seven European Countries." Journal of Monetary Economics, 21(2): 387409.

Summers, Lawrence, 1986. "Some Skeptical Observations on Real Business Cycle Theory." Federal Reserve Bank of Minneapolis, Quarterly Review, 10: 23-27.

Yi, Kei-Mu, 2003. "Can Vertical Specialization Explain the Growth of World Trade?" Journal of Political Economy, 111(1): 52-102. 


\section{A Additional Robustness Checks}

Tables 7 to 10 examine the sensitivity of the benchmark results to choices that I make in the benchmark estimation: the extent of measurement error in industries' intermediate input cost shares, the winsorization of outlier observations, and the de-trending procedure. In the first four columns of Table 7, I vary the fraction of observations that are winsorized; in the benchmark estimation, I trim the top and bottom $0.5 \%$ of the industry level prices, sales, and cost shares. The main difference is the overall magnitude of the aggregate productivity and demand shocks. These shocks are larger when fewer outliers are winsorized. Estimates of the elasticities of substitution and the relative importance of industry-specific shocks are unchanged. In the fifth and sixth columns, of Table 7, I choose a higher value of the labor supply elasticity (the benchmark estimation used $\varepsilon_{L S}=1$ ) and find little difference in the estimates. In the final columns, I use data from 1972 (instead of 1992, as in the benchmark calculations) to infer the steady-state relevant parameters $\Gamma_{I J}^{M}, \mu_{J}, \alpha_{J}$, and $\xi_{J} \cdot{ }^{41}$

In Table 8, I consider the effect of varying $\sigma_{M, A g g}$ and $\sigma_{M, I n d}$ (the standard deviation of the aggregate and industry-specific components of the intermediate input measurement error). In the benchmark estimation, $\sigma_{M, A g g}$ and $\sigma_{M, I n d}$ are both equal to $0.2 \%$. In the first column, I set both $\sigma_{M, A g g}$ and $\sigma_{M, \text { Ind }}$ equal to $0.1 \%$. In the second (respectively third) column, I set $\sigma_{M, I n d}$ (respectively $\sigma_{M, A g g}$ ) equal to $0.4 \%$ and leave the other standard deviation at its benchmark value. Decreasing both the aggregate and industry-specific components of the intermediate input measurement error affects neither the estimated elasticities of substitution nor the fraction of aggregate output volatility that originates from industry-specific shocks. On the other hand, increasing only the aggregate component of the measurement error leads to a more prominent role of industry-specific shocks (where these shocks account for $68 \%$ instead of $63 \%$ of the variation in aggregate output growth), while increasing only the industry-specific component of the measurement error has the opposite effect. These findings are consistent with the predictions of Proposition 1. For all of these differences, however, industry-specific shocks are the dominant source of aggregate output volatility. In other words, the paper's main empirical findings are robust to moderate changes in the degree to which intermediate inputs are mismeasured.

\footnotetext{
${ }^{41}$ The Capital Flows data necessary to construct $\Gamma_{I J}^{X}$ are unavailable for 1972 . For this reason, I use the 1992 Capital Flows Table to infer the $\Gamma_{I J}^{X}$ for the robustness check corresponding to the final columns of Table 7 .
} 


\begin{tabular}{|c|c|c|c|c|c|c|c|c|}
\hline & \multicolumn{2}{|c|}{ Trim $0.25 \%$} & \multicolumn{2}{|c|}{ Trim $1.0 \%$} & \multicolumn{2}{|c|}{$\varepsilon_{L S}=2$} & \multicolumn{2}{|c|}{ Steady State $=1972$} \\
\hline$\varepsilon_{D}$ & 0.611 & 1 & 0.670 & 1 & 0.661 & 1 & 1.450 & 1 \\
\hline$\varepsilon_{Q}$ & 0.049 & 1 & 0.043 & 1 & 0.046 & 1 & 0.056 & 1 \\
\hline$\varepsilon_{M}$ & 0.033 & 1 & 0.036 & 1 & 0.034 & 1 & 0.038 & 1 \\
\hline$\varepsilon_{X}$ & 2.861 & 1 & 2.713 & 1 & 2.877 & 1 & 3.454 & 1 \\
\hline$\sigma_{A, I n d}$ & 0.048 & 0.036 & 0.042 & 0.031 & 0.046 & 0.034 & 0.045 & 0.034 \\
\hline$\sigma_{B, I n d}$ & 0.119 & 0.001 & 0.100 & 0.000 & 0.110 & 0.000 & 0.104 & 0.000 \\
\hline$\sigma_{D, I n d}$ & 0.063 & 0.110 & 0.062 & 0.101 & 0.062 & 0.104 & 0.356 & 0.476 \\
\hline$\sigma_{A, A g g}$ & 0.009 & 0.007 & 0.006 & 0.006 & 0.010 & 0.007 & 0.007 & 0.000 \\
\hline$\sigma_{B, A g g}$ & 0.041 & 0.014 & 0.037 & 0.016 & 0.040 & 0.015 & 0.034 & 0.043 \\
\hline$\sigma_{D, A g g}$ & 0.002 & 0.028 & 0.000 & 0.029 & 0.002 & 0.027 & 0.001 & 0.167 \\
\hline$\rho_{A, I n d}$ & 0.992 & 1.000 & 0.999 & 1.000 & 1.000 & 1.000 & 0.998 & 1.000 \\
\hline$\rho_{B, \text { Ind }}$ & 0.942 & 1.000 & 0.996 & 1.000 & 0.892 & 1.000 & 0.997 & 1.000 \\
\hline$\rho_{D, \text { Ind }}$ & 0.887 & 0.959 & 0.889 & 0.951 & 0.948 & 0.954 & 0.886 & 0.942 \\
\hline$\rho_{A, A g g}$ & 0.987 & 0.877 & 0.963 & 0.890 & 1.000 & 0.878 & 0.926 & -0.212 \\
\hline$\rho_{B, A g g}$ & 0.968 & 0.793 & 0.977 & 0.797 & 0.991 & 0.793 & 0.999 & 1.000 \\
\hline$\rho_{D, A g g}$ & 0.999 & 0.870 & 0.999 & 0.872 & 1.000 & 0.864 & -0.933 & 0.799 \\
\hline Log Likelihood & 6493.3 & -105526.3 & 6979.7 & -76277.6 & 6735.3 & -94674.4 & 6735.3 & -96087.4 \\
\hline $\begin{array}{l}\% \text { of Variation } \\
\text { from Industry- } \\
\text { Specific Shocks }\end{array}$ & 65.4 & 52.5 & 64.6 & 46.4 & 67.4 & 48.8 & 74.6 & 36.6 \\
\hline
\end{tabular}

Table 7: MLE Estimates, Robustness Checks: Trimming Cut-off and the Calibrated Parameters.

Notes: The final row gives the fraction of aggregate output growth volatility that is due to industry-specific demand and productivity shocks. 


\begin{tabular}{cccc}
\hline & $\sigma_{M, \text { Ind }}=0.1 \%$ & $\sigma_{M, \text { Ind }}=0.4 \%$ & $\sigma_{M, \text { Ind }}=0.2 \%$ \\
& $\sigma_{M, \text { Agg }}=0.1 \%$ & $\sigma_{M, \text { Agg }}=0.2 \%$ & $\sigma_{M, A g g}=0.4 \%$ \\
\hline$\varepsilon_{D}$ & 0.650 & 0.663 & 0.652 \\
$\varepsilon_{Q}$ & 0.045 & 0.046 & 0.047 \\
$\varepsilon_{M}$ & 0.034 & 0.034 & 0.034 \\
$\varepsilon_{X}$ & 2.879 & 2.844 & 2.850 \\
$\sigma_{A, \text { Ind }}$ & 0.046 & 0.045 & 0.046 \\
$\sigma_{B, \text { Ind }}$ & 0.111 & 0.107 & 0.109 \\
$\sigma_{D, \text { Ind }}$ & 0.062 & 0.062 & 0.062 \\
$\sigma_{A, \text { Agg }}$ & 0.010 & 0.010 & 0.008 \\
$\sigma_{B, \text { Agg }}$ & 0.041 & 0.040 & 0.037 \\
$\sigma_{D, \text { Agg }}$ & 0.002 & 0.001 & 0.002 \\
$\rho_{A, \text { Ind }}$ & 0.999 & 0.999 & 0.998 \\
$\rho_{B, \text { Ind }}$ & 0.888 & 0.889 & 0.887 \\
$\rho_{D, \text { Ind }}$ & 0.949 & 0.950 & 0.949 \\
$\rho_{A, \text { Agg }}$ & 1.000 & 1.000 & 0.998 \\
$\rho_{B, \text { Agg }}$ & 1.000 & 0.984 & 1.000 \\
$\rho_{D, \text { Agg }}$ & 1.000 & 1.000 & 0.999 \\
\hline Log Likelihood & 6493.3 & 6758.0 & 6748.1 \\
\hline$\%$ of Variation & & & 68.9 \\
from Industry- & 64.2 & 62.4 & \\
Specific Shocks & & & \\
\hline
\end{tabular}

Table 8: MLE Estimates, Robustness Checks: Measurement Error.

Notes: The final row gives the fraction of aggregate output growth volatility that is due to industry-specific demand and productivity shocks. 


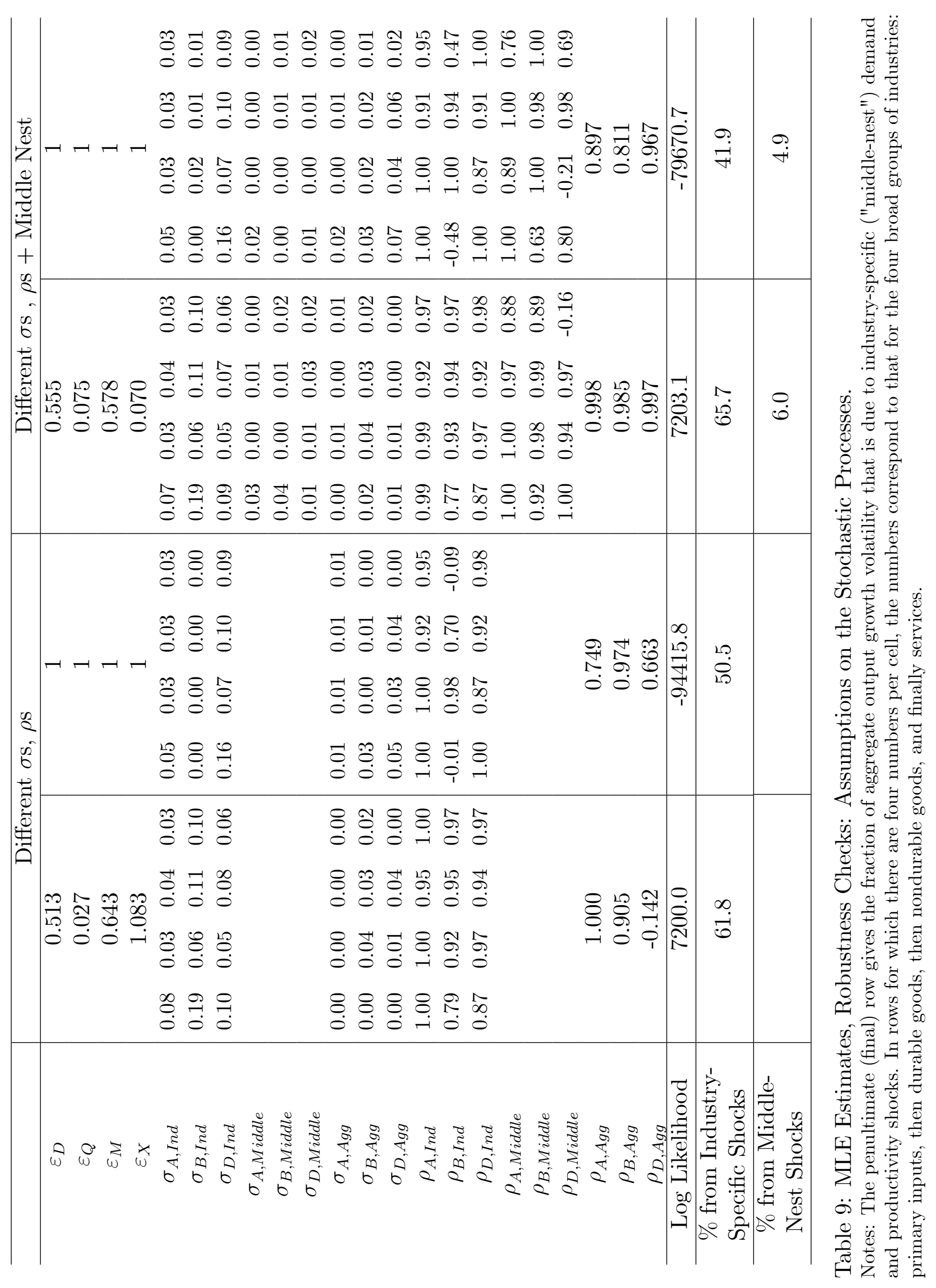


In Table 9, I consider the effect of relaxing the assumptions regarding the stochastic processes. In the benchmark specification, both the standard deviation of innovations and the persistence of the stochastic processes are identical for all industries. In the first columns of Table 9, I relax this assumption by allowing the $\sigma_{\vartheta, \text { Ind }}, \sigma_{\vartheta, A g g}$, and $\rho_{\vartheta, \text { Ind }}$ (for $\vartheta \in\{A, B, D\}$ ) to differ across broad groups of industries, $S$, (where $S=$ \{primary inputs, durable goods, non-durable goods, services\}). ${ }^{42}$ In other words, Equations 9 to 14 are changed to:

$$
\begin{aligned}
\log \vartheta_{t+1, J} & =\rho_{\vartheta, \text { Ind }}^{S} \cdot \log \vartheta_{t J}+\sigma_{\vartheta, \text { Ind }}^{S} \cdot \omega_{t J}^{I n d, \vartheta}, \text { and } \\
\log \vartheta_{t+1, A g g} & =\rho_{\vartheta, \text { Agg }} \cdot \log \vartheta_{t, A g g}+\sigma_{\vartheta, A g g}^{S} \cdot \omega_{t}^{A g g, \vartheta} \quad \text { for } \vartheta \in\{A, B, D\} .
\end{aligned}
$$

In the final columns, I also add a "middle-nest" of shocks, so that the exogeneous demand and productivity processes co-vary more strongly within the broad groups of industries than across these broad groups.

$$
\log \vartheta_{t+1, S}=\rho_{\vartheta, \text { Middle }}^{S} \cdot \log \vartheta_{t, \text { Agg }}+\sigma_{\vartheta, \text { Middle }}^{S} \cdot \omega_{t}^{\text {Middle } \vartheta} \quad \text { for } \vartheta \in\{A, B, D\}
$$

The two main results of Table 9 are that a) neither the estimate of $\varepsilon_{Q}$ nor the estimated relative importance of industry-specific shocks is sensitive to allowing for differential volatilities and persistencies to the stochastic processes; and b) the "middle-nest" shocks account for a small fraction, roughly $5 \%$, of aggregate output growth volatility.

A final robustness check considers the sensitivity of the main results to the de-trending procedure. In the benchmark calculations, I had linearly de-trended each industry-level observable before performing the maximum likelihood estimation procedure. In Table 10, I consider two alternate de-trending procedures: a linear trend with a break in the trend at 1983, and a Hodrick-Prescott filter. Including a trend break has almost no effect on the parameter estimates or the resulting relative importance of industry-specific shocks. (see the first two columns of Table 10). On the other hand, applying a Hodrick-Prescott filter results in a somewhat higher estimate for the relative importance of industry-specific shocks.

\footnotetext{
${ }^{42}$ Primary Inputs are the following five industries: Agriculture, Metal Mining, Coal Mining, and Crude Oil Extraction. Durable Goods comprise Construction, Lumber, Furniture, Leather, Stone and Glass, Primary Metals, Fabricated Products, Non-Electrical Machinery, Motor Vehicles, Other Transportation Equipment, Instruments, and Miscellaneous Manufacturing. Nondurable Goods comprise Food and Kindred Products, Tobacco, Textile Mill Products, Apparel, Paper, Printing, Chemicals, Petroleum, and Rubber and Plastic. Finally, Services comprise the remaining industries (Transportation and Warehousing, Communications, Electric Utilities, Gas Utilities, Wholesale and Retail, F.I.R.E., Personal and Business Services).
} 


\begin{tabular}{ccccc}
\hline & \multicolumn{2}{c}{ Linearly De-trended, } & \multicolumn{2}{c}{ Hodrick-Prescott } \\
& \multicolumn{2}{c}{ Break at 1983} & 0.209 & 1 \\
$\varepsilon_{D}$ & 0.652 & 1 & 0.039 & 1 \\
$\varepsilon_{Q}$ & 0.050 & 1 & 0.510 & 1 \\
$\varepsilon_{M}$ & 0.0 .34 & 1 & 0.060 & 1 \\
$\varepsilon_{X}$ & 3.158 & 1 & 0.028 & 0.026 \\
$\sigma_{A, I n d}$ & 0.045 & 0.033 & 0.072 & 0.001 \\
$\sigma_{B, \text { Ind }}$ & 0.105 & 0.001 & 0.048 & 0.086 \\
$\sigma_{D, \text { Ind }}$ & 0.061 & 0.101 & 0.006 & 0.000 \\
$\sigma_{A, \text { Agg }}$ & 0.009 & 0.007 & 0.025 & 0.019 \\
$\sigma_{B, \text { Agg }}$ & 0.037 & 0.017 & 0.002 & 0.023 \\
$\sigma_{D, \text { Agg }}$ & 0.002 & 0.014 & 0.477 & 1.000 \\
$\rho_{A, \text { Ind }}$ & 1.000 & 1.000 & 0.174 & 1.000 \\
$\rho_{B, \text { Ind }}$ & 0.858 & 1.000 & 0.356 & 0.786 \\
$\rho_{D, \text { Ind }}$ & 0.899 & 0.941 & 0.777 & 0.936 \\
$\rho_{A, \text { Agg }}$ & 1.000 & 0.859 & 1.000 & 0.643 \\
$\rho_{B, \text { Agg }}$ & 0.938 & 0.818 & 1.000 & 0.992 \\
$\rho_{D, \text { Agg }}$ & 1.000 & 0.227 & 8230.0 & -45667.8 \\
\hline Log Likelihood & 6887.2 & -83619.5 & \\
\hline$\%$ of Variation & \multicolumn{5}{c}{76.4} & 39.3 \\
from Industry- & 63.1 & 46.5 & & \\
Specific Shocks & & &
\end{tabular}

Table 10: MLE Estimates, Robustness Checks: De-trending.

Notes: The final row gives the fraction of aggregate output growth volatility that is due to industry-specific demand and productivity shocks. 


\section{B U.S. Data: Additional Details}

This section provides details on the construction of various industry-level variables.

Table 11 presents these expenditure shares for the 34 industries in the benchmark sample. Intermediate inputs comprise $54.9 \%$ of the costs of the average industry. Labor and capital are represent $28.7 \%$ and $16.3 \%$, respectively, of the expenditures of the average industry. Purchased intermediate inputs are especially important within manufacturing, accounting for $59.3 \%$ of the costs in these industries.

The final columns of Table 11 give the consumption expenditure share and the gross output share of each industry. The total gross output of each industry is taken directly from Dale Jorgenson's dataset. The consumption expenditures are taken from the BEA 1992 Input-Output Table, the sales to the following three BEA IOIND industries: 910000 (personal consumption expenditures), 920000 (private fixed investment), and 940000 (exports of goods and services).

Depreciation rates for durable goods are given in Table 12. The set of durable goods are those designated as such by Basu, Fernald, and Kimball (2006), plus the Construction industry. The depreciation rates are taken from the BEA, which in turn draws on Hulten and Wykoff (1981). For durable goods with depreciation rates that are not estimated by Hulten and Wykoff: I set the depreciation rate for Lumber and Wood Products to be equal to $11.8 \%$ (the same as the depreciation rate of Furniture and Fixtures), and the depreciation rate for other goods to be equal to $16.5 \% .^{43}$

\begin{tabular}{clccccc}
\hline Industry & Name & Capital & Labor & Materials & Consumption & Output \\
\hline 1 & Agriculture, Forestry, Fisheries & $19.3 \%$ & $23.7 \%$ & $57.0 \%$ & $2.2 \%$ & $2.8 \%$ \\
2 & Metal Mining & $20.5 \%$ & $21.8 \%$ & $57.7 \%$ & $0.1 \%$ & $0.1 \%$ \\
3 & Coal Mining & $22.9 \%$ & $34.9 \%$ & $42.3 \%$ & $0.3 \%$ & $0.3 \%$ \\
4 & Crude Oil and Gas Extraction & $36.9 \%$ & $14.3 \%$ & $48.7 \%$ & $1.1 \%$ & $1.4 \%$ \\
5 & Non-Metallic Mineral Mining & $28.6 \%$ & $32.8 \%$ & $38.6 \%$ & $0.1 \%$ & $0.2 \%$ \\
6 & Construction & $3.9 \%$ & $39.6 \%$ & $56.5 \%$ & $6.7 \%$ & $6.5 \%$ \\
7 & Food and Kindred Products & $12.7 \%$ & $17.0 \%$ & $70.4 \%$ & $4.2 \%$ & $4.3 \%$ \\
8 & Tobacco Manufactures & $34.5 \%$ & $17.2 \%$ & $48.4 \%$ & $0.4 \%$ & $0.3 \%$ \\
9 & Textile Mill Products & $9.8 \%$ & $23.9 \%$ & $66.3 \%$ & $0.6 \%$ & $0.8 \%$ \\
10 & Apparel and Other Textiles & $7.6 \%$ & $27.7 \%$ & $64.7 \%$ & $0.9 \%$ & $0.7 \%$ \\
11 & Lumber and Wood Products & $11.5 \%$ & $25.5 \%$ & $63.0 \%$ & $0.9 \%$ & $0.9 \%$
\end{tabular}

Continued on next page

${ }^{43}$ The $16.5 \%$ figure is the value that the BEA uses to impute missing durable good depreciation rates. 


\begin{tabular}{|c|c|c|c|c|c|c|}
\hline 12 & Furniture and Fixtures & $7.4 \%$ & $39.1 \%$ & $53.4 \%$ & $0.4 \%$ & $0.5 \%$ \\
\hline 13 & Paper and Allied Products & $13.0 \%$ & $25.6 \%$ & $61.4 \%$ & $1.3 \%$ & $1.4 \%$ \\
\hline 14 & Printing and Publishing & $14.0 \%$ & $41.5 \%$ & $44.5 \%$ & $1.7 \%$ & $1.8 \%$ \\
\hline 15 & Chemicals and Allied Products & $20.3 \%$ & $21.4 \%$ & $58.3 \%$ & $2.5 \%$ & $3.3 \%$ \\
\hline 16 & Petroleum Refining & $7.4 \%$ & $6.2 \%$ & $86.3 \%$ & $1.5 \%$ & $1.7 \%$ \\
\hline 17 & Rubber and Plastic Products & $9.5 \%$ & $35.1 \%$ & $55.4 \%$ & $1.6 \%$ & $1.2 \%$ \\
\hline 18 & Leather and Leather Products & $15.1 \%$ & $22.8 \%$ & $62.1 \%$ & $0.1 \%$ & $0.1 \%$ \\
\hline 19 & Stone, Clay, and Glass Products & $11.1 \%$ & $37.7 \%$ & $51.2 \%$ & $0.5 \%$ & $0.7 \%$ \\
\hline 20 & Primary Metals & $9.4 \%$ & $20.7 \%$ & $69.9 \%$ & $1.4 \%$ & $1.5 \%$ \\
\hline 21 & Fabricated Metal Products & $11.0 \%$ & $32.8 \%$ & $56.2 \%$ & $1.7 \%$ & $1.8 \%$ \\
\hline 22 & Non-Electrical Machinery & $9.4 \%$ & $33.7 \%$ & $56.9 \%$ & $2.5 \%$ & $2.8 \%$ \\
\hline 23 & Electrical Machinery & $18.5 \%$ & $28.8 \%$ & $52.7 \%$ & $2.1 \%$ & $2.3 \%$ \\
\hline 24 & Motor Vehicles & $4.7 \%$ & $17.1 \%$ & $78.2 \%$ & $2.3 \%$ & $2.5 \%$ \\
\hline 25 & Other Transportation Equipment & $5.3 \%$ & $44.3 \%$ & $50.4 \%$ & $1.3 \%$ & $1.6 \%$ \\
\hline 26 & Instruments & $8.4 \%$ & $50.4 \%$ & $41.1 \%$ & $1.3 \%$ & $1.4 \%$ \\
\hline 27 & Miscellaneous Manufacturing & $15.5 \%$ & $29.3 \%$ & $55.2 \%$ & $0.4 \%$ & $0.4 \%$ \\
\hline 28 & Transportation and Warehousing & $12.0 \%$ & $39.1 \%$ & $48.9 \%$ & $3.9 \%$ & $4.1 \%$ \\
\hline 29 & Communications & $35.0 \%$ & $22.4 \%$ & $42.6 \%$ & $2.4 \%$ & $2.5 \%$ \\
\hline 30 & Electric Utilities (Services) & $42.2 \%$ & $19.1 \%$ & $38.7 \%$ & $1.9 \%$ & $2.5 \%$ \\
\hline 31 & Gas Utilities (Services) & $12.0 \%$ & $6.4 \%$ & $81.6 \%$ & $0.9 \%$ & $0.6 \%$ \\
\hline 32 & Wholesale and Retail Trade & $13.0 \%$ & $48.1 \%$ & $38.9 \%$ & $11.1 \%$ & $13.6 \%$ \\
\hline 33 & F.I.R.E. & $42.5 \%$ & $23.5 \%$ & $34.0 \%$ & $16.8 \%$ & $13.1 \%$ \\
\hline 34 & Personal and Business Services & $11.0 \%$ & $53.7 \%$ & $35.4 \%$ & $22.7 \%$ & $20.4 \%$ \\
\hline
\end{tabular}

Table 11: Industry Definitions, Preference Weights, and Factor Shares.

Figure 4 presents the flows of material and capital inputs across pairs of industries. The figures depict shares of expenditures of each destination industry, so that the rows of each of these figures sum to 1 .

These data are taken from the 1992 BEA Input-Output Table and 1992 BEA Capital Flows Table. I make one adjustment to the 1992 Capital Flows Table when producing the right panel of Figure 4 to account for the maintenance and repair expenditures that are not included in the Capital Flows Table. As McGrattan and Schmitz (1999) report, maintenance expenditures are substantial, potentially accounting for $50 \%$ of total physical capital investment. Following Foerster, Sarte, and Watson (2011), I add a 25\% share to the diagonal entries of this matrix, to account for these maintenance and repair expenditures. This augmentation presumes that capital-good repairs draw on within-industry resources 


\begin{tabular}{clc}
\hline Industry & Name & Depreciation Rate \\
\hline 6 & Construction & $2.1 \%$ \\
11 & Lumber and Wood Products & $11.8 \%$ \\
12 & Furniture and Fixtures & $11.8 \%$ \\
19 & Stone, Clay, and Glass Products & $16.5 \%$ \\
20 & Primary Metals & $16.5 \%$ \\
21 & Fabricated Metal Products & $16.5 \%$ \\
22 & Non-Electrical Machinery & $16.5 \%$ \\
23 & Electrical Machinery & $17.0 \%$ \\
24 & Motor Vehicles & $35.3 \%$ \\
25 & Other Transportation Equipment & $16.5 \%$ \\
26 & Instruments & $16.7 \%$ \\
27 & Miscellaneous Manufacturing & $16.2 \%$ \\
\hline
\end{tabular}

Table 12: Depreciation rates of durable goods.

(e.g., firms that produce a product use their own labor to repair their capital equipment).

Two patterns emerge from these figures. First, the diagonal entries of the matrices are larger than average. In the left panel, the average own-industry share of intermediate input expenditures is $27 \%$. This large share is due, in part, to the coarseness of industry definitions. To give an example, one of the 34 industries in the benchmark sample is Food Manufacturers (2-digit SIC, 20). Within this industry are producers of flour and producers of bread. A bakery, which purchases flour, will be recorded as purchasing inputs from within the same industry according to my 34-industry categorization. Using a finer categorization, this purchase would have been classified as an across-industry purchase.

The second pattern is that certain industries are used, as intermediate or investment inputs, by a large number of other industries. For intermediate inputs, these are the Transportation and Warehousing, Wholesale and Retail, F.I.R.E., and Personal and Business Services industries. For investment inputs, the main sources are the Construction industry and the several industries that are categorized as producing different types of machinery.

\section{Data from Outside the U.S.}

The data from other countries come from two sources. The flows of intermediate inputs are collected by the Organization for Economic Co-operation and Development (OECD). ${ }^{44}$ The data on industries' output and intermediate input purchases are collected and main-

\footnotetext{
${ }^{44}$ The data can be downloaded at http://www.oecd.org/trade/input-outputtables.htm . I use, in this section, the 2002 edition of the data.
} 

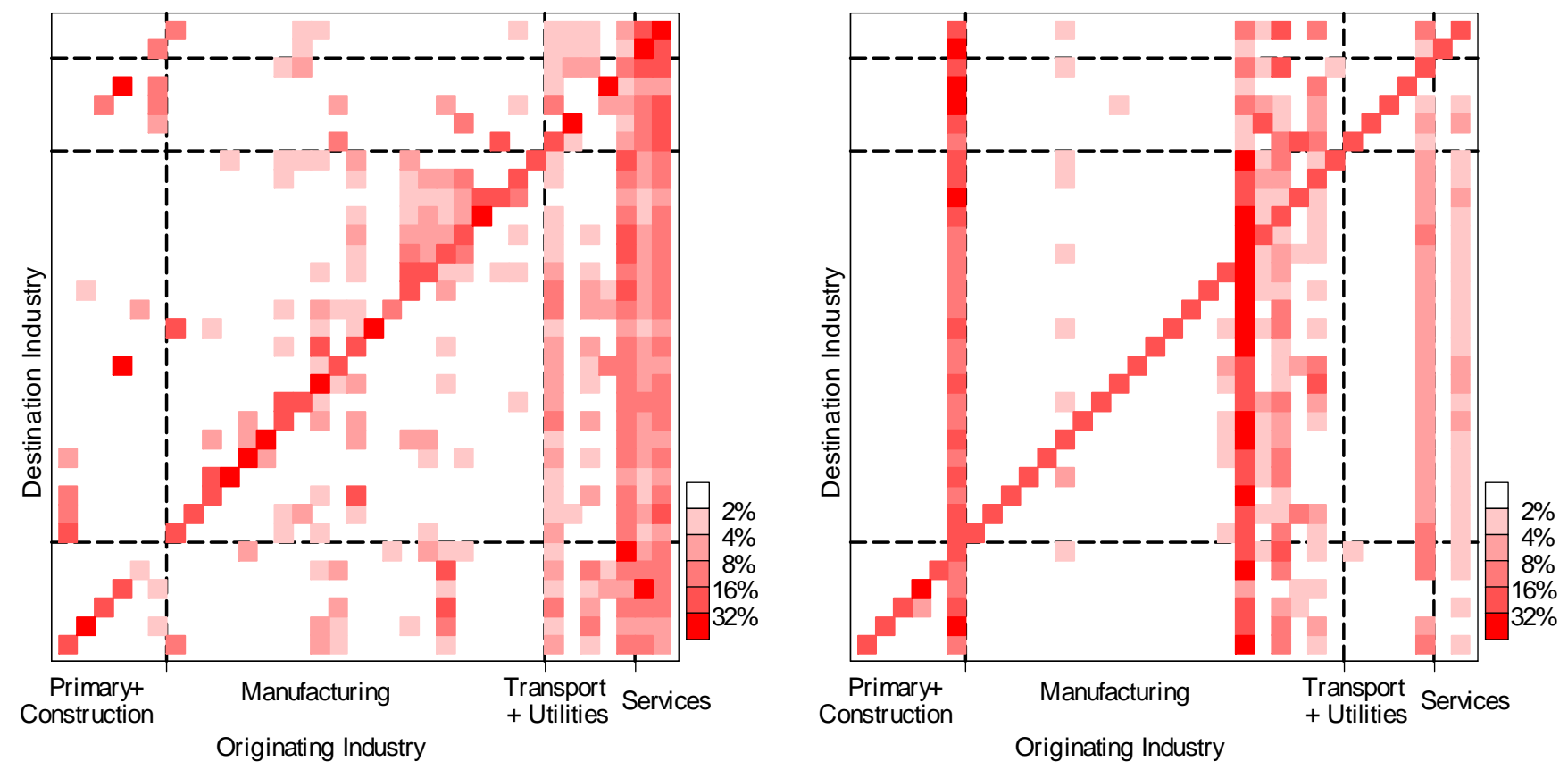

Figure 4: Flows of intermediate inputs and capital investment goods.

Notes: The left panel gives the intensity of intermediate input flows among the 34 industries, and the right panel gives the corresponding set of flows of capital investment inputs.

tained by the European Union KLEMS Growth and Productivity Accounts (EUKLEMS). ${ }^{45}$ The EUKLEMS data are reviewed, in detail, in Timmer et al. (2007) and O'Mahony and Timmer (2009). Durable good depreciation rates and flows of investment goods are not available for other countries. For these variables, I imputed values using data from the United States.

Of the thirty countries that are included in the EUKLEMS dataset, I restrict attention to six: Denmark, France, Italy, Japan, the Netherlands, and Spain. Many of the countries that I discarded are Eastern Bloc countries - such as Latvia, Lithuania, and Poland - for which pre-1990 data are unavailable. There are other countries, such as England, for which-for at least half of the sample period - intermediate input purchases and gross output are imputed from value added data. Data from all countries span 1970 to 2007, with the exception of Japan, France, and Spain, countries whose samples begin in 1973, 1978, and 1981.

The industry definitions in the EUKLEMS database differ from those in the U.S. dataset. Service industries are more finely defined. For example, F.I.R.E. is now broken out between finance and insurance on the one hand and real estate on the other. Mining and manufacturing industries are more coarse. As with the United States data, I discard the Government

\footnotetext{
${ }^{45}$ The data can be downloaded at http://www.euklems.net/. I use, in this section, the ISIC Rev. 3 edition of the data.
} 


\begin{tabular}{|c|c|c|c|c|c|c|c|c|}
\hline$\#$ & Name & Denmark & France & Italy & Japan & Netherlands & Spain & U.S. Ind. \\
\hline 1 & Agriculture & $1.6 \%$ & $1.7 \%$ & $1.9 \%$ & $0.8 \%$ & $3.1 \%$ & $2.6 \%$ & 1 \\
\hline 2 & Mining & $0.6 \%$ & $0.1 \%$ & $0.0 \%$ & $0.0 \%$ & $1.2 \%$ & $0.1 \%$ & $2-5$ \\
\hline 3 & Food and Tobacco & $8.8 \%$ & $8.2 \%$ & $7.0 \%$ & $5.9 \%$ & $9.0 \%$ & $7.0 \%$ & $7-8$ \\
\hline 4 & Textiles and Leather & $2.4 \%$ & $2.7 \%$ & $6.0 \%$ & $1.9 \%$ & $2.4 \%$ & $3.1 \%$ & $9-10,18$ \\
\hline 5 & Wood Products & $0.5 \%$ & $0.1 \%$ & $0.2 \%$ & $0.0 \%$ & $0.2 \%$ & $0.2 \%$ & 11 \\
\hline 6 & Paper and Publishing & $1.3 \%$ & $1.2 \%$ & $1.1 \%$ & $0.6 \%$ & $2.0 \%$ & $1.3 \%$ & $13-14$ \\
\hline 7 & Petroleum Refining & $0.8 \%$ & $2.0 \%$ & $1.9 \%$ & $0.7 \%$ & $1.6 \%$ & $1.1 \%$ & 16 \\
\hline 8 & Chemicals & $3.1 \%$ & $4.0 \%$ & $1.9 \%$ & $1.1 \%$ & $7.3 \%$ & $2.9 \%$ & 15 \\
\hline 9 & Rubber and Plastics & $0.9 \%$ & $0.7 \%$ & $0.6 \%$ & $0.2 \%$ & $1.1 \%$ & $0.6 \%$ & 17 \\
\hline 10 & Stone, Clay, and Glass & $0.5 \%$ & $0.4 \%$ & $0.7 \%$ & $0.2 \%$ & $0.4 \%$ & $0.6 \%$ & 19 \\
\hline 11 & Metal products & $1.7 \%$ & $2.4 \%$ & $1.8 \%$ & $0.7 \%$ & $3.1 \%$ & $1.9 \%$ & $20-21$ \\
\hline 12 & Non-electrical Machinery & $5.4 \%$ & $3.4 \%$ & $5.2 \%$ & $4.3 \%$ & $3.2 \%$ & $2.4 \%$ & 22 \\
\hline 13 & Electrical Machinery & $4.5 \%$ & $4.5 \%$ & $4.1 \%$ & $6.8 \%$ & $6.7 \%$ & $3.5 \%$ & 23,26 \\
\hline 14 & Transportation Equipment & $2.9 \%$ & $6.7 \%$ & $4.3 \%$ & $4.2 \%$ & $4.4 \%$ & $7.0 \%$ & $24-25$ \\
\hline 15 & Misc. Manufacturing & $2.3 \%$ & $1.6 \%$ & $2.4 \%$ & $1.1 \%$ & $1.9 \%$ & $1.8 \%$ & 12,27 \\
\hline 16 & Utilities & $1.7 \%$ & $2.1 \%$ & $1.7 \%$ & $1.3 \%$ & $1.5 \%$ & $1.3 \%$ & 30,31 \\
\hline 17 & Construction & $8.2 \%$ & $9.0 \%$ & $9.5 \%$ & $15.4 \%$ & $6.5 \%$ & $11.7 \%$ & 6 \\
\hline 18 & Wholesale and Retail & $12.1 \%$ & $9.7 \%$ & $14.8 \%$ & $13.3 \%$ & $12.4 \%$ & $10.7 \%$ & 32 \\
\hline 19 & Hotels and Restaurants & $1.9 \%$ & $3.7 \%$ & $4.6 \%$ & $6.3 \%$ & $1.9 \%$ & $10.7 \%$ & 34 \\
\hline 20 & Transport and Warehousing & $6.4 \%$ & $2.8 \%$ & $4.1 \%$ & $3.8 \%$ & $4.6 \%$ & $3.2 \%$ & 28 \\
\hline 21 & Communications & $0.9 \%$ & $0.9 \%$ & $0.9 \%$ & $0.9 \%$ & $0.9 \%$ & $1.1 \%$ & 29 \\
\hline 22 & Finance and Insurance & $2.0 \%$ & $2.0 \%$ & $1.4 \%$ & $1.6 \%$ & $2.3 \%$ & $1.3 \%$ & 33 \\
\hline 23 & Real Estate & $8.5 \%$ & $10.1 \%$ & $7.2 \%$ & $10.3 \%$ & $5.8 \%$ & $6.8 \%$ & 33 \\
\hline 24 & Business Services & $1.9 \%$ & $4.4 \%$ & $1.8 \%$ & $2.4 \%$ & $4.0 \%$ & $2.6 \%$ & 34 \\
\hline 25 & Education & $5.1 \%$ & $4.5 \%$ & $5.3 \%$ & $4.2 \%$ & $3.4 \%$ & $5.0 \%$ & 34 \\
\hline 26 & Health and Social Work & $10.5 \%$ & $7.7 \%$ & $6.9 \%$ & $6.4 \%$ & $6.7 \%$ & $6.0 \%$ & 34 \\
\hline 27 & Other Personal Services & $3.5 \%$ & $3.2 \%$ & $2.7 \%$ & $5.3 \%$ & $2.4 \%$ & $3.3 \%$ & 34 \\
\hline
\end{tabular}

Table 13: Industry definitions and consumption shares in the EUKLEMS dataset.

Notes: The final column shows the correspondence between the EUKLEMS industry definitions and the industry definitions for the United States data. 


\begin{tabular}{|c|c|c|c|c|c|c|c|}
\hline$\#$ & Name & Denmark & France & Italy & Japan & Netherlands & Spain \\
\hline 1 & Agriculture & $75.7 \%$ & $76.7 \%$ & $74.3 \%$ & $63.8 \%$ & $77.8 \%$ & $77.5 \%$ \\
\hline 2 & Mining & $64.8 \%$ & $65.6 \%$ & $64.5 \%$ & $63.0 \%$ & $68.8 \%$ & $69.0 \%$ \\
\hline 3 & Food and Tobacco & $60.4 \%$ & $64.3 \%$ & $59.6 \%$ & $66.3 \%$ & $64.3 \%$ & $68.1 \%$ \\
\hline 4 & Textiles and Leather & $56.3 \%$ & $65.5 \%$ & $61.8 \%$ & $57.4 \%$ & $60.3 \%$ & $66.7 \%$ \\
\hline 5 & Wood Products & $96.2 \%$ & $87.1 \%$ & $76.5 \%$ & $53.5 \%$ & $90.0 \%$ & $83.2 \%$ \\
\hline 6 & Paper and Publishing & $58.2 \%$ & $73.1 \%$ & $70.6 \%$ & $61.6 \%$ & $68.2 \%$ & $67.3 \%$ \\
\hline 7 & Petroleum Refining & $54.4 \%$ & $60.7 \%$ & $64.6 \%$ & $66.1 \%$ & $65.3 \%$ & $65.9 \%$ \\
\hline 8 & Chemicals & $55.1 \%$ & $60.5 \%$ & $59.9 \%$ & $56.8 \%$ & $59.9 \%$ & $58.5 \%$ \\
\hline 9 & Rubber and Plastics & $56.9 \%$ & $63.3 \%$ & $65.6 \%$ & $63.7 \%$ & $64.6 \%$ & $63.4 \%$ \\
\hline 10 & Stone, Clay, and Glass & $55.9 \%$ & $66.2 \%$ & $65.6 \%$ & $60.2 \%$ & $65.3 \%$ & $61.8 \%$ \\
\hline 11 & Metal products & $60.8 \%$ & $66.5 \%$ & $60.8 \%$ & $62.3 \%$ & $72.9 \%$ & $65.7 \%$ \\
\hline 12 & Non-electrical Machinery & $68.4 \%$ & $77.4 \%$ & $72.6 \%$ & $73.5 \%$ & $77.6 \%$ & $75.5 \%$ \\
\hline 13 & Electrical Machinery & $60.2 \%$ & $60.5 \%$ & $66.4 \%$ & $62.3 \%$ & $49.6 \%$ & $68.0 \%$ \\
\hline 14 & Transportation Equipment & $61.8 \%$ & $49.4 \%$ & $54.8 \%$ & $41.3 \%$ & $51.3 \%$ & $54.8 \%$ \\
\hline 15 & Misc. Manufacturing & $35.2 \%$ & $26.7 \%$ & $31.5 \%$ & $27.2 \%$ & $43.1 \%$ & $25.3 \%$ \\
\hline 16 & Utilities & $28.7 \%$ & $21.3 \%$ & $8.8 \%$ & $14.1 \%$ & $34.5 \%$ & $25.0 \%$ \\
\hline 17 & Construction & $41.1 \%$ & $44.2 \%$ & $39.7 \%$ & $44.1 \%$ & $44.1 \%$ & $45.5 \%$ \\
\hline 18 & Wholesale and Retail & $55.5 \%$ & $50.5 \%$ & $37.3 \%$ & $43.4 \%$ & $53.7 \%$ & $38.5 \%$ \\
\hline 19 & Hotels and Restaurants & $22.4 \%$ & $39.3 \%$ & $31.2 \%$ & $52.6 \%$ & $23.8 \%$ & $52.9 \%$ \\
\hline 20 & Transport and Warehousing & $37.2 \%$ & $53.5 \%$ & $45.3 \%$ & $48.5 \%$ & $71.2 \%$ & $51.4 \%$ \\
\hline 21 & Communications & $66.3 \%$ & $54.8 \%$ & $59.5 \%$ & $54.4 \%$ & $64.8 \%$ & $65.4 \%$ \\
\hline 22 & Finance and Insurance & $43.5 \%$ & $42.2 \%$ & $46.9 \%$ & $34.9 \%$ & $41.1 \%$ & $41.8 \%$ \\
\hline 23 & Real Estate & $54.7 \%$ & $51.1 \%$ & $49.6 \%$ & $52.8 \%$ & $52.1 \%$ & $46.2 \%$ \\
\hline 24 & Business Services & $37.2 \%$ & $46.7 \%$ & $31.0 \%$ & $33.5 \%$ & $43.7 \%$ & $36.4 \%$ \\
\hline 25 & Education & $24.1 \%$ & $14.8 \%$ & $16.6 \%$ & $15.4 \%$ & $18.9 \%$ & $14.3 \%$ \\
\hline 26 & Health and Social Work & $24.7 \%$ & $25.7 \%$ & $35.4 \%$ & $45.2 \%$ & $27.4 \%$ & $33.0 \%$ \\
\hline 27 & Other Personal Services & $40.0 \%$ & $43.1 \%$ & $41.8 \%$ & $36.7 \%$ & $56.7 \%$ & $51.8 \%$ \\
\hline
\end{tabular}

Table 14: Cost shares of intermediate inputs.

Enterprises industry. Table 13 describes the EUKLEMS industry classification, in addition to the consumption shares of each of the 27 industries. The main takeaway from this table is that the five countries are broadly similar in their industry composition.

Intermediate input shares for the six countries are given in Table 14. The intermediate input share of each country is roughly one-half, ranging from $50 \%$ for Japan to $56 \%$ for the Netherlands. These figures are close to the United States intermediate input share. Again, similar to the United States, other countries' intermediate input shares are higher for the primary and manufacturing sectors, and lower for the service sector.

Figure 5 presents the flows of intermediate inputs for two countries, Italy (left panel) and Japan (right panel). Similar to the United States tables, the diagonal elements of these tables are large: an average industry supplies approximately one-quarter of its own 

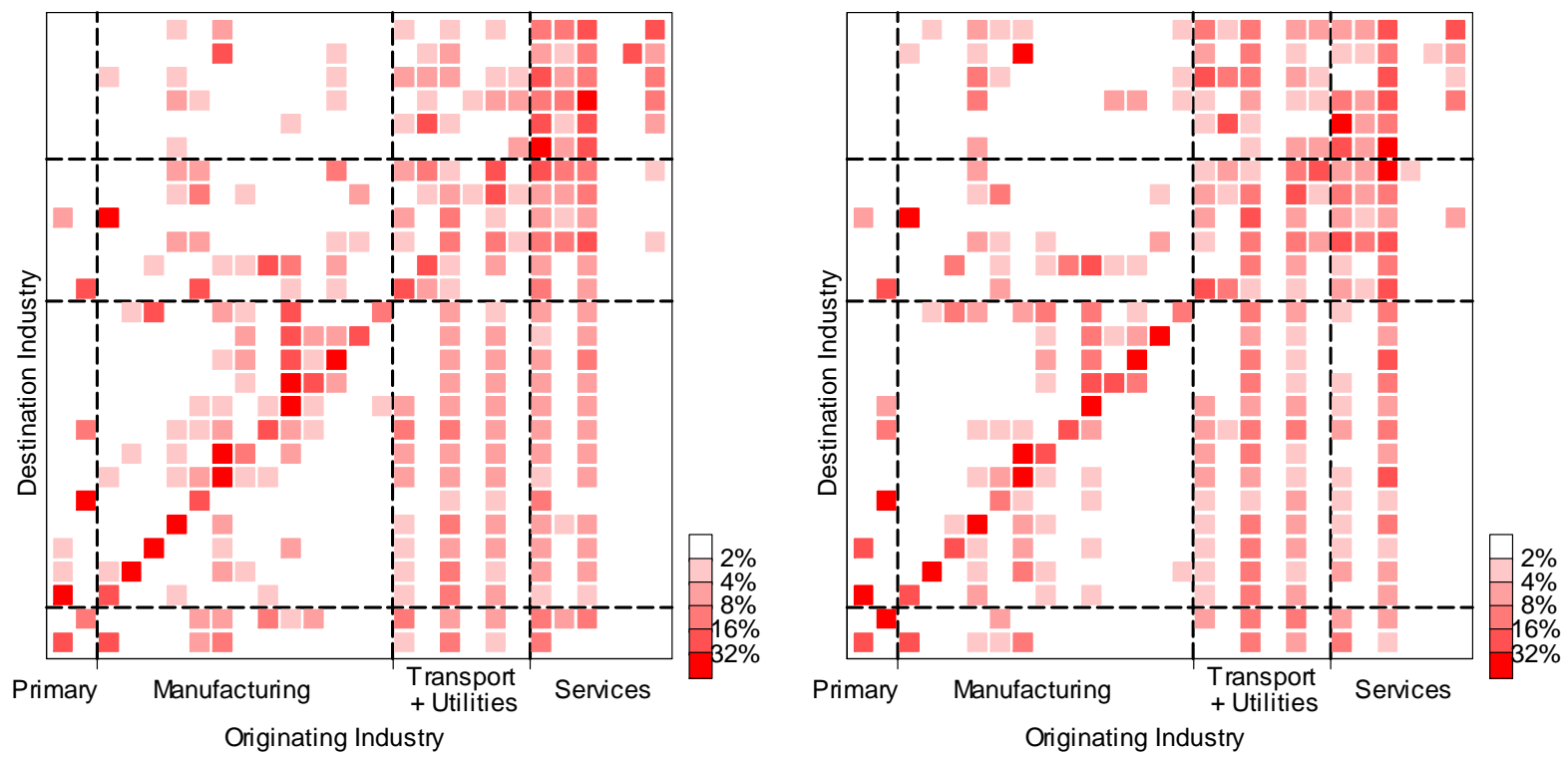

Figure 5: Flows of intermediate inputs.

Notes: Data for Italy are given in the left panel; data for Japan are given in the right panel.

intermediate input purchases.

Correlations and standard deviations of industries' gross output and intermediate input purchases are given in Table 15; the analogous values, for the United States, are given in Table 1. As with the U.S., industries' gross output is the most volatile statistic. The intermediate input cost share is somewhat more volatile in these six countries than it is for the United States (the corresponding standard deviation, there, was 2.5\%). As in the U.S. data, gross output and output prices are positively correlated with one another. The intermediate input expenditure share is also consistently positively correlated with the relative price of intermediate inputs. The correlations between $\Delta m^{\text {share }}$ and $\Delta \pi$ given in the final row of Table 15 are somewhat larger than the corresponding value $(21.2 \%)$ derived from the United States data.

\section{Solution of the Section-2 Model and Calibration De- tails}

\section{D.1 First-Order Conditions}

To begin, I write the Lagrangian related to the constrained maximization problem of a social planner. (Since this economy satisfies the conditions of the Welfare Theorems, 


\begin{tabular}{|c|c|c|c|c|c|c|}
\hline Statistic & Denmark & France & Italy & Japan & Netherlands & Spain \\
\hline $\operatorname{SD}(\Delta y)$ & $6.8 \%$ & $4.2 \%$ & $5.3 \%$ & $5.5 \%$ & $5.8 \%$ & $5.5 \%$ \\
\hline $\mathrm{SD}(\Delta p)$ & $4.6 \%$ & $3.7 \%$ & $4.3 \%$ & $3.9 \%$ & $3.9 \%$ & $2.5 \%$ \\
\hline $\mathrm{SD}\left(\Delta m^{\text {share }}\right)$ & $5.1 \%$ & $2.8 \%$ & $3.9 \%$ & $3.7 \%$ & $2.8 \%$ & $3.1 \%$ \\
\hline $\mathrm{SD}\left(\Delta p^{m a t}\right)$ & $4.3 \%$ & $3.6 \%$ & $5.1 \%$ & $5.3 \%$ & $4.7 \%$ & $3.0 \%$ \\
\hline $\operatorname{SD}(\Delta \pi)$ & $3.3 \%$ & $2.1 \%$ & $3.7 \%$ & $4.0 \%$ & $3.4 \%$ & $2.2 \%$ \\
\hline $\operatorname{Corr}(\Delta y, \Delta p)$ & $58.3 \%$ & $65.1 \% *$ & $61.2 \% *$ & $60.0 \% *$ & $52.8 \%$ & $33.7 \% *$ \\
\hline $\operatorname{Corr}\left(\Delta y, \Delta m^{\text {share }}\right)$ & $-10.2 \% *$ & $-3.5 \%$ & $-2.3 \%$ & $14.9 \% *$ & $-17.3 \% *$ & $17.9 \% *$ \\
\hline $\operatorname{Corr}\left(\Delta y, \Delta p^{m a t}\right)$ & $45.2 \% *$ & $55.4 \% *$ & $44.4 \% *$ & $44.5 \% *$ & $21.7 \% *$ & $23.4 \% *$ \\
\hline $\operatorname{Corr}(\Delta y, \Delta \pi)$ & $-23.4 \% *$ & $-18.4 \% *$ & $-9.3 \% *$ & $0.6 \%$ & $-30.5 \% *$ & $-6.3 \%$ \\
\hline $\operatorname{Corr}\left(\Delta p, \Delta m^{\text {share }}\right)$ & $-10.4 \% *$ & $-13.4 \% *$ & $-10.3 \% *$ & $11.0 \% *$ & $-12.5 \% *$ & $-9.5 \% *$ \\
\hline $\operatorname{Corr}\left(\Delta p, \Delta p^{m a t}\right)$ & $72.8 \% *$ & $8.8 \% *$ & $70.1 \% *$ & $67.5 \% *$ & $70.2 \% *$ & $70.4 \% *$ \\
\hline $\operatorname{Corr}(\Delta p, \Delta \pi)$ & $-46.4 \% *$ & $-30.4 \% *$ & $-18.5 \% *$ & $-8.0 \% *$ & $-17.4 \% *$ & $-17.4 \% *$ \\
\hline $\operatorname{Corr}\left(\Delta m^{\text {share }}, \Delta p^{\text {mat }}\right)$ & $17.3 \% *$ & $7.7 \% *$ & $30.1 \% *$ & $51.3 \% *$ & $28.8 \% *$ & $8.2 \% *$ \\
\hline $\operatorname{Corr}\left(\Delta m^{\text {share }}, \Delta \pi\right)$ & $36.9 \% *$ & $37.2 \% *$ & $53.4 \% *$ & $58.4 \% *$ & $54.0 \% *$ & $22.2 \% *$ \\
\hline $\operatorname{Corr}\left(\Delta p^{m a t}, \Delta \pi\right)$ & $26.9 \% *$ & $26.4 \% *$ & $57.1 \% *$ & $68.2 \% *$ & $58.0 \% *$ & $57.7 \% *$ \\
\hline
\end{tabular}

Table 15: Correlations and standard deviations of the annual growth rates of industry-level statistics.

Notes: Stars indicate that the correlation is statistically different from 0 , at the $5 \%$ level.

the planner's solution will correspond to an equilibrium outcome.) In this constrained maximization problem, let $P_{t J}$ refer to the Lagrange multiplier associated with the marketclearing-condition for the output of industry $J$ in period $t$, and let $P_{t J}^{i n v}$ refer to the Lagrange multiplier associated with the market-clearing condition for the industry $J$ investment good in period $t$. Finally, $\mathbb{E}_{t}$ refers to the expectation operator; the expectations are formed at time $t$.

$$
\begin{aligned}
\mathcal{L}= & \mathbb{E}_{0} \sum_{t=0}^{\infty} \beta^{t}\left\{D_{t, A g g} \cdot\left(\sum_{J=1}^{N} \xi_{J} \cdot D_{t J}\right) \cdot \log \left[\left[\sum_{J=1}^{N}\left(\xi_{J} \cdot D_{t J}\right)^{\frac{1}{\varepsilon_{D}}}\left(\delta_{C_{J}} \cdot C_{t J}\right)^{\frac{\varepsilon_{D}-1}{\varepsilon_{D}}}\right]^{\frac{\varepsilon_{D}}{\varepsilon_{D}-1}}\right]\right. \\
& -\frac{\varepsilon_{L S}}{\varepsilon_{L S}+1}\left(\sum_{J=1}^{N} L_{t J}\right)^{\frac{\varepsilon_{L S}+1}{\varepsilon_{L S}}}+\sum_{J=1}^{N} P_{t J}^{i n v}\left[X_{t J}+\left(1-\delta_{K}\right) K_{t J}-K_{t+1, J}\right] \\
& \left.+\sum_{J=1}^{N} P_{t J}\left[Q_{t J}+\left(1-\delta_{C_{J}}\right) C_{t+1, J}-C_{t J}-\sum_{I=1}^{N}\left[M_{t, J \rightarrow I}+X_{t, J \rightarrow I}\right]\right]\right\}
\end{aligned}
$$

For convenience, I re-state the expression for $Q_{t J}$ :

$Q_{t J}=A_{t J} \cdot A_{t, A g g} \times$ 


$$
\left[\left(1-\mu_{J}\right)^{\frac{1}{\varepsilon_{Q}}}\left(\left(\frac{K_{t J}}{\alpha_{J}}\right)^{\alpha_{J}}\left(\frac{L_{t J} \cdot B_{t J} \cdot B_{t, A g g}}{1-\alpha_{J}}\right)^{1-\alpha_{J}}\right)^{\frac{\varepsilon_{Q}-1}{\varepsilon_{Q}}}+\left(\mu_{J}\right)^{\frac{1}{\varepsilon_{Q}}}\left(M_{t J}\right)^{\frac{\varepsilon_{Q}-1}{\varepsilon_{Q}}}\right]^{\frac{\varepsilon_{Q}}{\varepsilon_{Q}-1}}
$$

The first-order conditions for the planner are:

$$
\begin{aligned}
{\left[C_{t J}\right]: \quad } & P_{t J}=\left(D_{t, A g g} \cdot D_{t J} \cdot \xi_{J}\right)^{\frac{1}{\varepsilon_{D}}} \cdot\left(\delta_{C_{J}}\right)^{\frac{\varepsilon_{D}-1}{\varepsilon_{D}}}\left(C_{t J}\right)^{-\frac{1}{\varepsilon_{D}}} \cdot\left(\sum_{I=1}^{N} \xi_{I} \cdot D_{t I}\right) \\
& \times\left(\sum_{I=1}^{N}\left(D_{t I} \cdot \xi_{I}\right)^{\frac{1}{\varepsilon_{D}}}\left(\delta_{C_{I}} \cdot C_{t I}\right)^{\frac{\varepsilon_{D}-1}{\varepsilon_{D}}}\right)^{-1}+P_{t+1, J}\left(1-\delta_{C_{J}}\right) . \\
{\left[M_{t, I \rightarrow J}\right]: } & \left(A_{t J} \cdot A_{t, A g g}\right)^{\frac{\varepsilon_{Q}-1}{\varepsilon_{Q}}}\left(\frac{Q_{t J} \cdot \mu_{J}}{M_{t J}}\right)^{\frac{1}{\varepsilon_{Q}}}\left(\frac{M_{t J} \cdot \Gamma_{I J}^{M}}{M_{t, I \rightarrow J}}\right)^{\frac{1}{\varepsilon_{M}}}=\frac{P_{t I}}{P_{t J}} \cdot \\
{\left[X_{t, I \rightarrow J}\right]: } & P_{t I}=P_{t J}^{i n v}\left(\frac{X_{t J} \cdot \Gamma_{I J}^{X}}{X_{t, I \rightarrow J}}\right)^{\frac{1}{\varepsilon_{X}}} \cdot \\
{\left[L_{t J}\right]: } & \left(\sum_{J^{\prime}=1}^{N} L_{t J^{\prime}}\right)^{\frac{1}{\varepsilon_{L S}}}=P_{t I} \cdot\left(A_{t J} \cdot A_{t, A g g}\right)^{\frac{\varepsilon_{Q}-1}{\varepsilon_{Q}}} \cdot B_{t J} \cdot B_{t, A g g} \\
& \times\left(Q_{t J}\left(1-\mu_{J}\right)^{\frac{1}{\varepsilon_{Q}}}\left(\frac{K_{t J}}{\alpha_{J}}\right)^{\alpha_{J} \cdot \frac{\varepsilon_{Q}-1}{\varepsilon_{Q}}}\left(\frac{L_{t J} \cdot B_{t J} \cdot B_{t, A g g}}{1-\alpha_{J}}\right)^{\frac{\alpha_{J}-1-\alpha_{J} \cdot \varepsilon_{Q}}{\varepsilon_{Q}}}\right. \\
{\left[K_{t+1, J}\right]: } & P_{t J}^{i n v}=\beta \cdot \mathbb{E}_{t}\left[P_{t+1, J}\left(Q_{t+1, J}\left(1-\mu_{J}\right)\right)^{\frac{1}{\varepsilon_{Q}}}\left(A_{t+1, J} \cdot A_{t+1, A g g}\right)^{\frac{\varepsilon_{Q}-1}{\varepsilon_{Q}}}\right. \\
& \times\left(\frac{K_{t+1, J}}{\alpha_{J}}\right)^{-1+\alpha_{J} \cdot \frac{\varepsilon_{Q}-1}{\varepsilon_{Q}}}\left(\frac{L_{t+1, J} \cdot B_{t+1, J} \cdot B_{t+1, A g g}}{1-\alpha_{J}}\right)^{\left.\left(1-\alpha_{J}\right)^{\frac{\varepsilon_{Q}-1}{\varepsilon_{Q}}}\right]} \\
& +\beta\left(1-\delta_{K}\right) \mathbb{E}_{t}\left[P_{t+1, J}^{i n v}\right] .
\end{aligned}
$$

Finally, I re-state the market-clearing condition of each industry $J$ :

$$
Q_{t J}=C_{t J}+\left(1-\delta_{C_{J}}\right) C_{t-1, J}+\sum_{I=1}^{N}\left[X_{t, J \rightarrow I}+M_{t, J \rightarrow I}\right] .
$$

Equations 36 through 42 are sufficient to characterize the dynamics of the model, given information on the steady-state allocation. I turn to the determination of the steady state allocation in the following subsection. 


\section{D.2 Solution of the Steady State and Calibration Details}

The solution to the steady-state allocation, as well as the calibration of the production and preference parameters $\left(\xi_{J}, \mu_{J}, \alpha_{J}, \Gamma_{I J}^{X}\right.$, and $\left.\Gamma_{I J}^{M}\right)$, are determined using a two-step fixed-point algorithm. In the "inner" fixed-point algorithm, the prices of each of the $N$ steady-state prices are jointly determined, given the steady-state wage and the production and preference parameters. In the "outer" algorithm, the wage, steady-state allocations, and the production and preference parameters are jointly determined. Here, and throughout the remainder of the section, I use $V_{I}^{s s}$ to refer to the steady-state value of the variable $V_{I}$. Finally, all exogeneous processes are normalized at 1 , in the steady state: $A_{A g g}^{s s}, B_{A g g}^{s s}, D_{A g g}^{s s}$, $A_{J}^{s s}, B_{J}^{s s}$, and $D_{J}^{s s}$ all equal 1.

\section{The Inner Algorithm}

Fix $W^{s s}, \xi_{J}, \mu_{J}, \alpha_{J}, \Gamma_{I J}^{X}$, and $\Gamma_{I J}^{M}$. The algorithm is used to determine the steady-state prices of the $N$ goods.

The cost-minimization problem of the industry $I$ representative firm generates the following expression for the marginal cost of good $I$ :

$$
P_{I}^{s s}=\left[\left(1-\mu_{I}\right)\left(W^{s s}\right)^{\left(1-\alpha_{I}\right)\left(1-\varepsilon_{Q}\right)} \cdot\left(R_{I}^{s s}\right)^{\alpha_{I} \cdot\left(1-\varepsilon_{Q}\right)}+\mu_{I}\left(\sum_{J} \Gamma_{J I}^{M}\left(P_{J}^{s s}\right)^{1-\varepsilon_{M}}\right)^{\frac{1-\varepsilon_{Q}}{1-\varepsilon_{M}}}\right]^{\frac{1}{1-\varepsilon_{Q}}}
$$

Using a no-arbitrage (the industry $I$ representative firm can either rent a unit of capital or, instead, purchase the goods necessary to make the unit of capital and then sell the undepreciated part in the subsequent period) argument, the rental price of a unit of capital equals:

$$
\begin{aligned}
R_{I}^{s s} & =\frac{1-\beta(1-\delta)}{\beta} P_{I}^{i n v} \\
& =\frac{1-\beta(1-\delta)}{\beta}\left(\sum_{J}\left(\Gamma_{J I}^{X}\right) \cdot\left(P_{J}^{s s}\right)^{1-\varepsilon_{X}}\right)^{\frac{1}{1-\varepsilon_{X}}}
\end{aligned}
$$

Equation 43 comprises a set of $N$ non-linear equations, which can be used to solve for the $N P_{I}^{s s}$ s. The solution to these $N$ equations, which is achieved using a fixed-point algorithm, constitutes the inner loop.

Note that, given the solution to these equations, the $R_{I}^{s s}$ 's can be solved for, using Equation 44. 


\section{The Outer Algorithm}

In the outer algorithm, I solve for $W^{s s}, \xi_{J}, \mu_{J}, \alpha_{J}, \Gamma_{I J}^{X}$, and $\Gamma_{I J}^{M}$. In each iteration, of the fixed point algorithm, the production and preference parameters are read off of the data and the relative prices (which were solved for in the inner algorithm). The iteration is on $W^{s s}$, which converges to a value such that labor supply and demand are equated.

Let $s_{J}^{K}, s_{J}^{L}$, and $s_{J}^{M}$ refer to the expenditure share of industry $J$ on capital, labor, and intermediate inputs. Also let $s_{J}^{C}$ refer to the consumer's expenditure share on the industry $J$ product. These $s$ s can be read off of Table 11. Finally let $s_{I \rightarrow J}^{M}$, and $s_{I \rightarrow J}^{X}$ refer to the share of the industry $I$ input in the production of the industry $J$ intermediate input and capital input. These ss refer to the flows depicted in Figure 4.

During each iteration of the outer algorithm, the production function and preference parameters are chosen so that the following equations hold:

$$
\begin{aligned}
\Gamma_{I J}^{X} & =s_{I \rightarrow J}^{X} \cdot\left(\frac{P_{I}^{s s}}{\left(P_{J}^{i n v}\right)^{s s}}\right)^{\varepsilon_{X}-1} \cdot \\
\Gamma_{I J}^{M} & =s_{I \rightarrow J}^{M} \cdot\left(\frac{P_{I}^{s s}}{\left(P_{J}^{\text {mat }}\right)^{s s}}\right)^{\varepsilon_{M}-1} \cdot \\
\mu_{J} & =s_{J}^{M} \cdot\left(\frac{\sum \Gamma_{I J}^{M} \cdot P_{I}^{s s}}{P_{J}^{s s}}\right)^{\varepsilon_{Q}-1} . \\
\xi_{J} & =s_{J}^{C} \cdot\left(\frac{P_{J}^{s s}}{P^{s s}}\right)^{\varepsilon_{D}-1} . \\
\alpha_{J} & =\frac{s_{J}^{K}}{s_{J}^{K}+s_{J}^{L}} .
\end{aligned}
$$

In other words, the production and preference parameters are chosen so the data on cost and consumption expenditure shares exactly match the corresponding model-predicted values.

The first-order conditions, given by Equations 37 to 40 imply that, in the steady-state, the following equations hold:

$$
\begin{aligned}
\delta_{C_{J}} \cdot C_{J}^{s s}= & \xi_{J} \cdot\left(P_{J}^{s s}\right)^{-\varepsilon_{D}} \cdot\left(\sum_{I}\left(\xi_{I}\right)^{\frac{1}{\varepsilon_{D}}}\left(\delta_{C_{I}} \cdot C_{I}^{s s}\right)^{\frac{\varepsilon_{D}-1}{\varepsilon_{D}}}\right)^{-\varepsilon_{D}} \cdot \\
M_{J \rightarrow I}^{s s}= & Q_{I}^{s s} \cdot \mu_{I} \cdot \Gamma_{J I}^{M} \cdot\left(P_{J}^{s s}\right)^{-\varepsilon_{M}}\left(P_{I}^{s s}\right)^{\varepsilon_{Q}}\left[\sum_{J^{\prime}} \Gamma_{J^{\prime} I}^{M} \cdot\left(P_{J^{\prime}}^{s s}\right)^{1-\varepsilon_{M}}\right]^{\frac{\varepsilon_{M}-\varepsilon_{Q}}{1-\varepsilon_{M}}} \cdot \\
X_{J \rightarrow I}^{s s}= & \delta \cdot Q_{I}^{s s}\left(1-\mu_{I}\right) \cdot \alpha_{I} \cdot\left(\frac{R_{I}^{s s}}{W^{s s}}\right)^{\alpha_{I}-1}\left[\left(R_{I}^{s s}\right)^{\alpha_{I}}\left(W^{s s}\right)^{1-\alpha_{I}}\right]^{-\varepsilon_{Q}} \\
& \times\left(P_{I}^{s s}\right)^{\varepsilon_{Q}} \cdot \Gamma_{J I}^{X} \cdot\left(P_{J}^{s s}\right)^{-\varepsilon_{X}}\left(\frac{R_{I}^{s s} \beta}{1-\beta(1-\delta)}\right)^{\varepsilon_{X}}
\end{aligned}
$$




$$
L_{I}^{s s}=Q_{I}^{s s}\left(1-\mu_{I}\right)\left(1-\alpha_{I}\right)\left(\frac{R_{I}^{s s}}{W^{s s}}\right)^{\alpha_{I}}\left[\left(R_{I}^{s s}\right)^{\alpha_{I}}\left(W^{s s}\right)^{1-\alpha_{I}}\right]^{-\varepsilon_{Q}}\left(P_{I}^{s s}\right)^{\varepsilon_{Q}}
$$

To sum up, $C_{J}^{s s}, M_{J \rightarrow I}^{s s}, X_{J \rightarrow I}^{s s}$, and $L_{J}^{s s}$ can be solved for given information $R_{J}^{s s}$ and $P_{J}^{s s}$ (which were solved for earlier) and $Q_{J}^{s s}$ and $W^{s s}$ (which are still unknown).

The supply of good $I$, in the steady state, is a function of $L_{I}^{s s}, X_{J \rightarrow I}^{s s}$, and the $M_{J \rightarrow I}^{s s}$ : $Q_{I}^{s s}=\Lambda^{I}\left(L_{I}^{s s}, X_{J \rightarrow I}^{s s}, M_{J \rightarrow I}^{s s}\right)$. Moreover, the demand of good $I$ is the sum over the $X_{I \rightarrow J}^{s s}$, $M_{I \rightarrow J}^{s s}$, and $C_{I}^{s s}$. Except for the prices (which, again, have already been solved for) and the wage (which has yet to be solved for), the $L_{I}^{s s}, X_{J \rightarrow I}^{s s}, M_{J \rightarrow I}^{s s}$ and $C_{I}^{s s}$ depend only on the $N$ $Q^{s s}$ 's. In other words, we have $N$ non-linear equations for the $N$ unknown $Q^{s s}$ s:

$$
\Lambda^{I}\left(L_{I}^{s s}, X_{J \rightarrow I}^{s s}, M_{J \rightarrow I}^{s s}\right)=\delta_{C_{I}} \cdot C_{I}^{s s}+\sum_{J} X_{I \rightarrow J}^{s s}+M_{I \rightarrow J}^{s s}
$$

Moreover, the wage can be read off of the labor supply relation:

$$
L^{s s}=\left(W^{s s}\right)^{\varepsilon_{L S}}
$$

Solving the $N+1$ equations given in Equations 50 and 51, numerically, and then applying Equations 47 to 49 yields the desired expressions for the steady-state allocation. In practice, Equations 50 and 51 can be solved using a tatonnement-like process.

\section{E Calculations Related to Section 5.1}

In this section, I solve for the covariance of industries' real sales, relative prices, and intermediate input cost shares. The solution involves four steps. First, I solve for the wage. Second, I solve for the relative prices and intermediate input cost shares. Third, I solve for real sales. Fourth, I write out the covariances of these variables.

Step 1: For later use, I will first solve for the wage in each period. For this portion of the analysis, it will be sufficient to examine how much the consumer much to work and how much of the consumption bundle to consume. The objective function for the consumer is

$$
\mathcal{U}=\left(D_{A g g} \cdot \sum_{J=1}^{N} \frac{D_{J}}{N}\right) \cdot \log C-\frac{\varepsilon_{L S}}{\varepsilon_{L S}+1} L^{\frac{\varepsilon_{L S}+1}{\varepsilon_{L S}}}
$$

The budget constraint for this consumer is:

$$
P \cdot C=W \cdot L
$$


The solution to this constrained optimization problem is:

$$
\begin{aligned}
W & =L^{\frac{1}{\varepsilon_{L S}}} \\
C & =\frac{1}{P} \cdot D_{A g g} \cdot \sum_{J=1}^{N} \frac{D_{J}}{N}
\end{aligned}
$$

Invoking the budget constraint of the representative consumer:

$$
L^{\frac{\varepsilon_{L S}+1}{\varepsilon_{L S}}}=D_{A g g} \cdot \sum_{J=1}^{N} \frac{D_{J}}{N}
$$

Thus:

$$
W=\left[D_{A g g} \cdot \sum_{J=1}^{N} \frac{D_{J}}{N}\right]^{\frac{1}{1+\varepsilon_{L S}}}
$$

The log-linear approximation (around the point at which the $D$ s are equal to 1 ) to Equations 52 and 53 are:

$$
\begin{aligned}
\log (P \cdot C) & \approx \log D_{A g g}+\frac{1}{N} \sum_{J=1}^{N} \log D_{J}, \text { and } \\
\log W & \approx \frac{1}{1+\varepsilon_{L S}}\left[\log D_{A g g}+\frac{1}{N} \sum_{J=1}^{N} \log D_{J}\right]
\end{aligned}
$$

Step 2: Now consider the cost-minimization problem of the representative firm in industry $J$. As we argued in the text, the cost-minimization problem implies the following recursive equation for the marginal cost (equivalently, price) of industry J's good:

$$
P_{J}=\left(A_{J} \cdot A_{A g g}\right)^{-1}\left[(1-\mu)\left(\frac{W}{B_{J} \cdot B_{A g g}}\right)^{1-\varepsilon_{Q}}+\mu\left[\sum_{I=1}^{N} \frac{1}{N} P_{I}\right]^{1-\varepsilon_{Q}}\right]^{\frac{1}{1-\varepsilon_{Q}}} \text { for } J=\{1, \ldots N\}
$$

The log-linear approximation to the previous equation is:

$$
\log P_{J}=-\log \left(A_{J} \cdot A_{A g g}\right)+(1-\mu) \cdot\left[\log W-\log \left(B_{J} \cdot B_{A g g}\right)\right]+\frac{\mu}{N} \sum_{I=1}^{N} \log P_{I}
$$

Note that:

$$
\log P_{I}+\log A_{I}+(1-\mu) \log B_{I} \approx \log P_{J}+\log A_{J}+(1-\mu) \log B_{J}
$$


for all pairs of industries, so that Equation 55 implies:

$$
\begin{aligned}
\log P_{J} \approx & -\log \left(A_{J} \cdot A_{A g g}\right)+(1-\mu) \cdot\left[\log W-\log \left(B_{J} \cdot B_{A g g}\right)\right] \\
& +\frac{\mu}{N} \sum_{I=1}^{N} \log P_{J}+\log A_{J}+(1-\mu) \log B_{J}-\log A_{I}-(1-\mu) \log B_{I} .
\end{aligned}
$$

Re-arranging, and also plugging in Equation 53:

$$
\begin{aligned}
\log P_{J} \approx & \frac{1}{1+\varepsilon_{L S}}\left[\log D_{A g g}+\frac{1}{N} \sum_{I=1}^{N} \log D_{I}\right]-\frac{\log \left(A_{J}+A_{A g g}\right)}{1-\mu} \\
& -\log \left(B_{J}+B_{A g g}\right)+\frac{\mu}{N} \sum_{I=1}^{N}\left[\frac{\log A_{J}-\log A_{I}}{1-\mu}+\log B_{J}-\log B_{I}\right] .
\end{aligned}
$$

Because all industries' cost shares are identical (both in the consumer's preferences and in the production of each industry's intermediate input bundle):

$\log P_{J}^{m a t} \approx \log P$

$$
\approx \frac{1}{1+\varepsilon_{L S}}\left[\log D_{A g g}+\frac{1}{N} \sum_{J} \log D_{J}\right]-\frac{1}{N} \sum_{I=1}^{N} \frac{\log A_{A g g}+\log A_{I}}{1-\mu}+\log B_{J}+\log B_{A g g} .
$$

Thus:

$$
\log \left(\frac{P_{J}}{P}\right)=\log \left(\frac{P_{J}}{P_{J}^{m a t}}\right) \approx \frac{1}{N} \sum_{I=1}^{N} \log \left(\frac{A_{I}}{A_{J}}\right)+(1-\mu) \log \left(\frac{B_{I}}{B_{J}}\right)
$$

And:

$$
\begin{aligned}
M_{J}^{\text {share }}= & \mu \cdot\left(A_{J} \cdot A_{A g g}\right)^{\varepsilon_{Q}-1} \cdot\left(\frac{P_{J}^{\text {mat }}}{P_{J}}\right)^{1-\varepsilon_{Q}} \cdot M_{J}^{\text {error }} \cdot M_{A g g}^{\text {error }} \\
\log M_{J}^{\text {share }} \approx & \log \mu+\left(\varepsilon_{Q}-1\right) \log \left(A_{A g g}\right)-\left(\varepsilon_{Q}-1\right)(1-\mu) \log \left(B_{J}\right) \\
& +\left(\varepsilon_{Q}-1\right) \cdot\left[\frac{1}{N} \sum_{I=1}^{N} \log \left(A_{I}\right)+(1-\mu) \log \left(B_{I}\right)\right]+\log \left(M_{J}^{\text {error }} \cdot M_{A g g}^{\text {error }}\right) .
\end{aligned}
$$

Equations 57 and 58 appear in the body of the paper.

Step 3: The next task is to solve for $\frac{Y_{J}}{P}$, the real sales of industry $J$. To do so, apply the market clearing condition for good $I$, plug in the intermediate input demand by customers' 
of $I$, then re-arrange:

$$
\begin{aligned}
Q_{I} & =C_{I}+\sum_{J=1}^{N} M_{I \rightarrow J} . \\
P_{I} Q_{I} & =P_{I} C_{I}+\frac{1}{N} P_{I} \sum_{J=1}^{N} M_{I \rightarrow J} \\
& =P_{I} C_{I}+P_{I} \sum_{J=1}^{N} \frac{\mu}{N} Q_{J}\left(A_{J} \cdot A_{A g g}\right)^{\varepsilon_{Q}-1}\left(\frac{P_{J}^{\text {mat }}}{P_{J}}\right)^{-\varepsilon_{Q}} .
\end{aligned}
$$

Next, take the steady-state approximation and use the definition of $Y_{I} \equiv P_{I} \cdot Q_{I}$

$$
\begin{aligned}
\log \left(Y_{I}\right) \approx & \log \left(\frac{1}{1-\mu}\right)+(1-\mu)\left(\log P_{I}+\log C_{I}\right)+\frac{\mu}{N} \sum_{J} \varepsilon_{Q} \log \left(\frac{P_{J}}{P_{J}^{\text {mat }}}\right) \\
& +\frac{\mu}{N} \sum_{J=1}^{N} \log Y_{J}+\left(\varepsilon_{Q}-1\right) \log \left(A_{J} \cdot A_{A g g}\right)+\log P_{I}-\log P_{J} . \\
\log Y_{I}-\frac{\mu}{N} \sum_{J} \log Y_{J} \approx & \log \left(\frac{1}{1-\mu}\right)-(1-\mu)\left(\log P_{I}+\log C_{I}\right) \\
& +\frac{\mu}{N} \sum_{J=1}^{N}\left(\varepsilon_{Q}-1\right) \log \left(A_{J} \cdot A_{A g g}\right)+\log P_{I}-\log P_{J}
\end{aligned}
$$

Equation 59 is a system of $N$ linear equations for the $N$ unknown $Y$ s. The solution to this system of equations is:

$$
\begin{aligned}
\log Y_{I} \approx & \log \left(\frac{1}{1-\mu}\right)+(1-\mu)\left(\log P_{I}+\log C_{I}\right)+\frac{\mu}{N} \sum_{J}\left(\log P_{J}+\log C_{J}\right) \\
& +\frac{\mu}{N} \sum_{J=1}^{N} \frac{\varepsilon_{Q}-1}{1-\mu} \log \left(A_{J} \cdot A_{A g g}\right)+\log P_{I}-\log P_{J}
\end{aligned}
$$

Given the preferences of the representative consumer, the demand function for good $I$ is:

$$
\log C_{I}=\log \left(D_{A g g}\right)+\log \left(D_{I}\right)-\varepsilon^{D} \log \left(\frac{P_{I}}{P}\right)-\log P .
$$

Plug this expression back into Equation 60, and re-arrange:

$$
\log \left(Y_{I}\right) \approx \log \left(\frac{1}{1-\mu}\right)+\log D_{A g g}+(1-\mu) \log D_{I}+\frac{\mu}{N} \sum_{J=1}^{N} \log D_{J}
$$




$$
+\left(1-\varepsilon^{D}(1-\mu)\right) \log \left(\frac{P_{I}}{P}\right)+\frac{\mu}{N} \sum_{J=1}^{N} \frac{\varepsilon_{Q}-1}{1-\mu} \log \left(A_{J} \cdot A_{g g}\right)
$$

Use the expression for relative prices (from Equation 60):

$$
\begin{aligned}
\log \left(Y_{I}\right) \approx & \log \left(\frac{1}{1-\mu}\right)+\log D_{A g g}+(1-\mu) \log D_{I}+\frac{\mu}{N} \sum_{J=1}^{N} \log D_{J} \\
& +\frac{1-\varepsilon_{D}(1-\mu)}{N} \sum_{J=1}^{N}\left[\log \left(\frac{A_{J}}{A_{I}}\right)+(1-\mu) \log \left(\frac{B_{J}}{B_{I}}\right)\right] \\
& +\frac{\mu}{N} \sum_{J} \frac{\left(\varepsilon_{Q}-1\right)}{1-\mu} \log \left(A_{J} \cdot A_{g g}\right) .
\end{aligned}
$$

Finally, subtract the price index (which I have already solved for) from Equation 61:

$$
\begin{aligned}
\log \left(\frac{Y_{I}}{P}\right) \approx & \log \left(\frac{1}{1-\mu}\right)+\frac{\varepsilon^{L S}}{\varepsilon^{L S}+1} \log D_{A g g}+\frac{1-\mu\left(1-\varepsilon^{Q}\right)}{1-\mu} \log A_{A g g}+\log B_{A g d}(62) \\
& +\left(1-\varepsilon^{D}(1-\mu)\right)\left(-\log A_{I}-(1-\mu) \log B_{I}\right)+(1-\mu) \log D_{I} \\
& +\frac{1}{N}\left(\mu-\frac{1}{\varepsilon^{L S}+1}\right) \sum_{J=1}^{N} \log D_{J} \\
& +\frac{1}{N}\left[\frac{1-\mu\left(1-\varepsilon^{Q}\right)}{1-\mu}+\left(1-\varepsilon^{D}(1-\mu)\right)\right] \sum_{J=1}^{N} \log A_{J} \\
& +\frac{1}{N}\left[1+\left(1-\varepsilon^{D}(1-\mu)\right)(1-\mu)\right] \sum_{J=1}^{N} \log B_{J} .
\end{aligned}
$$

Equation 62 is equivalent to the expression given in the body of the paper.

Step 4: Having written out the log-linear approximations to the variables of interest, it is straightforward to compute the covariances among the relative prices, intermediate input shares, and sales using Equations 57, 58, and 62. All that is involved is recognizing that all underlying distinct shocks are uncorrelated (e.g., that $\operatorname{cov}\left(D_{J}, D_{I}\right) \neq 0$ only if $I=J$, and also that $\operatorname{cov}\left(D_{J}, D_{A g g}\right)=\operatorname{cov}\left(D_{J}, A_{A g g}\right)=\operatorname{cov}\left(D_{J}, A_{I}\right)=0=\operatorname{cov}\left(D_{J}, B_{A g g}\right)=$ $\left.\operatorname{cov}\left(D_{J}, B_{I}\right)=0\right)$. The log-linear approximations of the covariances are:

$$
\begin{aligned}
\operatorname{Cov}\left(\log \left(\frac{P_{I}}{P}\right), \log \left(\frac{P_{J}}{P}\right)\right) & =\left[\mathbf{1}_{I=J}-\frac{1}{N}\right] \sigma_{A, \text { Ind }}^{2}+(1-\mu)^{2}\left[\mathbf{1}_{I=J}-\frac{1}{N}\right] \sigma_{B, \text { Ind }}^{2} . \\
\operatorname{Cov}\left(\log \left(\frac{P_{I}}{P}\right), \log \left(M_{J}^{\text {share }}\right)\right) & =(1-\mu)^{2}\left[\mathbf{1}_{I=J}-\frac{1}{N}\right]\left(\varepsilon_{Q}-1\right) \sigma_{B, \text { Ind }}^{2} .
\end{aligned}
$$




$$
\begin{aligned}
\operatorname{Cov}\left(\log \left(\frac{P_{I}}{P}\right), \log \left(\frac{Y_{J}}{P}\right)\right)= & \left(1-\varepsilon^{D}(1-\mu)\right)\left[\mathbf{1}_{I=J}-\frac{1}{N}\right] \sigma_{A, \text { Ind }}^{2} \\
& +(1-\mu)^{2}\left(1-\varepsilon^{D}(1-\mu)\right)\left[\mathbf{1}_{I=J}-\frac{1}{N}\right] \sigma_{B, \text { Ind }}^{2} \\
\operatorname{Cov}\left(\log \left(M_{I}^{\text {share }}\right), \log \left(M_{J}^{\text {share }}\right)\right)= & \left(\varepsilon^{Q}-1\right)^{2}\left[\sigma_{A, A g g}^{2}+\frac{1}{N} \sigma_{A, I n d}^{2}\right]+\left(\varepsilon^{Q}-1\right)^{2}\left[\mathbf{1}_{I=J} \sigma_{B, \text { Ind }}^{2}-\frac{1}{N} \sigma_{B, \text { Ind }}^{2}\right] \\
& +\mathbf{1}_{I=J} \sigma_{M, I n d}^{2}+\sigma_{M, A g g}^{2} \cdot \\
\operatorname{Cov}\left(\log \left(M_{I}^{\text {share }}\right), \log \left(\frac{Y_{J}}{P}\right)\right)= & \left(\varepsilon^{Q}-1\right) \frac{1-\mu\left(1-\varepsilon^{Q}\right)}{1-\mu}\left[\sigma_{A, A g g}^{2}-\frac{1}{N} \sigma_{A, I n d}^{2}\right] \\
& \left(\varepsilon_{Q}-1\right)\left(1-\varepsilon_{D}(1-\mu)\right)(1-\mu)^{2}\left[\mathbf{1}_{I=J}-\frac{1}{N}\right] \sigma_{B, \text { Ind }}^{2} \\
\operatorname{Cov}\left(\log \left(\frac{Y_{I}}{P}\right), \log \left(\frac{Y_{J}}{P}\right)\right)= & \left(\frac{1-\mu\left(1-\varepsilon^{Q}\right)}{1-\mu}\right)^{2} \sigma_{A, A g g}^{2}+\sigma_{B, A g g}^{2}+\left(\frac{\varepsilon^{L S}}{\varepsilon^{L S}+1}\right)^{2} \sigma_{D, A g g}^{2} \\
& +\left[\mathbf{1}_{I=J}(1-\mu)^{2}+\frac{1}{N}\left(\mu-\frac{1}{\varepsilon^{L S}+1}\right)\left(1-\mu+\frac{\varepsilon^{L S}}{\varepsilon^{L S}+1}\right)\right] \sigma_{D, I n d}^{2} \\
& +\mathbf{1}_{I=J}\left(1-\varepsilon^{D}(1-\mu)\right)^{2} \sigma_{A, I n d}^{2} \\
& \frac{1}{N}\left[\left(\frac{1-\mu\left(1-\varepsilon^{Q}\right)}{1-\mu}\right)^{2}-\left(1-\varepsilon^{D}(1-\mu)\right)^{2}\right] \sigma_{A, I n d}^{2} \\
& +\mathbf{1}_{I=J}(1-\mu)^{2}\left[\left(1-\varepsilon^{D}(1-\mu)\right)^{2}\right] \sigma_{B, I n d}^{2} \\
+ & \frac{1}{N}\left[1-\left(1-\varepsilon^{D}(1-\mu)\right)^{2}\right] \sigma_{B, I n d}^{2}
\end{aligned}
$$

Dropping the terms that involve $\frac{1}{N}$ yields the expressions given in Proposition 1 .

\section{F Cross-Sectional Estimates}

By now, it is hopefully clear that the value of the elasticity of substitution between intermediate inputs and the capital-labor bundle is a key component of an assessment of the importance of industry-specific shocks. Since few papers have previously estimated this parameter, I will try to corroborate the structural estimates that were given in Table 2. Towards this objective, I estimate the industry-level elasticity of substitution - between material inputs and other inputs - using micro-data from a handful of individual industries. I pursue the following two-part strategy. For each industry, I estimate how easily individual plants substitute across their factors of production, by relating plants' materials purchases to their materials prices. Then, I apply the methods developed in Oberfield and Raval (2013), 
which allow me to combine information on a) the plant-level elasticity of substitution, b) the dispersion of materials cost shares, and c) the elasticity of plant scale to marginal costs so that I can ascertain the corroborating estimates of $\varepsilon_{Q}$.

To preview the main results of this section, the elasticity of substitution for the plantlevel production function is approximately 0.65. Because within-industry variation in materials expenditure shares is small for each of the ten industries, the industry level production function's elasticity of substitution is only somewhat higher, 0.75. Moreover, across the industries in the sample, the industry level elasticities of substitution are similar to one another.

\section{F.1 Data Source and Sample}

The data source, for this section, is the Census of Manufacturers. This dataset contains plant-level information for each manufacturer in the United States, and is collected once every five years, in years ending in a "2" or a "7." For certain industries, plants with greater than five employees are asked to provide information on each of the material inputs that they consume and each of the products that they produce. Critically, for the empirical analysis of this section, the Census Bureau elicits information on both the quantities and values of these inputs and outputs, allowing me to construct plant-level prices. Additionally, the Census Bureau records a plant identifier, which will allow me to compare the intermediate input purchases of the same plant across different time periods.

The sample in this section is identical to that which was used in an earlier paper (see Atalay 2013). The industries are those for which outputs and inputs are relatively homogeneous. This choice reflects a desire to, as much as possible, rule out heterogeneous quality as a source of input or output price variation. The ten industries that comprise the sample are corrugated boxes (with the years 1972-1987 and 1992-1997 analyzed separately), ground coffee, ready-mix concrete, white wheat flour, gasoline, bulk milk, packaged milk, raw cane sugar, and grey cotton yarn; see Table 16. For additional details regarding the sample, see Appendix B of Atalay (2013).

\section{F.2 Environment and Assumptions}

Each industry, $I$, is comprised of a set of plants $i \in I$, who combine capital, labor, material inputs, and purchased services to produce a single product. The production function is constant-returns to scale; separable between material inputs, $N$, and other inputs, $O$; with 


\begin{tabular}{lccc}
\hline \multicolumn{1}{c}{ Sample } & Units of Output & Material Inputs & $N$ \\
\hline Boxes, Year $\leq 1987$ & Short Tons & Paper/Paperboard (90\%) & 1820 \\
\hline Boxes, Year $\geq 1992$ & Square Feet & Paper/Paperboard (89\%) & 646 \\
\hline Ground Coffee & 1000 Pounds & Green Coffee Beans (80\%) & 300 \\
\hline Ready-Mix Concrete & 1000 Cubic Yards & $\begin{array}{c}\text { Cement (53\%) } \\
\text { Sand/Gravel (28\%) }\end{array}$ & 3708 \\
\hline White Wheat Flour & 50-Pound Sacks & Wheat (90\%) & 503 \\
\hline Gasoline & 1000 Barrels & Crude Petroleum (84\%) & 692 \\
\hline Milk, Bulk & 1000 Pounds & $\begin{array}{c}\text { Unprocessed } \\
\text { Whole Milk (88\%) }\end{array}$ & 127 \\
\hline Milk, Packaged & 1000 Quarts & $\begin{array}{c}\text { Unprocessed } \\
\text { Whole Milk (72\%) }\end{array}$ & 2099 \\
\hline Raw Cane Sugar & Short Tons & Sugar Cane (93\%) & 177 \\
\hline Carded Cotton Yarn & 1000 Pounds & $\begin{array}{c}\text { Cotton Fibers (80\%), } \\
\text { Polyester Tow (10\%) }\end{array}$ & 431 \\
\hline Pooled & - & - & 10,503 \\
\hline
\end{tabular}

Table 16: Description of the 10 industries in the sample.

Notes: The percentages that appear in the Material Inputs column are the fraction of materials expenditures that go to each particular material input. The Material Inputs column shows the inputs that represent greater than $6 \%$ of the average plant's total material purchases.

constant elasticity of substitution, $\eta_{P}$ :

$$
\begin{aligned}
Q_{i t}\left(K_{i t}, L_{i t}, S_{i t}, N_{i t}\right) & =\left[\left(A_{i t} \cdot O_{i t}\right)^{\frac{\eta_{P}-1}{\eta_{P}}}+\left(B_{i t} \cdot N_{i t}\right)^{\frac{\eta_{P}-1}{\eta_{P}}}\right]^{\frac{\eta_{P}}{\eta_{P}-1}}, \\
\text { where } O_{i t} & =F\left(K_{i t}, L_{i t}, S_{i t}\right)
\end{aligned}
$$

Also by assumption, $F$ exhibits constant returns to scale. Plants are allowed to flexibly alter their input choices, including capital, each period. Furthermore, the factor prices that each plant faces, both for the material input and for the other input aggregate, are constant in the amount purchased. These assumptions serve a dual purpose. Not only do these assumptions greatly simplify the estimation of $\eta_{P}$, they also allow me to apply Oberfield and Raval (2013)'s methodology to estimate $\varepsilon_{Q}$ from $\eta_{P}$.

Use $P_{i t}^{o t h}$ and $P_{i t}^{m a t}$ to denote the factor prices for a unit of the other input aggregate and the material input, respectively. Let $A_{i t}$ and $B_{i t}$ represent the two plant-level productivity measures (other-input-augmenting and materials augmenting).

The demand curve faced by each plant, $i$, has constant elasticity, $\varepsilon_{D}$ :

$$
Q_{i t}=\exp \left\{\theta_{i t}\right\} \cdot\left(P_{i t}^{\text {out }}\right)^{-\eta_{D}}
$$

In equation $64, \theta_{i t}$ represents a plant-year specific demand shifter. The assumption of a 
constant elasticity demand curve, while probably counterfactual, is again useful for multiple reasons. The constant-demand-elasticity assumption allows me to directly apply the Foster, Haltiwanger, and Syverson (2008) methodology to estimate $\eta_{D}$. Moreover, the same assumption is invoked by Oberfield and Raval (2013) — whose work I apply, here - in their aggregation of plant-level to industry level production functions.

The profit-maximizing levels of $N_{i t}$ and $O_{i t}$ yield the following expression for the materialoutput ratio:

$$
\log \left[\frac{N_{i t}}{Q_{i t}}\right]=-\eta_{P} \cdot \log \left[\frac{P_{i t}^{m a t}}{P_{i t}}\right]+\eta_{P} \cdot \log \left[\frac{\eta_{D}-1}{\eta_{D}}\right]+\left(\eta_{P}-1\right) \log B_{i t}
$$

This equation will form the basis of the estimation of $\eta_{P}$, a task to which I now turn.

\section{F.3 The Micro Elasticity of Substitution}

In this subsection, I estimate the plant-level elasticity of substitution between purchased inputs and other inputs. The baseline regression that I run is:

$$
n_{i t}-q_{i t}=-\eta_{P} \cdot\left(p_{i t}^{m a t}-p_{i t}\right)+\epsilon_{i t}
$$

In Equation 66, and throughout the remainder of the section, I use lower-case letters to denote the logged, de-meaned values of the variable of interest. In other words, $\eta_{P}$ is estimated only using within industry year variation. To emphasize, both $n_{i t}$ and $q_{i t}$ refer to the number of physical units, and not the values, of the material good that plant $i$ purchases and the output that it produces.

Ordinary least squares results are presented in the first column of Table 17. For most industries, the estimate of $\eta_{P}$ lies between 0.5 and 0.7 , with concrete and flour having two of the lower estimates and bulk milk and raw cane sugar with two of the higher estimates.

There are at least two concerns regarding the interpretation of $\eta_{P}$-from an OLS estimate of Equation 66 - as an estimate of the micro elasticity of substitution. First, to the extent that the constant elasticity of demand assumption - embodied in Equation 64 - is violated, Equation 66 suffers from omitted variable bias. A positive correlation between $\log \left[\frac{\eta_{D}-1}{\eta_{D}}\right]$ and $\left(p_{i t}^{\text {mat }}-p_{i t}\right)$ will engender a positive bias in $\eta_{P}$. Second, I have assumed that the materials supply curve that each $i$ faces is flat. It is likely, however, that each plant's factor supply curve is upward sloping. This instance of simultaneity bias - whereby a high- $B_{i t}$ plant pays a high materials price - will also engender a positive bias in $\eta_{P}$.

I offer two different approaches to circumvent these problems. Fist, I append plantlevel fixed effects to Equation 66. These fixed effects aim to capture long-run cross-sectional 
variation in the conditions in output and factor markets. As Foster, Haltiwanger, and Syverson $(2008,2012)$ argue, the factor market conditions that a plant faces are substantially more persistent than its productivity.

In a second specification, I instrument plants' output and materials prices with the prices paid and charged by competitor plants. Specifically, the two instrumental variables, for $p_{i t}^{\text {mat }}-p_{i t}$, are a) the year- $t$ average materials price for plants that are within 50 miles of plant $i$, and $\mathrm{b}$ ) the year- $t$ average output price for plants that are within 50 miles of plant $i$. The idea behind these instruments is that the price of materials in nearby markets is correlated the price that $i$ pays for its material inputs (if, for example, there is spatial correlation in the abundance of primary inputs used in the production of $i$ 's intermediate inputs, or if there is a very productive, low marginal-cost supplier nearby), but should not in any other way affect the propensity for $i$ have exceptionally high or low materials expenditure shares. ${ }^{46}$

Results from the two sets of regressions are given in the second and third columns of Table 17. In the second column, estimates of $\eta_{P}$ range from 0.40 to 0.92 , with the two largest estimates corresponding to two of the smaller-sample industries, coffee and sugar. The pooled estimate of $\eta_{P}$ is 0.68 .

The instrumental variables are weak for the six smallest samples. For this reason, the I.V. specification is performed only on the samples of plants in the corrugated boxes, readymix concrete, packaged milk, and petroleum industries. In the third specification, the parameter estimates are smaller and much less precisely estimated. The biggest difference is for the ready-mix concrete industry, for which the estimate of $\eta_{P}$ is essentially 0 .

\footnotetext{
${ }^{46}$ Results from first-stage regressions indicate that these instruments are relevant, at least for the four largest subsamples: materials prices and output prices are each spatially correlated.
} 


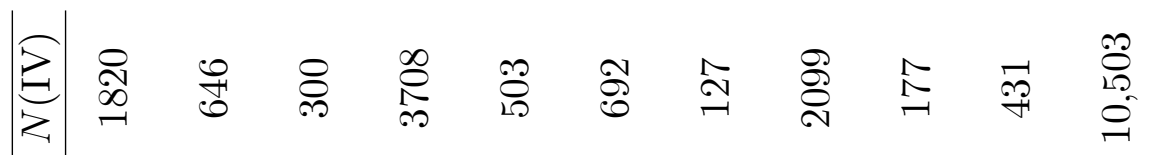

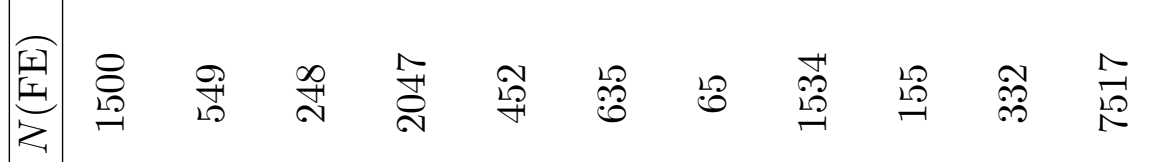

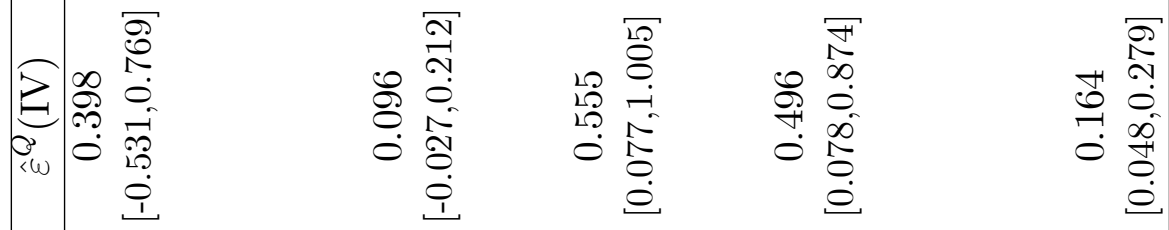

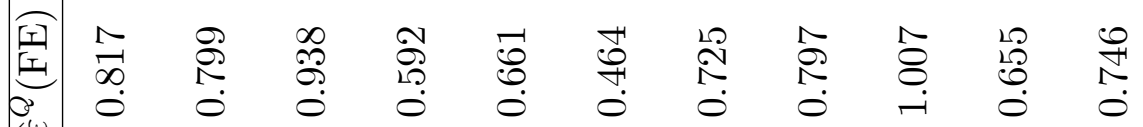

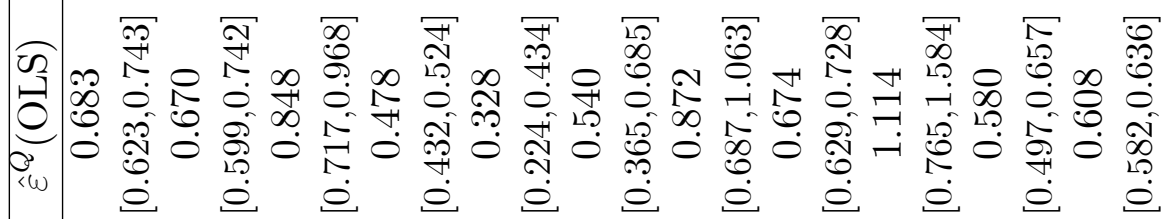

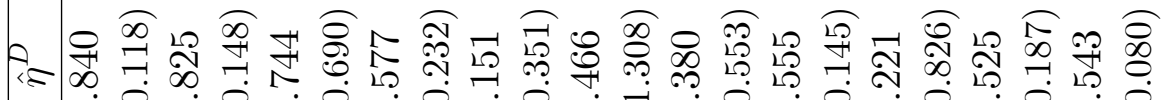

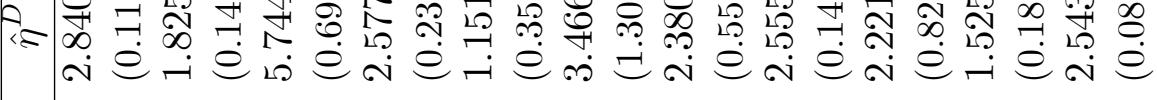

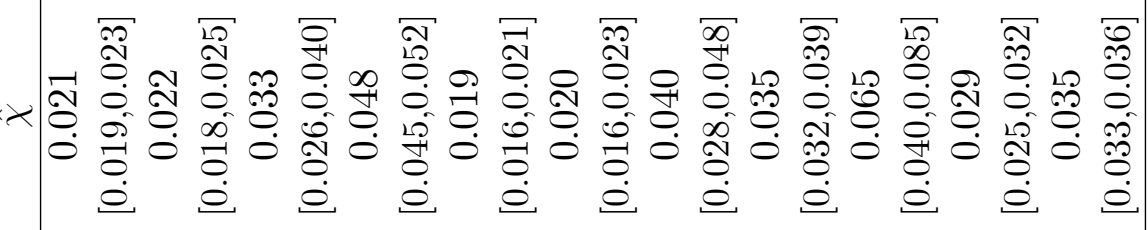

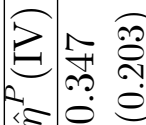
홍항
虽要 영

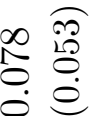

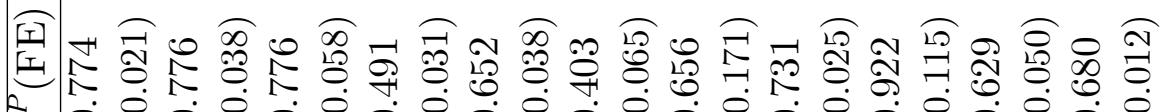

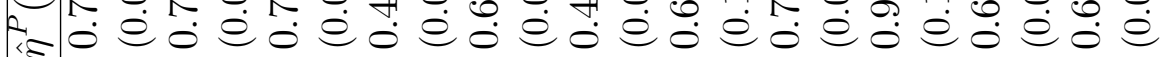

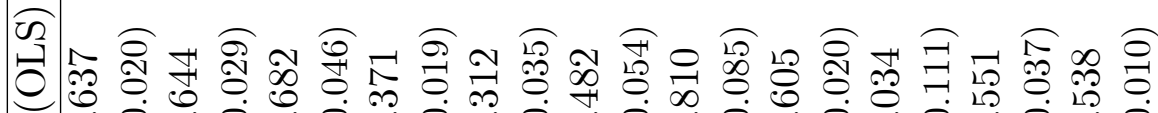

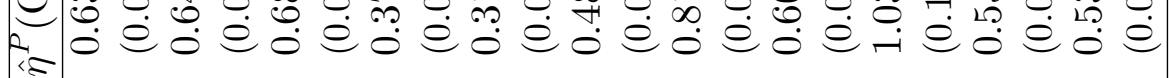

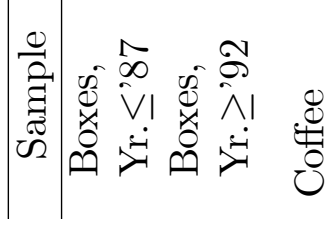

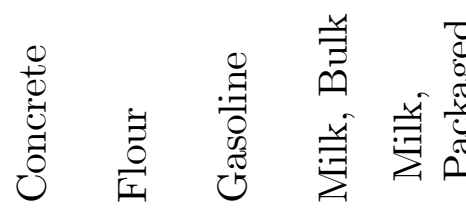
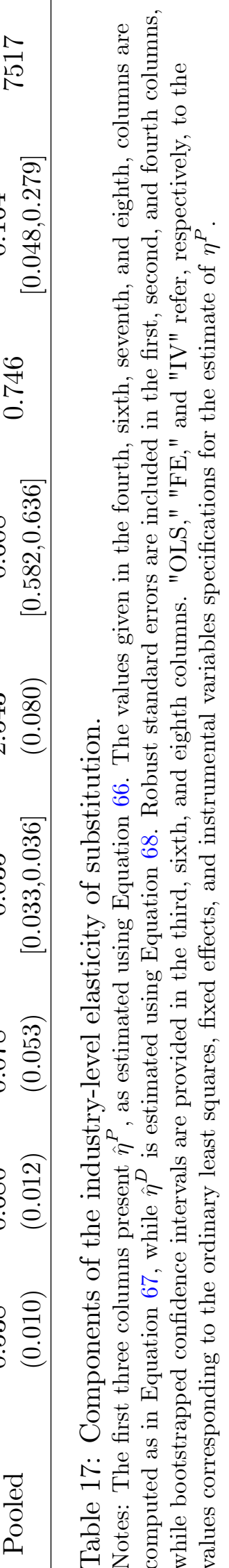

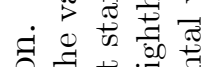
. 굴 تُ की $\approx$ 舟 क

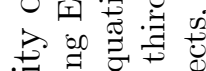

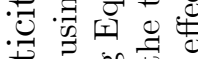
च $). \Xi$ $\widetilde{0}$ D. 考古

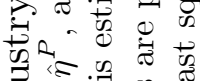

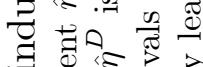
न के 秀 फ 을 월 0.00

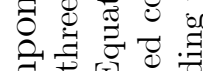
हृ .. 可 焉 플 焉范

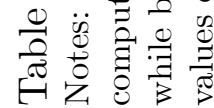




\section{F.4 The Industry Level Elasticity of Substitution}

The previous subsection provided an estimate for the ease with which individual plants substitute between material inputs and other inputs. This is related to, but distinct from, how easily an industry substitutes between material inputs and other inputs.

Changes in the scale, across plants, potentially makes the industry-level elasticity of substitution larger than the corresponding plant-level elasticity. The difference between the plant-level and industry-level elasticities of substitution depends on a) the heterogeneity of materials shares, within the industry, and b) how much inputs shift across plants, in response to a change in relative factor prices.

Given the assumptions, specified in Section F.2, the industry-level elasticity of substitution has a simple expression: ${ }^{47}$

$$
\begin{aligned}
\varepsilon_{Q} & =\chi_{t I} \cdot \eta_{D}+\left(1-\chi_{t I}\right) \cdot \eta_{P}, \text { where } \\
\chi_{t I} & \equiv \underbrace{\frac{1}{S_{t I}\left(1-S_{t I}\right)}}_{(1)} \cdot \sum_{i \in I} \underbrace{\left(S_{t I}-\frac{M_{i t} P_{i t}^{i n}}{M_{i t} P_{i t}^{i n}+O_{i t} P_{i t}^{o t h}}\right)^{2}}_{\text {(2) }} \cdot \underbrace{\frac{M_{i t} P_{i t}^{\text {mat }}+O_{i t} P_{i t}^{o t h}}{\sum_{j \in I} M_{j t} P_{j t}^{\text {mat }}+O_{j t} P_{j t}^{\text {oth }}}}_{\text {(3) }}, \text { and } \\
S_{t I} & \equiv \sum_{i \in I} \frac{M_{i t} P_{i t}^{\text {mat }}}{M_{i t} P_{i t}^{\text {mat }}+O_{i t} P_{i t}^{\text {oth }}}
\end{aligned}
$$

In words, the industry-level elasticity of substitution is a convex combination of the plantlevel elasticity of substitution and the plant-level elasticity of demand. The demand elasticity parameterizes how sensitive the scale of the plant is to changes in its marginal cost of production. Consider, for example, an increase in the price of the material input. The marginal cost of production will increase more for plants with relatively large materials cost shares. As a result, low materials share plants will produce relatively more of the total industry output following the increase of the materials price. The elasticity of demand determines how much less the high-materials-share plants will produce, following the increase in the materials price.

The scope for this across-plant factor substitution depends on the dispersion of materials intensities. According to Equation 67, the appropriate measure of the dispersion of materials intensity is a weighted, normalized variance of the materials cost shares. The fraction of total industry expenditures incurred by plant $i$ (given in term (3)) is the appropriate weight for summing over the within-industry deviation in materials cost shares (given in term (2)). The normalization, given in term (1), ensures the $\chi_{t I}$ lies within the unit interval.

What remains, then, is to provide estimates for the normalized variance of materials

\footnotetext{
${ }^{47}$ A proof is given in Oberfield and Raval (2013). See Appendix A.1 of that paper.
} 
shares, $\chi$, and the elasticity of demand, $\eta_{D}$, for the ten industries in my sample.

The normalized variance of materials shares, $\chi$, ranges from 0.019 (for flour) to 0.065 (for sugar). ${ }^{48}$ Given these low values, the industry elasticity of substitution will closely track the micro elasticity of substitution. In other words, the estimate of $\varepsilon_{Q}$ will be, for the most part, insensitive to the way in which $\eta_{D}$ is estimated.

I estimate $\eta_{D}$ via the regression defined by the following equation:

$$
q_{i t}=\alpha_{t}+\alpha_{1} \cdot \log I N C O M E_{\Upsilon t}+\eta_{D} \cdot p_{i t}+\theta_{i t}
$$

This specification, and the variable definitions, follow Foster, Haltiwanger, and Syverson (2008). In Equation 68, INCOME $\mathrm{\Upsilon}_{t}$ is the aggregate income in establishment $i$ 's market, $\Upsilon$, at time $t$. This variable is included to account for any differences in establishment scale that may exist between areas of high and low density of economic activity.

A positive relationship between the demand shifter $\left(\theta_{i t}\right)$ and output price $\left(p_{i t}\right)$ potentially induces a downward bias to the OLS estimates of $\eta_{D}$. Like Foster, Haltiwanger, and Syverson (2008), I instrument $p_{i t}$ with the marginal cost of plant $i$ in year $t$. This instrumental variable is certainly relevant: plants with lower marginal costs have significantly lower output prices. Validity of the instrument rests, then, on the orthogonality of marginal costs and $\theta_{i t}$. Foster, Haltiwanger, and Syverson (2008) discuss two potential threats to the validity of the instrument (measurement error in plants' marginal costs, and a selection bias that induces a negative relationship between demand shocks and marginal costs), propose robustness checks to assess the salience of these two threats, and find that their results are similar across the different robustness checks.

The results of these regressions are presented in the fourth column of Table $17 .{ }^{49}$ In each of the ten industries, the estimate for elasticity of demand is greater than 1, reassuringly indicating that plants are pricing on the elastic portion of their demand curve.

Combining the estimates of $\eta_{P}, \eta_{D}$, and $\chi$ yields the object of interest: the industrylevel elasticity of substitution, $\varepsilon_{Q}$. Since there are three sets of estimates of $\eta_{P}$, there are also three sets of estimates of $\varepsilon_{Q}$. For the estimates corresponding to the fixed effects regression, $\varepsilon_{Q}$ is 0.75 for the pooled sample. ${ }^{50}$ Except for sugar and coffee (two of the

\footnotetext{
${ }^{48}$ To give the reader some idea, the (unnormalized) standard deviations of materials shares range from $4.3 \%$ to $11.4 \%$ across the ten industries, again lowest for bulk milk and highest for raw cane sugar.

${ }^{49}$ The results reported here are slightly different from those in Foster, Haltiwanger, and Syverson (2008): I restrict my sample to those plants for which I can observe materials prices, while Foster, Haltiwanger, and Syverson make no such restriction. Their estimate of $\eta_{D}$ is lower for petroleum $\left(\hat{\eta}_{D}=1.42\right)$ and higher for ready-mix concrete $\left(\hat{\eta}_{D}=5.93\right)$. Again, because the normalized variances of materials shares are so small, these differences have will have only a moderate impact on the estimates of $\varepsilon_{Q}$.

${ }^{50}$ One dissimilarity between the analysis of the current section and that of Section 2 to 5 concerns the industry definitions that I have used: to credibly compare the material purchases and material prices, I
} 
smallest industries, representing only $5 \%$ of the sample), the industry-level elasticities of substitution range between 0.46 (for gasoline) and 0.82 (for corrugated boxes). For seven of the ten industries in the sample (with the exceptions being the smallest three subsamples), the data would reject a null hypothesis of $\varepsilon_{Q}=1$.

The estimates of $\varepsilon_{Q}$ that correspond to the instrumental-variables-based estimate of $\eta_{P}$ are even smaller, though again much less precisely estimated. The point estimate for $\varepsilon_{Q}$ is 0.10 for the ready-mix concrete subsample, and is somewhat higher (between 0.40 and $0.55)$ for the other three industries. For the pooled sample, and three of the four industry subsamples, the data reject a null hypothesis of $\varepsilon_{Q}=1$.

In summation, micro data on plants' materials usage patterns indicate that material inputs are gross complements to other factors of production. For most specifications (all except for the I.V. specification for the ready-mix concrete subsample, or the fixed effects specification for the smaller industries), the data indicate that $\varepsilon_{Q}$ ranges between 0.45 and 0.80 .

\section{Additional References}

Atalay, Enghin, 2013. "Materials Prices and Productivity." Journal of the European Economic Association, forthcoming.

Basu, Susanto, John G. Fernald, and Miles S. Kimball, 2006. "Are Technology Improvements Contractionary?" American Economic Review, 96(5): 1418-1448.

Foster, Lucia, John Haltiwanger, and Chad Syverson, 2012. "The Slow Growth of New Plants: Learning about Demand?" NBER Working Paper No. 17853.

Hulten, Charles R. and Frank C. Wykoff, 1981. "The Measurement of Economic Depreciation." In Depreciation, Inflation, and the Taxation of Income from Capital, edited by Charles Hulten, Washington, DC: Urban Institute.

McGrattan, Ellen and James Schmitz, 1999. "Maintenance and Repair: Too Big to Ignore." Federal Reserve Bank of Minneapolis, Quarterly Review, 23: 2-13.

Oberfield, Ezra and Devesh Raval, 2013. "Micro Data and the Macro Elasticity of Substi-

define products narrowly in this section. At the same time, limitations of the dataset necessitate a rather coarse industry definition in Sections 2 to 5 . Going from a narrow to coarse industry classification should not systematically alter the estimates of $\eta_{P}$ or $\eta_{D}$, but will cause an increase in the estimate for, $\chi$, the within-industry variation in materials cost shares. For this reason, a coarser industry classification would, in turn, lead to a larger estimate of $\varepsilon_{Q}$. As it turns out, the overall estimate of $\varepsilon_{Q}$ is not particularly sensitive to the value of $\chi$ : Doubling the value of $\chi$ increases the OLS-based estimate of $\varepsilon_{Q}$ from 0.61 to 0.67 , and increases the fixed effects-based estimate from 0.75 to 0.80 . 
tution." mimeo.

O’ Mahony, Mary and Marcel P. Timmer, 2009. "Output, Input and Productivity Measures at the Industry Level: The EU KLEMS Database." Economic Journal, 119(538): 374403.

Timmer, Marcel, Ton van Moergastel, Edwin Stuivenwold, Gerard Ypma, Mary O' Mahony, and Mari Kangasniemi, 2007. "EU KLEMS Growth and Productivity Accounts Version 1.0." mimeo. 